Maurice Halbwachs (1938)

Professeur au Collège de France

\title{
ESQUISSE D'UNE PSYCHOLOGIE DES CLASSES SOCIALES
}

Un document produit en version numérique par Jean-Marie Tremblay, professeur de sociologie

Courriel:jmt_sociologue@videotron.ca

Site web: http://pages.infinit.net/sociojmt

Dans le cadre de la collection: "Les classiques des sciences sociales"

Site web: http://www.uqac.uquebec.ca/zone30/Classiques_des_sciences_sociales/index.html

Une collection développée en collaboration avec la Bibliothèque

Paul-Émile-Boulet de l'Université du Québec à Chicoutimi

Site web: http://bibliotheque.uqac.uquebec.ca/index.htm 
Cette édition électronique a été réalisée par Jean-Marie Tremblay, professeur de sociologie au Cégep de Chicoutimi à partir de :

\section{Maurice Halbwachs (1938)}

\section{Esquisse d'une psychologie des classes sociales}

Une édition électronique réalisée à partir du livre de Maurice Halbwachs (1938), Esquisse d'une psychologie des classes sociales. Paris : Librairie Marcel Rivière et Cie.

Polices de caractères utilisée :

Pour le texte: Times, 12 points.

Pour les citations : Times 10 points.

Pour les notes de bas de page : Times, 10 points.

Édition électronique réalisée avec le traitement de textes Microsoft Word 2001 pour Macintosh.

Mise en page sur papier format

LETTRE (US letter), 8.5' x 11'’)

Édition complétée le 26 février 2002 à Chicoutimi, Québec. 


\section{TABLE DES MATIÈRES}

$\underline{\text { Avant-Propos }}$

Bibliographie des Oeuvres de Maurice Halbwachs

(établie par Maurice Halbwachs lui-même)

ESQUISSE D'UNE PSYCHOLOGIE DES CLASSES SOCIALES

I. INTRODUCTION

II. LA CIVILISATION TRADITIONNELLE ET LES CLASSES PAYSANNES.

Technique agricole, attachement à la terre

III. LES MILIEUX URBAINS ET LA CIVILISATION INDUSTRIELLE.

Première partie : les entrepreneurs, la bourgeoisie

IV. LES MILIEUX URBAINS ET LA CIVILISATION INDUSTRIELLE.

Deuxième partie : les ouvriers de la grande industrie

V. LES MILIEUX URBAINS ET LA CIVILISATION INDUSTRIELLE.

Troisième partie : les classes moyennes

VI. CONCLUSION.

Représentation de classe, patriotisme, religion, science, arts, politique, morale sociale 


\section{AVANT-PROPOS}

Cette étude de Maurice Halbwachs a paru d'abord, sous le titre Analyse des mobiles dominants qui orientent l'activité des individus dans la vie sociale, dans les «Enquêtes sociologiques » de l'Université libre de Bruxelles (Institut de sociologie Solvay), en 1938. Elle constitue un véritable traité de sociologie. 


\title{
BIBLIOGRAPHIE DES GEUVRES DE MAURICE HALBWACHS
}

\author{
Établie par Maurice Halbwachs lui-même
}

$\underline{\text { Retour à la table des matières }}$

\section{A) LIVRES}

Leibniz, Collection : les Philosophes, 1907, nouvelle édition très augmentée, Mellottée, 1928.

La Classe ouvrière et les niveaux de vie. Recherches sur la hiérarchie des besoins dans les sociétés industrielles contemporaines. Travaux de l'Année sociologique, Alcan, 1913.

La Théorie de l'homme moyen, essai sur Quételet et la Statistique morale, Alcan, 1913.

Le Calcul des probabilités à la portée de tous, en collaboration avec Maurice Fréchet, Dunod, 1924.

Les Origines du sentiment religieux d'après Durkheim, Stock, 1925.

Les Cadres sociaux de la Mémoire. Travaux de l'Année sociologique, Alcan-Presses Universitaires de France, 1925.

La Population et les tracés de voies à Paris depuis cent ans, avec deux plans hors texte, Cornély, 1928.

Les Causes du suicide. Travaux de l'Année sociologique, Alcan-P.U.F., 1930.

L'Évolution des besoins dans les classes ouvrières, Alcan-P.U.F., 1933.

L'Espèce humaine (3e partie) : le point de vue du nombre, dans ]'Encyclopédie française, tome VII, en collaboration avec Alfred Sauvy, 1936.

Morphologie sociale, Collection Armand Colin, 1938, nouvelle éd., 1946. 
La Topographie légendaire des Évangiles en Terre sainte, étude de mémoire collective, P.U.F., 1942.

La Mémoire collective, reproduction du mémoire publié dans l'Année sociologique de 1949 sous le titre Mémoire et Société, Bibliothèque de Sociologie contemporaine, P.U.F., 1950.

\section{B) ARTICLES ET COURS}

Budgets de familles ouvrières et paysannes en France en 1907, Bulletin de la Statistique générale de la France, octobre 1914, p. 47 à 83.

La Doctrine d'Émile Durkheim, Revue philosophique, mai-juin 1918.

La Doctrine sociologique de Vilfredo Pareto, Revue d'Économie politique, 1918 et 1920.

Matière et société, Revue philosophique, 1921, p. 89 à 122.

L'Instinct ouvrier dans l'art industriel (Étude sur la sociologie de Thorstein Veblen), Revue philosophique, 1921, p. 214 à 233.

L'Interprétation du rêve chez les primitifs, Journal de Psychologie, 1922, p. 577 à 604.

Le Rêve et les images-souvenirs, contribution à une théorie sociologique de la mémoire, Revue philosophique, mars 1923, p. 57 à 97.

L'Expérimentation statistique et les probabilités, Revue philosophique, 1923, p. 340 à 371 .

Les Plaies d'extension de Paris du XVIIe au XIXe siècles, la Vie urbaine, 1924.

La Population et les tracés de voies à Paris depuis cent ans, Metron (Padova), 1925, $23 \mathrm{p}$.

Les Origines puritaines du capitalisme (d'après Max Weber), Revue d'histoire et de philosophie religieuses, Strasbourg, 1925, p. 132-157.

Histoires dynastiques et légendes religieuses en Chine,' d'après un livre récent de M. Marcel Granet. Revue de l'histoire des religions, 1926.

Max Weber : un homme, une oeuvre, Annales d'histoire économique et sociale, 1929.

Le Suicide et les maladies mentales, Revue philosophique, 1929, p. 321 à 360.

La Psychologie collective d'après Charles Blondel, Revue philosophique, 1929. 
Les Économistes étrangers : Gottl von Ottlilienfeld, Revue d'économie politique, 1930.

La Représentation de l'âme chez les Grecs : le double corporel et le double spirituel, Revue de Métaphysique et de Morale, 1930, p. 493 à 534.

Chicago, expérience ethnique, Annales d'histoire économique et sociale, janvier 1932, 42 pages avec deux plans.

Les Budgets de familles ouvrières aux États-Unis, Bulletin de la Statistique générale de la France, 1931, p. 395-430.

Une Théorie expérimentale du salaire (d'après le livre de François Simiand), Revue philosophique, 1932, p. 321 à 363.

Recherches statistiques sur la détermination du sexe à la naissance. Communication à la Société de statistique, Journal de la Société de Statistique de Paris, mai 1933, 32 pages, graphiques.

Un grand marchand d'Amérique : John Jacob Astor, Annales d'histoire économique et sociale, 1933.

La Loi en sociologie, cinquième semaine du Centre international de synthèse, 1934, p. 173 à 196.

« Gross-Berlin »: grande agglomération ou grande ville ? Annales d'histoire économique et sociale, nov. 1934, p. 547-570.

Les Débuts du Néo-malthusianisme en Angleterre, extrait des Mélanges Edgard Milhaud, 1934.

Les Facteurs biologiques et la population, Revue philosophique, 1935, p. 285 à 303.

La Nuptialité en France pendant et depuis la guerre (1914-18), mémoire dans les Annales sociologiques, série E, fasc. 1, 1935, 46 p.

La Méthodologie de François Simiand : un empirisme rationaliste, Revue philosophique, mai-juin 1936, p. 281 à 319.

Les Méthodes en science économique : le point de vue du sociologue, dans X-Crise, Centre polytechnicien d'études économiques, no 35, 1937.

La Population de la terre et des continents, Congrès international de la Population, Paris, 1937, Hermann, 1938, tome VII, 8 p.

La Psychologie collective du raisonnement, Zeitschrift für Sozialforschung, 1938, p. 357 à 375.

La Notion du double et les rites funéraires en Chine, Journal de Psychologie, 1938, p. 518-547. 
Analyse des mobiles dominants qui orientent l'activité des individus dans la vie sociale, Institut de sociologie Solvay, Bruxelles, 1938, p. 59 à 210 [c'est le mémoire ici reproduit].

La Mémoire collective chez les musiciens, Revue philosophique, 1939, p. 136-165.

Individual and collective Consciousness, The American Journal of Sociology, 1939.

Genres de vie. De la France d'avant-guerre à la France d'aujourd'hui, Revue d'économie politique, 1939, p. 439 à 455.

Sociologie économique et démographie, Chronique annuelle de l'Institut international de collaboration philosophique, Hermann 1940, 63 p.

Célestin Boufflé sociologue, Revue de Métaphysique et de Morale, 1941, p. 24 à 47.

La Population d'Istanbul depuis un siècle, mémoire dans les Annales sociologiques, série E, fasc. 3 et 4, 1942, p. 16 à 43.

COURS DE SORBONNE. Les Classes sociales, Centre de Documentation Universitaire, 1937. - La Psychologie collective, C.D.U., 1942. - La Statique et la Dynamique sociales chez Aug. Comte, C. D. U., 1943.

Mémoire et Société, dans l'Année sociologique, 3" série, vol. 19-10-48, P.U.F., 1949, p. 3 à 177. 


\section{ESQUISSE D'UNE PSYCHOLOGIE, DES CLASSES SOCIALES}

\section{INTRODUCTION}

$\underline{\text { Retour à la table des matières }}$

Entre les hommes qui ont vécu avant nous, surtout longtemps avant nous, et nousmêmes, d'où vient que nous imaginons communément qu'il y ait une différence si profonde et presque infranchissable ? Certes, le temps est irréversible. Pas plus qu'un individu, une société ne peut remonter le cours des âges. Mais là n'est point la seule raison de ce sentiment d'étrangeté que nous inspirent les figures du passé. Elles nous paraissent loin de nous non seulement dans le temps, mais sur l'échelle des êtres, comme si elles appartenaient à une autre espèce, semblable à nous par la forme extérieure, mais plongée dans une atmosphère où l'on ne respirait pas le même air, où les idées, les sentiments, les sensations elles-mêmes ne pouvaient être les mêmes qu'aujourd'hui. C'est bien ce qu'on imagine, lorsqu'on lit des livres d'histoire ou des romans historiques, lorsqu'on visite des bâtiments anciens, des lieux où tout est demeuré inchangé depuis un demi-siècle, plus encore lorsqu'on évoque ceux qui ont vécu dans ce décor, passé le long de ces murs, et qui sont aussi loin de nous que des fantômes ou les habitants inconnus de quelque planète inaccessible.

De tels sentiments s'expliqueraient sans peine, si, indépendamment de tout ce qui a pu se transformer dans le milieu social, et même en supposant qu'il ne change pas, ou qu'il change peu, si l'homme lui-même, c'est-à-dire l'espèce humaine était soumise à une évolution. Alors, nous ne nous reconnaîtrions plus comme des êtres faits de la même substance, ayant les mêmes organes, et capables de réagir de la même manière aux impressions qui viennent du monde matériel. Chaque génération serait considérée comme répondant à une phase définie de cette évolution organique. Elle apporterait sur la scène du monde un ensemble de types physiques : tempéraments, corpulences, 
traits, regards, paroles et gestes, qui ont été réalisés à cette date, mais dont le moule est brisé, et que nous ne rencontrons plus autour de nous. Ainsi Hésiode et les anciens croyaient que des races d'hommes diverses se sont succédé à la surface de la terre, chacune paraissant, puis disparaissant à son tour, ne laissant point de trace, si ce n'est des ossements qui semblent provenir de géants, ou des souvenirs d'exploits qui supposaient des organes d'une vigueur que nous n'avons plus.

Mais tout cela semble n'être qu'une illusion. Sans aller, comme MICHELET, jusqu'à dire que, de tous les êtres et de toutes les choses, depuis que le monde existe, c'est l'homme qui a le moins changé, reconnaissons qu'à considérer notre corps seulement, notre organisme, notre vie organique, nos organes des sens, et même notre système nerveux, entre nous et les contemporains dont les cendres d'Herculanum et de Pompéi ont conservé la forme, ceux mêmes qui se cachent dans l'ombre de la préhistoire, il n'y a pas de différence assez appréciable pour que nous ne reconnaissions en eux nos semblables et nos proches. Les traits humains d'adultes, d'enfants, de vieillards, tels qu'ils ont été peints aux diverses époques, ne les retrouvons-nous point autour de nous, et ne les reconnaissons-nous pas ? Tel ovale du visage, tel port de tête, la couleur de ces yeux, la teinte de ces cheveux, le grain de cette chair, nous les découvrons aujourd'hui chez plus d'un de nos contemporains, comme dans un portrait du XVIe siècle. Le costume a changé, niais la nature physique des êtres est demeurée : c'est un vieux Gaulois, c'est un Franc, c'est une Flamande du temps de Guillaume d'Orange, des hommes et des femmes tels qu'on en rencontrait au Palais Royal à la veille de la Révolution, qui circulent encore tu milieu de nous, et que nous pouvons saluer au passage. Il y a communauté de substance entre toutes les branches successives qui ont poussé sur ce grand arbre qui représente l'humanité : elles portent des feuilles de même dessin, des fleurs et des fruits identiques.

M. Bergson n'a pas hésité à déclarer : «Il y a une nature fondamentale, et il y a des acquisitions qui se superposent à la nature, l'imitent sans se confondre avec elle... Nous sommes imbus (fil préjugé que les acquisitions intellectuelles et inondes de l'humanité, s'incorporant à la substance des organismes individuels, se sont transmises héréditairement. Nous naîtrions donc tout différents de ce que furent nos ancêtres. Mais l'hérédité n'a pas cette vertu. C'est plutôt l'éducation, ce sont les mœurs, les institutions, le langage même, qui conservent certaines acquisitions intellectuelles ou morales, et transforment ainsi les générations. Mais si l'on éliminait de l'homme actuel tout ce qui y a été déposé du dehors, sous l'influence et par l'action de la société, on le retrouverait identique, ou à peu près, à ses ancêtres les plus lointains ${ }^{1}$. »

Ainsi les hommes seraient, au fond, toujours les mêmes, depuis, sans doute, que l'espèce humaine est apparue, avec ses traits fondamentaux, nettement détachée de l'ensemble des êtres vivants. Considérons le petit enfant, pendant les deux premières années, et même au delà - s'agit-il non plus seulement de son être physique, mais de ses impressions, du monde obscur et informe de ses représentations, de ses appétits, de ses désirs, de ses émotions, enfin, et de ses attitudes vis-à-vis des objets et des personnes ? Où voit-on une différence entre le petit enfant, envisagé sous ce rapport, au XXe siècle, dans un milieu paysan, ouvrier, bourgeois, et le petit enfant dans une de ces tribus que nous appelons primitives, qui sont seulement un peu plus proches que nous de leur point de départ, et par conséquent moins évoluées ? C'est le même

$1 \quad$ Les deux Sources de la morale et de la religion, 1932, p. 169. 
être, obéissant aux mêmes motifs, dans les deux cas, que le petit homme de Kipling, en toute cette période où l'influence de l'entourage social n'a pas encore prise sur sa nature. Si cette action ne s'exerçait pas à partir du moment où l'enfant est capable d'habitude, et surtout où il acquiert le langage, nous nous retrouverions dans le même état que les premiers sauvages, et nos actions ne connaîtraient pas d'autres motifs que les leurs.

Apercevons ici jusqu'à quel point l'homme est conditionné par la société, et combien il y a loin, comme le dit M. Charles BLONDEL, de la psycho-physiologie, qui se place surtout au point de vue biologique et porte sur la part de la vie psychique en rapport étroit avec l'organisme, et la psychologie des groupes, ou psychologie collective ${ }^{1}$. La première nous expliquera le comportement de l'homme dans la mesure où il est isolé, et ne se souvient même pas d'avoir été membre d'une société humaine, c'est-à-dire ses réactions machinales ou instinctives en présence des divers aspects du monde extérieur. Quant à ses sensations réfléchies, combinées de façon plus ou moins intelligente, et accompagnées de représentations qui se rapportent à leur but, et à leurs motifs, comment les étudier et les expliquer autrement qu'en replaçant les individus dans les groupes où ils baignent habituellement et auxquels toutes leurs pensées les rattachent?

Quels autres motifs d'agir dans la vie sociale pourraient avoir les individus, que ceux qui leur sont présentés, suggérés, et bien souvent imposés par la société ? Où découvrir les tendances religieuses ailleurs que dans les groupes confessionnels ? Et les sentiments familiaux pourraient-ils s'élaborer et se développer autrement que par le groupe domestique?

Certes on ne peut oublier que les influences d'un groupe s'exercent inégalement sur les individus, suivant leur nature personnelle, suivant aussi, qu'ils subissent déjà plus ou moins l'action de telles sociétés distinctes de ce groupe.

Considérons-nous une société religieuse? Parmi les fidèles qu'elle comprend, et qui tous acceptent en principe et, autant que possible, en fait ses prescriptions, il y a lieu, cependant, de distinguer, de la masse des tièdes ou des indifférents, ceux qui témoignent de plus d'ardeur et de plus d'esprit de prosélytisme. Dans une enquête très

Introduction à la psychologie collective, 1929, pp. 32 et 193. Voir aussi notre compte rendu : Revue Philosophique, 1929, nos 5 et 6 : La Psychologie collective d'après Charles Blondel. Résumant la conception d'Auguste COMTE - « Il n'y a as une psychologie, mais bien trois psychologies, dit le Dr BLONDEL. Il y a d'abord la psycho-physiologie, qui traite en particulier des fonctions sensori-motrices. C'est une science toute biologique, où les phénomènes psychiques trouvent immédiatement leur clef et leur raison d'être dans leurs conditions morphologiques et physiologiques, sans qu'il y ait jamais eu lieu de faire appel à des considérations d'un autre ordre et à l'influence de la vie en société... Vient ensuite une psycho-sociologie, une psychologie de l'homme tel que le révèlent l'histoire et la ie sociale. Cette psychologie émane de la sociologie et serait impossible sans elle. Plutôt qu'une psychologie de la collectivité, qu'une psychologie collective, elle est une psychologie de l'espèce, car elle nous apporte en réalité la psychologie de l'homme en général, puisqu'il n'y a qu'une nature humaine, puisque le social prolonge le biologique. Enfin, il y a une psychologie proprement individuelle. » (Ibid., p. 32). Pour notre part, nous désignerions du nom «psychologie de l'espèce » plutôt la première. 
importante et entièrement neuve, qui a été faite récemment par $\mathrm{M}$. Gabriel LE BRAS ${ }^{1}$ sur les croyances religieuses en France, d'après les rapports et données tenus à jour des paroisses et des diocèses, et qui constituent en quelque sorte l'état civil des âmes, on a adopté un cadre assez simple : parmi les fidèles, combien pratiquent effectivement leur religion, vont à la messe, et souvent aux vêpres, lotis les dimanches de l'année, communient ait moins à Pâques, etc. ; combien sont des observants des quatre saisons, c'est-à-dire, à chacune des grandes saisons de leur vie, naissance, âge de discrétion, adolescence, et mort, passent par l'église pour le baptême, la première communion, le mariage et les obsèques; combien, enfin, bien qu'ayant été baptisés, se marient et se font enterrer civilement?

Nous reviendrons sur les résultats de cette enquête. Observons seulement ici que cette diversité d'attitude s'explique par deux sortes de causes. Les unes tiennent au tempérament, au caractère, à la disposition d'esprit ; tel naît porté au mysticisme, à la méditation intérieure ; tel éprouve naturellement le besoin de se plier à des rites, de s'agréger à une confession. Il y a, à cet égard, de véritables familles spirituelles qui débordent les cadres des groupes confessionnels, et dont on retrouve les membres dans les religions les plus éloignées, à travers le temps oit l'espace. Chez de tels êtres, le motif religieux sera tout-puissant parce qu'il trouve le terrain tout préparé, il tombe sur un sol qui semble attendre depuis longtemps la semence. Pénétrant en eux, il éveillera un ensemble de tendances toutes prêtes à se manifester : il prendra la forme individuelle.

D'autres offriront une prise moins aisée à la religion, soit par suite d'un peu plus de sécheresse d'âme et de sensibilité, soit, tu contraire, parce qu'ils obéissent à des attraits plus sensibles, à la force des appétits, a l'entraînement des passions. Membres d'un groupe religieux, parce qu'ils sont nés dans une famille qui s'y rattachait déjà, par habitude et comme par prescription, ils se confondent dans la troupe passive de ceux qui suivent le courant. A leur propos on peut bien dire que leur religion vient du dehors, qu'elle s'impose à eux, qu'elle leur est véritablement extérieure. De tels fidèles feront les gestes obligatoires, et accepteront de porter l'étiquette, le nom de leur groupe, tant que le motif puisera sa force dans l'adhésion des autres; tout dépendra de l'intensité des croyances autour d'eux, et, aussi, du nombre plus ou moins grand des croyants.

Quant à l'autre cause, c'est le fait d'appartenir, par la profession, par le cercle de ses relations, et encore par son habitat, à des groupes dont l'action favorise ou contrarie les motifs confessionnels : c'est, si l'on veut, tout le reste de la personnalité de l'individu, en dehors de ce qu'il engage de lui-même dans le groupe religieux.

Mais il en est de même de beaucoup d'autres motifs collectifs. D'abord, de l'esprit de famille. Il est commun, apparemment, à tous les membres du groupe domestique. Rarement un père, une mère, un fils déteste les siens, et même ne pense à eux qu'avec froideur. "Famille, je te hais », dira un écrivain, qui tirera quelque raison d'orgueil de son détachement même. Qu'on lise cependant, dans le Journal de Jules RENARD, qui sut nous apitoyer sur le martyre de Poil de Carotte, c'est-à-dire de lui-même enfant,

1 Les Transformations religieuses des campagnes françaises depuis la fin du XVIIe siècle (Annales sociologiques, série E, fasc. 2, 1937, p. 12). - [Cette enquête s'est largement développée depuis 1937. Voir notamment, du même auteur, Introduction à l'étude de la pratique religieuse en France, Bibl. de l'École des Hautes Études, section des Se. religieuses, tome LVII, 1943-45, 2 vol., et de nombreux articles de revues.] A.C. 
qu'on lise les lignes et les pages où il est question de la mort de son père : douleur sincère, profonde, et regrets émouvants qui ne cherchent pas à se cacher, et dont l'auteur répète et prolonge l'écho, sans souci des autres, sans respect humain, et connue s'il avait renoncé, pour quelque temps, à jouer un personnage.

Pourtant, l'esprit de famille est senti à des profondeurs inégales, suivant qu'on est en quelque sorte prédisposé, on qu'on ne l'est point, à s'épanouir à la chaleur du foyer, dans l'atmosphère familiale. C'est pourquoi l'on peut toujours, dans une famille, désigner quelqu'un (ce n'est pas toujours nécessairement le «père de famille », on la mère, ou le fils aîné, c'est quelquefois une vieille tante, ou un cousin éloigné), qui, plus due les autres, est attaché aux traditions familiales, les comprend, en assure la continuité. A partir de celui-là ou celle-là, qui en est ni en quelque sorte le centre, on peut distinguer encore bien des degrés dans l'intensité de l'esprit domestique, qui ne s'entretient chez beaucoup de parents que par la force de l'habitude, qui pâlirait vite jusqu'à s'évanouir et se disperser, si les parents ne restaient pas serrés l'un contre l'autre, ou ne multipliaient pas les occasions de se réunir.

Ainsi les dispositions innées interviennent toujours : tout homme sans doute aime les siens comme s'il les avait choisis, mais les liens familiaux sont renforcés par les affinités individuelles et presque électives ${ }^{1}$. Il y a d'autre part des personnes qui ne se réalisent que dans le rôle du père, de la mère, de l'époux, du frère, etc. La famille ne serait qu'un centre inerte, si elle n'était pas animée et vivifiée par de tels êtres qui sont comme un don que lui fait la nature.

Que dire, pour prendre un dernier exemple, de la politique, des sentiments qui nous attachent à un parti ou à une cause, qui se trouvent si répandus, qui en certains moments s'emparent de l'homme tout entier, lui dictent ses paroles et ses actes, le dressent contre ses meilleurs amis, et qui passent tellement à l'arrière-plan, chez beaucoup d'autres, et même chez tous en beaucoup de périodes?

Il ne s'agit point là, à vrai dire, de préoccupations éphémères et superficielles. Que les convictions politiques (quelle que soit d'ailleurs leur profondeur, et si restreinte qu'apparaisse la place qu'elles tiennent dans beaucoup d'existences), (tue les sentiments par lesquels on se sent lié à ceux qui pensent comme nous sur les problèmes de gouvernement, soient relativement très stables, et changent très lentement, dans un pays, c'est ce qui résulte de la comparaison qu'on a pu l'aire entre les résultats électoraux d'une époque a l'autre. M. Siegfried a observé pendant une longue période la distribution des partis dans toute une partie de la France, et souligné à quel point les positions demeurent stables à cet égard, à travers tout un demi-siècle ${ }^{2}$.

C'est donc que les attitudes politiques ne résultent point des dispositions individuelles, de l'humeur, du caractère, mais sont en rapport avec des conditions collectives permanentes, ou qui ne se transforment que très lentement. On aperçoit bien d'ailleurs ici, et M. SIEGFRIED a indiqué quelles étaient ces conditions elles-mêmes : subsistance, dans l'Anjou, le Maine, toute une partie de la Bretagne 'et de la Normandie, de grandes propriétés qui n'ont pas été démembrées par la Révolution ; puissance

Sur le rôle de la personnalité, des personnalités que sont ses divers membres dans la famille, voir notre livre : Les Cadres sociaux de la mémoire, Paris, 1925 da mémoire collective de la famille, p. 222).

2 Tableau politique de la France de l'Ouest, Paris, 
effective et prestige des grandes familles, qui continuent les anciennes lignées nobles d'autrefois ; soit qu'elles portent leur nom, soit qu'en succédant à leurs biens elles aient pris leur place dans l'opinion. En tout cas, elles réussirent à conserver leurs privilèges, dans la mesure où ceux-ci étaient compatibles avec les lois. Elles ont maintenu en pleine vigueur beaucoup de vieilles coutumes par lesquelles le peuple des campagnes demeure moralement dans leur dépendance.

Ailleurs, et jusque dans ces régions elles-mêmes, en bordure des côtes, à l'embouchure des grands fleuves, aux points de croisement des lignes de chemin de fer, un esprit nouveau se fait jour. C'est que la population est détachée des traditions, qu'elle est dominée par ce qu'on peut appeler des représentations de classe, qu'à la sortie de l'usine, et dans les quartiers où ils habitent, les travailleurs se rapprochent, se confrontent, et prennent conscience, par opposition aux autres groupes sociaux, de l'identité de leur situation et de la communauté de leurs intérêts.

Vieilles oppositions, en somme, qu'on retrouve à l'aube de la vie et de la pensée politique, dans l'Athènes du Ve et du VIe siècle. Dès ce moment il y avait des conservateurs, comme Platon, attachés au principe de l'hérédité, regrettant le régime des castes tel qu'on en trouvait encore des vestiges en Crète ou dans le Péloponése. Ils recommandaient l'agriculture, la vie frugale et simple, la limitation des richesses. Se défiant du commerce parce qu'il introduit le goût des nouveautés, ils s'efforçaient aussi de réduire extrêmement et de supprimer si possible les rapports avec l'étranger. D'autre part, des démocrates, tournant le dos à cet idéal désuet d'un pays archaïque dominé par des vieillards et des prêtres, préfèrent se laisser traverser et porter par tous les courants de la vie moderne. Ils donnent toutes facilités aux marchands, développent leur marine de commerce, restent en contact avec les habitants des îles et des côtes lointaines, et s'efforcent d'accroître la richesse publique par des échanges avec l'étranger ${ }^{1}$.

Ainsi, à travers le temps, les différences et oppositions entre les tendances et les partis politiques se retrouvent, très comparables à une époque ou d'une société à une autre, parce qu'elles correspondent à une diversité de situation économique et sociale qui est elle-même un trait permanent de toute vie nationale comme de toute cité.

Cependant ici encore, comme à propos des croyances religieuses et de l'esprit de famille, on percevrait que l'ordre des motifs politiques comporte bien des degrés, quant à la force de son action sur les pensées et sur les conditions.

De ce foyer il y en a qui s'approchent tout près, qui en reçoivent tout le rayonnement, qui sont les premiers et les plus actifs à l'alimenter, et à qui il arrive de s'y consumer eux-mêmes. D'autres ne s'y exposent qu'à moitié, ou ne le regardent que de loin, ou même ne s'en préoccupent pas, et ne font aucun effort pour s'en approcher. De même que les fidèles des quatre saisons, il y a ceux qui ne s'intéressent à la politique qu'à des intervalles assez lointains, en période électorale peut-être ${ }^{2}$. En dehors de ceux-là, les indifférents, qui s'abstiennent même d'aller voter tous les quatre ans. Au delà, les « citoyens conscients », qui lisent des journaux nettement orientés ou, dans les journaux d'information, s'intéressent surtout à la rubrique électorale

Von WILAMOWITZ MOELLENDORFF, Platon, I. Band, 1920.

C'est ce dont témoignerait, d'après Durkheim de Suicide, étude sociologique, 1897, 21 éd., 1930), le fait qu'aux années d'élection, aux mois pendant lesquels dure la période électorale, la proportion des morts volontaires diminue sensiblement pour remonter ensuite. Voir aussi notre livre : Les Causes du suicide, Paris, 1930, pp. 336 et 349. 
parlementaire ou syndicale, et qui sont même affiliés à un parti. A l'extrémité, enfin, non seulement les professionnels de la politique, mais ceux qui se passionnent pour elle, et sont capables, plus que les autres, d'éprouver intensément le genre d'émotion et d'exaltation qu'elle suscite : animateurs, propagandistes, qui, par le discours, le journal, la conversation, s'efforcent de réduire et rebuter leurs adversaires, de gagner à leurs causes les hésitants, de ramener les défaillants ; autant d'occasions, d'ailleurs, de s'affermir eux-mêmes en leur voie et leur vocation.

Or il suffit de jeter un coup d'œil sur l'histoire moderne et ancienne : on aperçoit que ceux qui jouent ainsi les premiers rôles en politique, sur quelque théâtre d'ailleurs que ce soit, y sont portés et disposés par quelque trait de leur nature individuelle : tempérament expansif, passionné, tendances combatives, esprit d'intrigue, comme aurait dit FOURIER, esprit de coterie, ou esprit de partisan comme on dirait aujourd'hui, goût de la vie publique qui a ses agitations, ses accalmies, ses rumeurs, et ses vastes perspectives, comme la mer, sentiment qu'éprouve le «politique né » dans son élément, au cœur des assemblées petites et grandes où les courants d'opinion fermentent, se transforment, où l'on sent, où l'on pense à l'unisson des autres souvent, en tout cas toujours à leur contact et en liaison avec eux.

Ceux qui s'occupent des affaires publiques y sont, souvent aussi, préparés et prédisposés par leur milieu, leur situation sociale, la famille d'où ils sortent, le groupe professionnel auquel ils se rattachent. Ceci, d'ailleurs, en deux sens et comme sur deux plans assez différents.

Rappelons-nous, par exemple, comme CICÉRON, dans le Pro Sestio, définit les optimates ; disons, en écartant d'ailleurs toute pensée péjorative, " les bien pensants »: «On y trouve les premiers inscrits sur la liste du Conseil publie (principes consilii publici). On y trouve les sénateurs qui marchent à leur suite. On y trouve les citoyens des ordres les plus élevés auxquels est ouvert l'accès du Sénat, les chevaliers, les publicains, les tribuns du trésor. On y trouve les citoyens des municipes et de la campagne (municipales rusticique Romani). En somme, ceux qui, ayant l'âme saine, et se trouvant en une situation matérielle sans embarras, se conforment aveuglément, dans l'administration des affaires publiques, aux vues, aux intérêts, aux désirs des honnêtes gens. » C'est bien là une des sources de ce qu'on peut appeler le personnel de la politique. Mais il y en a une autre, moins pure, même boueuse et contaminée, au jugement de l'orateur latin. C'est le groupe de « ceux qui se trouvent (par leur condition) ne pas approcher du pouvoir, et qui voudraient s'emparer du gouvernement, ceux qui, conscients de leurs vices et de leurs crimes, sont avides de transformations ou de révolutions politiques, ceux qui, parce qu'ils sont nés en quelque sorte avec une âme de révolté, se repaissent des discordes et des dissensions civiles ou bien, en raison de l'état embrouillé de leurs affaires, aiment mieux périr dans l'incendie général que dans celui qui les touche seuls ».

Diptyque tendancieux : CICÉRON exalte ses amis, noircit ses ennemis, prête un sens moral à ce qui est surtout une distinction de classe. Il n'en est pas moins vrai qu'il y a des milieux sociaux où se recrutent surtout les dirigeants, ceux qui aspirent à l'être, d'autres d'où sortent sinon les révolutionnaires, du moins les hommes d'opposition. Sous le régime de la monarchie française, si peu favorable à la vie et à l'activité proprement politiques, il y a eu cependant des périodes de crise où « les deux sources » de la vie politique se peuvent assez clairement distinguer : au temps d'Étienne Marcel, des luttes entre Armagnacs et Bourguignons, des soulèvements 
municipaux du XVIe siècle ; plus tard, quand «les politiques » modérés, graves et conciliateurs au nom de l'intérêt publie, se heurtent aux fanatiques furieux et aux intrigants de la Ligue : mouvement politique et religieux, oit le motif religieux est tout coloré de politique plutôt que l'inverse peut-être, mais qui produira comme un remous retardé, la Fronde, oit le motif politique passera nettement -ait premier plan., incarné magnifiquement en un politique de première classe et intrigant de race, tel que le cardinal de Retz.

Mais c'est un siècle et demi plus tard, dans la Révolution française, que les deux espèces d'hommes politiques se manifesteront le mieux, constructeurs et destructeurs, si l'on veut ; mais on trouve des uns et des autres, à chaque phase, ou dans chaque acte de ce drame politique si concentré, et il arrive d'ailleurs, au cours de ces rapides changements à vue, qu'un destructeur d'hier révèle demain qu'il avait étoffe d'un homme d'ordre, et que, même, les deux natures contradictoires se montrent temporairement unies chez tel ou tel.

Ajoutons ceci : il arrive que des classes élevées sortent des natures d'agitateurs, et que s'élèvent des couches inférieures du peuple des êtres d'exception, doués pour le gouvernement et capables de politique constructive. Ainsi, causes individuelles et conditions sociales concourent à la fois, en proportions diverses, et en des sens imprévisibles, à élaborer et former tels caractères et tels esprits individuels, qui subiront plus pleinement que les autres l'action des motifs politiques, et qui en seront même bien souvent l'incarnation et la vivante image.

Mais, quelque compte qu'il faille tenir des dispositions naturelles des individus, et des différences entre eux, au sein d'un même groupe, qui ne tiennent en effet qu'à eux et à leur organisme, reconnaissons en tout cas qu'elles n'auraient pli s'épanouir, et ressortir avec un tel relief, sans un autre «climat », c'est-à-dire si l'individu ne s'était point trouvé pris en tel milieu ou telle organisation sociale.

Les motifs divers dont nous avons parlé, en effet, n'apparaissent point tels quels dans la pensée d'un homme ou d'un autre, comme s'ils n'étaient que le développement d'un germe où l'on pourrait les découvrir, préformés. Autant dire qu'un homme naît clerc de notaire, horloger, ou chimiste.

Soutiendra-t-on que nous apportons avec nous, dans le monde où nous entrons dès la naissance, des dispositions religieuses bien arrêtées ? Mais vers quelle religion ? 'Tel catholique, ardent prosélyte, qui réalise si pleinement l'idéal du croyant et même du saint, tel qu'on l'imagine, dans son église, et dont les traits, le caractère sont en quelque sorte fixés par une longue tradition supposons qu'il soit né protestant, et, plutôt, bouddhiste ou mahométan, membre d'une tribu oit d'un clan oit l'on croit aux totems, où l'on pratique des rites barbares. Croit-on qu'en tous ces groupes, et à leurs yeux, sa conduite eût été aussi édifiante, et qu'il se fût senti porté avec le même zèle vers des cultes et des formes de dévotions aussi diverses et même opposées ? Mais ce n'est pas dans les milieux les plus religieux du paganisme que se recrutèrent les premiers chrétiens. Pour beaucoup d'hommes qui ont le choix, c'est-à-dire qui entrent dans un groupe confessionnel, ce qui les attire dans une religion, c'est ce qu'ils ne trouvent pas, précisément, dans une autre. 
Entre les prêtres de toutes les religions, il y a, certes, des analogies et des affinités: tel curé de campagne qui appelle sur les champs, sur les troupeaux, la bénédiction du Seigneur, on le voit assez bien, au temps du paganisme, offrant un sacrifice en faveur d'une famille ou d'une cité. Il y a une attitude et une pompe sacerdotale par où le souverain pontife d'aujourd'hui rappelle le grand pontife d'autrefois. Pourtant n'oublions pas qu'au temps des Romains la prêtrise était une magistrature, qui ne durait le plus souvent qu'une année, et que le culte, chez eux comme chez les Grecs, offrait un caractère politique très accentué ${ }^{1}$.

Si l'on ne s'en tient pas au dehors, aux gestes, aux formules, on est frappé de ce que les divers cultes offrent satisfaction à des instincts et sentiments très différents, et surtout, de ce qu'ils sont bien conformes au caractère et aux coutumes nationales. L'organisation religieuse et le système de croyances qui est à sa base ne sont point comme l'épanouissement de tendances naturelles communes à un certain nombre d'hommes. Bien plutôt, le groupe religieux, qui, sans, doute, sait choisir, appeler à lui, utiliser en vue de ses fins ceux de ses membres en lesquels il se reconnaît le mieux. ce groupe, aussi, les modifie et les modèle à sa manière, et se crée ainsi des organes qui n'étaient point tels d'emblée, qu'il lui a fallu former en lui, peut-être à l'aide d'éléments pris ailleurs, et animés de son esprit.

Saint Martin, grossier soldat s'il fût resté dans le paganisme toute sa vie, tiendra une place de premier plan dans l'organisation catholique, dont il a sans doute compris tout de suite les tendances. Les chrétiens, de leur côté, ont reconnu en lui un de ceux qui, au nom du christianisme, seraient capables d'exorciser le malin, de donner aux hommes l'exemple de la pénitence. Il a été appelé sur un plan plus haut. Mais d'autres, pris dans le inonde, d'une éducation raffinée, d'une intelligence supérieure, tout paganisme, et même étrangers à toute religion formaliste et rituelle, ont été attirés vers le jansénisme par exemple, vers les formes les plus rigoureuses et les plus étroites de la spiritualité chrétienne. Pour les esprits modérés et de bon sens, ils sont descendus à un plan inférieur.

Le groupe religieux appelle ses auxiliaires des rangs les plus élevés comme les plus bas dans l'échelle sociale et quant aux degrés de la culture. Avec des éléments empruntés à d'autres groupes et milieux, il construit son édifice, frappe à son effigie de nouveaux modèles et de nouveaux mobiles, se félicitant d'ailleurs de rencontrer des matériaux de qualité, qui se plient mieux aux formes qu'il cherche, qui en portent même en eux, par hasard, les premiers linéaments.

Mais il en est de même, bien que nous paraissions toucher là un fond plus primitif, plus organique ou plus animal, le fond de l'espèce, il en est de même de l'esprit de famille, faisceau de sentiments dont il faut découvrir les racines. Plongent-elles dans la nature de l'individu comme tel ? Mais naît-on membre d'un groupe domestique, apporte-t-on dès la naissance tout ce qu'il faut pour comprendre ce groupe, et s'identifier à lui ? En puissance, oui, l'homme est fils, mari, père, grand-père : il suffit qu'il s'élève peu à peu dans l'échelle des âges, pour qu'il entre naturellement dans ces rôles successifs. Mais est-ce le rôle qui est fait pour l'acteur, ou l'acteur qui s'assimile au rôle ? Il y a eu et il y a encore bien des types de familles, sans remonter -au régime des clans, et à ce qu'on appelle les parentés classificatoires, et il y a eu une évolution bien nette de la grande famille patriarcale à la famille monogamique, laquelle tend à se réduire au couple des parents et aux enfants. Or, ni le père, ni l'enfant, dans ces

Fustel de Coulanges: La Cité antique (1864) et Jules Martha: Les Sacerdoces athéniens (1882). 
deux types, n'occupent la même place, et ne pourraient exactement se substituer l'un à l'autre.

L'esprit de famille, dans le premier type, c'est la tradition de la race, c'est l'orgueil du nom, et l'attachement au patrimoine : rien n'est inné, c'est de l'acquis, de l'appris, du transmis ${ }^{1}$. La force de tels sentiments imite la puissance des instincts naturels. On ne découvrira rien d'instinctif, pourtant, en des représentations et états affectifs dont l'intensité s'explique par la longue durée de ce groupe, par le nombre de ceux qui en font partie, et aussi par sa stabilité et sa consistance. Chacun de ses membres est sensible à la fois au volume et à la masse de la grande famille, à son étendue, dans l'espace et dans le temps. Le prestige du père est tel, et la docilité des enfants si entière, en ces sociétés, qu'il est difficile de distinguer ici l'individu de la fonction et ses qualités propres, de celles qu'on acquiert du fait seul qu'on l'exerce. Dans la masse des parents il en est toutefois, nous l'avons dit, qui sont plus en relief, qui seront des guides et des modèles ; intelligence de plus d'expérience, caractère plus impérieux ou volonté plus forte, don plus généreux de soi à son groupe, sensibilité, susceptibilité plus grande à tout ce qui représente pour lui la bonne on la mauvaise étoile, voilà ce qui explique que dans le groupe domestique étendu certains subissent plus que les autres l'action de ce motif qu'est l'esprit de famille. Il a fallu, en tout cas, pour qu'ils se forment et se manifestent, une longue éducation, et un milieu peuplé d'images familiales.

Mais la. même formation ne répond plus aux conditions de la famille conjugale et ce n'est plus le même ordre de sentiments qui intervient ${ }^{2}$. Qu'un jeune homme se sente opprimé, à l'étroit, dans une grande maison traditionnelle, avec les grandsparents et les cousins éloignés: il ne sera, dans un tel milieu, ni bon fils, ni bon père de famille. Qu'il s'en détache, forme un ménage, vive avec ses enfants et sa femme à l'écart du reste des siens, rien n'empêche qu'il se révèle bon époux et bon père ; foyer étroit, mais autour duquel les membres se resserrent d'autant plus, traditions courtes d'autant plus colorées et présentes.

$\mathrm{Au}$ reste, ces familles élémentaires, dont le noyau résistant est le ménage, plongent dans un milieu formé de tous les petits groupes semblables. Il circule une vie commune dans cet ensemble. Il s'y dégage des tendances (titi exercent une influence assez forte sur les ménages voisins, et qui ont pour effet d'établir de l'un à l'autre toute une série d'adaptations. Il ne suffit donc pas, polir alimenter l'esprit de famille, de s'enfermer dans son ménage. C'est une condition de la famille monogamique de s'ouvrir largement, en tout cas fréquemment, sur les autres, et sur le inonde social extérieur, et, au moins tant que le ménage est jeune, de se répandre un peu. On voit à quel point, le père, l'enfant, sont autres dans ce milieu moderne qu'au temps des grandes tribus familiales, et en même temps, qu'eux aussi sont formés de façon à bien remplir leur rôle, par tout un ensemble d'influences sociales. C'est la société moderne qui réussit à extraire en quelque sorte, d'un certain nombre d'hommes, les aptitudes à créer et développer les modes d'union conjugale et de la vie familiale adaptés aux

Sur la famille traditionnelle, la grande famille, voir - LE PLAY, Les Ouvriers européens, 5 vol., 1878 , en particulier vol. III, Populations stables soumises aux meilleures coutumes de l'Orient et du Nord.

2 Durkheim, La Famille conjugale (Revue philosophique, janvier-février 1921). Leçon extraite d'un cours inédit sur la famille, professé à l'Université de Paris. Voir aussi Georges Davy, Sociologues d'hier et d'aujourd'hui, Paris, 1931 : La Famille et la parenté d'après Durkheim, p. 103. 
conditions de la vie d'aujourd'hui. Ces qualités seraient demeurées inertes et inaccessibles, en toute autre espèce de civilisation.

Enfin toutes les dispositions à l'activité et à la pensée politiques qui existent, nous dit-on, dans la nature des hommes avant même qu'ils soient mêlés à la vie sociale, croit-on qu'elles puissent se développer hors de certaines circonstances, et que les formes sous lesquelles elles apparaissent au jour, et qui ne conviennent jamais qu'à une partie des natures ainsi disposées, ne résultent pas. des institutions, des croyances et du moment de l'évolution où le groupe se trouve parvenu?

Songeons aux hommes de la Révolution. Il est remarquable qu'en quelques mois soit sortie de la masse du peuple, plus exactement de la petite bourgeoisie, bien plus restreinte, une telle quantité d'hommes capables d'éprouver avec intensité toutes les passions qui naissent dans les assemblées, les sections, les comités, et que, sous la pression des événements, une telle somme d'efforts, d'émotions et de pensées politiques ait pu être concentrée en un si petit ensemble humain. D'autant plus que, lorsqu'on envisage individuellement chacun de ceux qui furent les principaux personnages du drame, il apparaît que rien ne les y préparait. Dans les villes de province où ils menaient auparavant une existence sans éclat, nombre d'entre eux, même, ne s'intéressaient que modérément à la marche des affaires publiques. Une fois transportés sur les lieux où s'agitent ces questions, rapprochés d'autres hommes semblables à eux, il a bien fallu que quelques-uns prennent la tête, et soient désormais les représentants des autres et du groupe.

Or ils ont été peut-être choisis, détachés de l'ensemble, mis en relief parce qu'ils se distinguaient en effet des autres par la puissance de. leurs convictions et, également, parce qu'ils réagissaient avec plus de force, parce qu'ils apportaient dans les débats une note plus originale, une figure plus personnelle. Mais si le groupe les a ainsi mis en vedette, c'est qu'en eux il se reconnaissait le mieux, parce que c'est lui qui avait donné cette orientation à leur pensée et ce ton à leur affectivité. "Je suis, je marche à la suite de celui qui me suit le mieux » : telle est bien l'attitude d'un ensemble d'hommes que domine une forte passion collective. Il y a du hasard, de la chance, en de tels choix et de tels succès politiques. Celui qui en profite, souvent n'a plus qu'à se laisser porter. C'est au cours des débats et des luttes que sa personnalité se dégagera, bien différente de ce qu'elle eût été en tout autre milieu, en tout autre temps.

Quand nous songeons aux hommes politiques de notre époque, nous nous figurons quelquefois qu'ils sont tels que nous les connaissons en raison de leur nature, et nous ne tenons pas assez compte de tout ce que leur physionomie emprunte aux milieux qu'ils ont traversés. Depuis les assemblées locales paysannes ou urbaines dont ils se sont lentement et insensiblement assimilé l'esprit, jusqu'aux comités parlementaires qui surent les pénétrer de leurs traditions, et faire d'eux, simplement, les meilleurs interprètes de tendances et d'opinions communes.

Ce qu'il faut retenir, en somme, de cette analyse, c'est que les divers motifs généraux, religion, esprit de famille, patriotisme, opinion politique (et nous en dirons autant de tous les autres) n'exercent pas sur tous les hommes, et sur tous les membres d'un groupe, une action uniforme, comme les gouttes de pluie ou les rayons de soleil tombent sur tous les arbres de la forêt, et cela est trop évident. Mais, en outre, il faut que dans toute société, il y ait comme une gradation, de ceux qui sont les plus 
sensibles aux idées et émotions communes, qui semblent mieux les manifester, à ceux qui sont plus indifférents, plus difficiles à ébranler et intéresser. Cette diversité entre les membres, cette différenciation dans la structure du groupe est le seul moyen d'assurer la durée et de maintenir la force des tendances qui le caractérisent, des motifs sociaux qu'il représente et impose aux hommes qu'il comprend.

En effet, la conservation de ces tendances et croyances ne s'opère pas d'ellemême, comme par l'action d'un pouvoir d'inertie. A mesure, au contraire, que le temps s'écoule, les croyances tendent à s'affaiblir, et les opinions s'obscurcissent, parce qu'elles se propagent au sein d'une masse humaine assez passive, et qui n'est pas naturellement disposée à faire l'effort nécessaire pour les retenir. Il faut donc qu'il y ait une région du groupe où elles se renforcent au -contraire et soient plus claires, plus manifestes, et, dans cette région, quelques individus qui concentrent en eux ces croyances et ces opinions et chez qui elles aient une telle force qu'à partir d'eux elles ne cessent pas de rayonner dans tout l'ensemble.

Nous l'avons vu pour le groupe confessionnel pour la famille, pour les partis politiques : toujours, dans chacune de ces sociétés, c'est le rôle de quelques personnes de représenter le plus nettement les tendances communes, et, par 1'exemple au moins, de les fortifier. Ajoutez que la pensée des hommes a besoin «incarner en des êtres comme eux, mais qu'ils imaginent très au-dessus d'eux par la nature de leur esprit et de leurs instincts, d'incarner en eux ces tendances elles-mêmes, comme S'ils en étaient les dépositaires et la source.

Qu'on songe à l'empereur de Chine, le fils du Ciel, qui, au renouvellement de l'année, parcourait les salles du palais orientées vers les points cardinaux, et s'arrêtait successivement face au nord, face à l'est, face au sud, face à l'ouest, pour remettre en ordre, rétablir dans son équilibre à la fois son empire et le monde ${ }^{1}$. Ainsi la société tout entière paraissait être concentrée dans l'empereur. De la même façon, il appartient, nous semble-t-il, à de tels individus parmi les autres, de réveiller la foi dans l'église, l'esprit de famille dans le groupe domestique, et les convictions politiques au sein des partis.

Bien que cette action ne cesse pas de s'exercer, de ces individus à J'ensemble, du centre aux parties, sous une forme ou l'autre, il y a cependant des époques, périodiques ou non, où elle se révèle particulièrement efficace. Il semble. qu'à intervalles plus ou moins longs, la consciente collective ait besoin d'être réveillée, en quelque sorte rechargée, et qu'à cette condition seulement les motifs généraux puissent pénétrer à nouveau dans les pensées individuelles, comme pour y commencer une nouvelle carrière, Quels motifs agissent sur les hommes, dans la vie sociale, nous demandions-nous ? Toute la question est de savoir à quel moment nous considérons les hommes, les individus. Nous ne dirons pas qu'ils mènent une vie double ou triple, etc. Certes, lorsqu'on analyse la conscience d'un individu, ou sa propre conscience, soit en s'observant, soit en se jugeant sur les actes qu'on a accomplis, durant un temps qui est nécessairement limité, mais qui petit comprendre toute une série de périodes successives, on aperçoit bien la diversité des motifs qui ont eu, qui ont encore prise sur nous. Il n'en n'est pas moins vrai que, suivant les moments, nous sommes surtout sous l'influence de tel d'entre eux, et que l'action des autres ne peut être alors que très amortie.

Marcel GRANET La Civilisation chinoise. La vie publique et la vie privée, Paris, 1929, p. 446 da « Maison du Calendrier -à). voir aussi, du même, La Pensée chinoise, Paris, 1934, p. 92. 
Nous placerons-nous, au contraire, au point de vue non de l'individu mais, successivement, au point de vue des divers groupes dont il fait partie ? Nous examinerons ces groupes, au moment où la vie collective y est le plus intense, et nous nous apercevrons que la vie de chaque groupe se développe suivant des périodes ou des Phases alternées plus ou moins longues, phase (je vie exaltée, de réveil et de plénitude, puis phase d'existence ralentie, de sécheresse et d'indifférence, dans la monotonie des occupations et pensées quotidiennes ${ }^{1}$. Temps des cérémonies religieuses, des réunions de famille à l'occasion d'un mariage, d'une naissance, d'un anniversaire, période de luttes politiques, et après, repos et oubli relatif des émotions vécues et des activités.

Or, si la vie collective se développe ainsi par périodes et comme suivant une série de cycles, c'est parce que toute dépense d'énergie, affective ou psychique, ne peut être que temporaire, et qu'il faut s'en remettre et réparer ses forces, mais c'est surtout parce qu'il y a en toute société, comme nous l'avons vu, une dualité d'éléments, les uns très représentatifs du groupe et plus pénétrés de son esprit que les autres, ceux-ci plus passifs, parcourus par des courants de pensées qui les soulèvent et les entraînent quelque temps, mais que, réduits à leurs forces, ils laisseraient se perdre. C'est pourquoi les éléments les plus actifs doivent périodiquement les rénover, et même les recréer.

N'en concluons pas que les forces qui règlent notre conduite dans la vie sociale ne sont que des motifs individuels, inventés par tels individus, reçus et propagés par les autres, inventions suivies d'imitations, comme l'avait soutenu Gabriel TARDE ${ }^{2}$. Car les individus en lesquels nous voyons les éléments les plus actifs, les seuls .vraiment actifs du groupe, nous avons montré aussi qu'ils ont été formés par le groupe à son image, et que toutes leurs originalités et tous leurs prestiges -viennent de ce qu'ils concentrent en eux une part plus grande des représentations collectives, et sont capables de les retenir plus longtemps. Ne nous contentons pas d'une opposition trop simple entre l'élite et la masse, les personnalités qui compteraient seules et les groupes anonymes, matière informe ou qui ne reçoit sa forme que de ceux qui s'en dégagent. Voyons plutôt le nombre des individus ou personnalités que produit n'importe quel ensemble social et leur qualité et aussi l'intensité et la vitalité de conscience dans le groupe tout entier.

Dès lors, si nous voulons passer en revue et décrire les principaux motifs dont s'inspirent les hommes dans la vie sociale, comment procéderons-nous ? Nous ne partirons pas d'une liste des mobiles de nos « conduites », comme disent les psychologues, d'une liste telle qu'un psychologue, en effet, pourrait d'avance la dresser ; on en trouvera dans beaucoup de manuels de sociologie, et nous ne mettons pas d'ailleurs en doute l'utilité didactique d'une telle présentation ${ }^{3}$. Mais la marche d'une enquête doit être différente, et même tout autre. Ces motifs généraux, esprit de famille, ambition, épargne, recherche des biens matériels, des distinctions, désir d'améliorer sa

Maurice Halbwachs, La loi en sociologie, dans Science et Loi, Cinquième Semaine internationale de Synthèse, 1933, p. 187.

Les Lois de l'imitation, Paris, 1895, 4e éd., 1904.

William Mac Dougall, An Introduction to Social Psychology, Londres, 1921, et The Group Mind : a Sketch of the Principles of Collective Psychology with Some Attempt ta apply them Io the Interpretation of National Life and Character, Cambridge, 1920. - Voir aussi G. Davy, Sociologues d'hier et d'aujourd'hui, Paris, 1931, 3e partie : La Psychologie sociale de Me Dougall et la Sociologie durkheimienne, pp. 159 et suivantes. 
condition, ils ne se présentent nulle part, chez aucun individu, à titre de tendance ou disposition isolée, abstraite. Ils sont en chacun parce qu'ils sont dans le groupe dont il est membre, et leur forme, leur intensité, résulte des conditions propres au groupe, de sa structure, de ses rapports avec les autres. C'est donc à une excursion scientifique à travers le monde social que nous convions le lecteur. Nous n'irons point voir quelques représentants de l'espèce humaine isolés, comme des carnassiers dans les cages d'un jardin zoologique, ou comme des animaux marins chambrés entre des cloisons derrière les glaces d'un aquarium. Les hommes, plutôt, se présenteront à. nous dans leurs formes de vie naturelles et propres à nous révéler, en la plénitude de ses instincts et de ses tendances, la nature humaine, qui est une nature sociale.

Nous devrons fixer notre attention sur les divers groupes humains, reconnaître quelles sont les représentations collectives dominantes dans ces ensembles, quelle est leur force et leur extension, quelles sont leurs limites. Nous aurons à les envisager aussi dans leurs rapports, à chercher si elles correspondent à des phases diverses d'une évolution dont les sociétés humaines en leur état actuel nous présenteraient, juxtaposées, des phases successives, et quelles prévisions quant à l'avenir proche on peut tirer d'une telle comparaison. C'est dans le cadre des classes sociales, classes diverses, le plus large et aussi le plus naturel, le moins artificiel de tous ceux qui s'imposent aux hommes vivant en société, que nous poursuivrons notre examen des motifs sous leur forme collective, quitte, plus tard, et pour ne rien oublier, à faire retour sur d'autres catégories, et sur d'autres formes d'associations. 


\title{
LA CIVILISATION TRADITIONNELLE ET LES CLASSES PAYSANNES
}

\author{
Technique agricole, attachement à la terre
}

\section{$\underline{\text { Retour à la table des matières }}$}

D'après les évaluations les plus récentes des statisticiens, en 1932 la population de la terre serait de près de deux milliards d'habitants, dont à peu près la moitié en Asie, un peu plus du quart (545 millions) en Europe, 250 millions dans

les deux Amériques, et peut-être 150 millions en Afrique ${ }^{1}$. Le monde est vaste. Si nous ne considérons que ce qu'on peut appeler la civilisation occidentale, en y comprenant l'Amérique, il s'agit à peu près des trois huitièmes de la population. Encore sommes-nous très insuffisamment informés de ce que sont les coutumes, les institutions, l'organisation sociale dans des régions de cette zone, par exemple dans l'Union Soviétique qui comprend près de 200 millions d'habitants, en Amérique du Sud, et même dans le Sud-Est de l'Europe. C'est, en somme, le quart de la population humaine dont nous pouvons parler avec assez de sécurité.

Il est vrai que cet ensemble compte plus sans doute, dans le monde moderne, qu'on ne le penserait à s'en tenir au nombre. C'est là qu'on trouve les formes de culture et de civilisation les plus avancées, qui exercent sur tout l'univers une action rayonnante de plus en plus forte et étendue. Telle était à peu près la situation de la Grèce et de Rome dans le monde connu des anciens.

W. F. WILLCOX, Population of the Earth, dans International Migrations, National Bureau of Economic Research, vol. Il, New-York, 1931. - Voir aussi : L'Encyclopédie française, tome VII : L'Espèce humaine, section 3 : Le point de vue du nombre, 1935, 7-78-3, par Maurice Halbwachs. [Chiffres récents (milieu de 1950): population de la terre, 2 milliards 400 millions ; Asie (U.R.S.S. non comprise), 1 milliard 272 millions ; Europe (U.R.S.S. non comprise), 396 millions ; Afrique, 198 millions ; Amérique du Nord, 216 millions ; Amérique du Sud, 111 millions ; Océanie, 12,9 millions ; U.R.S.S. (chiffre de 1946), 193 millions. - D'après le Bureau des Statistiques des Nations Unies.] A. C. 
D'autre part, et c'est cela surtout qui est à considérer, bien que notre étude doive porter sur une période d'une durée limitée, la période contemporaine, si nous nous en tenons à ce qui nous est connu par l'observation, le monde occidental nous présente aujourd'hui un tableau très large, où l'on atteint, à côté des types de vie sociale très évolués, beaucoup de formes qui subsistent d'un passé proche ou lointain. Bien des pays, et des régions dans certains pays, en sont restés à des modes de production et des genres de vie qui correspondent en France aux XVIIe et XVIIIe siècles, et même à la féodalité, au moyen âge. Contrastes qui permettent de mieux reconnaître le chemin parcouru, et aussi quels obstacles, quelles forces sociales d'inertie ralentissent le rythme de l'évolution.

Nous vivons, en effet, dans une période caractérisée par une transformation incessante, rapide et profonde, de toutes, les conditions de vie, qui réagit puissamment sur les manières de penser, sur les conceptions et croyances. Des groupes se dissolvent, perdent leurs traditions en même temps que leur possibilité de subsister dans un milieu qui n'est plus fait pour eux, ont le sentiment de leur déclin, meurent parfois sous nos yeux, tandis que d'autres prennent naissance et se développent, s'incorporant peu à peu bien des éléments de ceux qui sont en voie de disparaître, créant aux hommes un nouvel entourage, leur imposant des idées et des manières de sentir nouvelles.

Si l'on se reporte en pensée à deux ou trois générations en arrière, vers le milieu du XIXe siècle, il apparaît que les changements qui se sont produits depuis cette époque sont peut-être plus grands et plus décisifs que ceux qu'on observerait si l'on remontait en deçà jusqu'à cinq ou six siècles en arrière et peut-être plus.

Ce qui caractérisait cet état ancien, c'était avant tout l'attachement aux traditions, le goût de la stabilité, l'hostilité vis-à-vis de tout ce qui était nouveau et inaccoutumé.

Pittoresque, diverse, proche de la nature, peu fiévreuse, telle nous paraît avoir été l'existence de ces hommes, si étrangers à nos civilisations urbaines dominées par les méthodes mécaniques, qui introduisent partout, dans nos actes, nos pensées, nos besoins, une uniformité croissante, que nous verrions volontiers en eux non pas même des ancêtres lointains, mais comme une espèce différente.

Pourtant, nous savons bien qu'à la campagne, et dans les petites villes, les villes moyennes, nous retrouvons nombre de vestiges de la condition du vieux temps, - et comme l'atmosphère subsistante de ce passé. Fixons donc, d'abord, notre attention sur cette population paysanne qui a participé bien moins que les autres à l'évolution générale, et dans laquelle nous avons chance de trouver des façons de vivre et de se comporter collectivement qui s'inspirent d'autres motifs que dans nos agglomérations urbaines.

Il faut d'abord prendre quelque idée de l'importance numérique des paysans dans la population globale. Car il y a, à cet égard, certaines opinions communes que nous ne pouvons accepter sans examen.

Assurément, au cours du XIXe siècle, un grand nombre de paysans se sont rendus dans les villes et ont passé des occupations agricoles à des professions industrielles, 
mais la masse des ruraux est encore considérable. Calculons, en France, la proportion de la population agricole masculine par rapport à la population active totale ${ }^{1}$. Elle était, en moyenne, en 1921 , de 39 agriculteurs pour 100 personnes actives ${ }^{2}$. Mais nous trouvons dans beaucoup de départements des proportions plus élevées, surtout dans les départements alpestres, pyrénéens, dans la grosse masse du Plateau central et de ses confins, et encore dans la plus grande partie de la Bretagne et les régions qui la touchent à l'est. Elle s'élève la jusqu'à 55, 60 et même 75 et au delà. Trois départements seulement, la Seine, le Nord, les Bouches-du-Rhône, en comptent moins de $16 \%$, parce qu'on y trouve de très grandes villes ${ }^{3}$.

Comment cette proportion a-t-elle évolué de 1866 à 1921 ? D'une façon qui n'est pas simple et continue. Ainsi, jusqu'à 1880 elle ne diminue pas sensiblement. Entre 1881 et en 1901, elle est en diminution nette, alors que la proportion industrielle augmente. Mais, de 1901 à 1921, elle se stabilise, et il semble que, si elle a un peu diminué de 1921 à 1926, c'est parce que les pertes masculines résultant de la guerre ont été moins remplacées dans l'agriculture qu'ailleurs (car la population féminine, dans l'agriculture, n'a guère diminué durant la même période) ${ }^{4}$. On peut dire que les activités agricoles dans leur ensemble se sont moins réduites qu'on ne le croit. Il y a eu, certes, au cours du XIXe siècle, une diminution relative, mais cela ne signifie pas une diminution absolue, puisque la population totale a augmenté dans ces trois quarts de siècle.

Dans tout le cours et surtout à la fin du XIXe siècle, une quantité considérable d'hommes qui exerçaient un métier agricole et vivaient à la campagne sont allés dans les grandes villes pour y devenir ouvriers d'industrie. Un bien petit nombre de ces travailleurs des villes ont repris le chemin de la campagne. Pour s'être ainsi décidés à briser les liens traditionnels qui les reliaient à la terre, il faut bien qu'ils aient été attirés par certains avantages que devait présenter à leurs yeux la condition d'ouvriers. Mais, d'autre part, si tous n'ont pas suivi cet exemple, si un grand nombre de paysans ont préféré, délibérément, rester au village, n'est-ce point la preuve que la condition paysanne présente, elle aussi, des avantages auxquels on renonce en la quittant ? Cette population rurale où s'est recrutée la main-d'œuvre de la grande industrie paraît n'avoir représenté que la partie inférieure de la masse paysanne, ne connaissant que les aspects les plus pénibles de l'existence agricole ; elle a été surtout sensible à ce qui fait qu'un ouvrier se considère comme supérieur à un paysan.

1 François SIMIAND, Cours d'économie politique, 1re année, 1930-1931, p. 351. Ajoutons que la proportion de la population agricole est du même ordre qu'en France, en Norvège, Suède, Tchécoslovaquie, Danemark et au Canada ; plus faible, et même beaucoup plus, en GrandeBretagne, Belgique, Allemagne, aux Pays-Bas et même en Suisse, en Australie, aux Etats-Unis, en Argentine ; beaucoup plus forte en Italie, Espagne, Pologne, Irlande, et surtout Portugal, Union Soviétique, en Hongrie, Serbie, Bulgarie et Indes britanniques.

2 Chiffres actuels d'après : INSTITUT NATIONAL DE LA STATISTIQUE. Recensement général de la Population effectué le 10 mars 1946. État civil et activité professionnelle de la population présente : population active totale, 20.520 .466 ; population active agricole, 7.290 .794 ; la proportion est donc de 35,5 p. 100.] A.C.

3 [ Voir dans la Deuxième Semaine sociologique organisée par le Centre d'Études sociologiques sous la direction de Georges Friedmann: Villes et campagnes, A. Colin [1953], pp. 124 et 125, les deux cartes donnant la proportion de la population vivant de l'agriculture. On note six départements donnant une proportion de moins de $12 \% 100$ : la Seine, le Nord, les Bouches-duRhône, la Seine-et-Oise, la Meurthe-et-Moselle et le Rhône. ] A.C.

4 [Cf. le rapport cité ci-dessus de l'Institut national DE LA STATISTIQUE sur le Recensement de 1946, pp. XLV : «Entre 1936 et 1946, la proportion d'agriculteurs dans la population âgée de 14 ans et plus a légèrement diminué. La proportion d'hommes actifs dans les professions non agricoles a, au contraire, augmenté. »] A.C. 
Il se pourrait que la masse paysanne eût plus d'unité que nous ne pensons. N'oublions pas que les paysans descendent des anciens serfs, et que ceux-ci, pendant le moyen âge et jusqu'à la fin de l'ancien régime, constituaient une classe juridique bien définie. Affranchis aujourd'hui des incapacités de toutes sortes qui pesaient sur eux, ils ne se sont point fondus, cependant, avec le reste de la population.

PROUDHON opposait le paysan et le citadin. Pour l'un (le paysan), la propriété, c'est le francalleu; pour l'autre (le citadin), c'est le fief. "Comme autrefois, l'âme du paysan est dans l'idée allodiale. Il hait d'instinct l'homme du bourg, l'homme des corporations, maîtrises et jurandes, comme il haïssait le seigneur, l'homme aux droits féodaux. Sa grande préoccupation est, suivant une expression du vieux droit qu'il n'a pas oubliée, d'expulser le forain. Il veut régner seul sur la terre, et, au moyen de cette domination, se rendre maître des villes et leur dicter la loi ${ }^{1}$. »

L'attachement au sol, l'attachement au pays (d'où leur nom de paysans), tel parait bien être le mobile ou le motif essentiel, qui explique qu'ils ne veuillent pas quitter le petit coin où ils sont nés, où ils ont pris racine, où leur famille vit depuis un temps qui leur paraît indéfini. Mais ce terme est un peu général.. Il recouvre en réalité plusieurs notions qu'il faut distinguer.

Un sociologue français, M. Maunier, a étudié successivement les groupements de parenté, et les groupements de localité, qui lui paraissent représenter les types anciens de vie commune, et que l'on retrouve en effet, très vivants et tenaces, dans les milieux de la campagne. Dans les populations rurales, la famille parait bien être le groupe par excellence : c'est là qu'elle est le-plus étendue, que les hommes connaissent peut-être le mieux leurs parents et les rapports de filiation, de cousinage, d'alliance par lesquels ils se rattachent. Mais, nous le verrons, c'est par les conditions générales de la vie paysanne que parait s'expliquer l'intensité des sentiments familiaux ${ }^{2}$.

D'autre part si nous considérons, toujours à la campagne, les groupes de voisins et de proches, nous voyons bien ce qui les caractérise : c'est le fait de résider et demeurer ensemble en un même lieu. Les membres d'un tel groupe occupent un sol, un pays, un territoire qui, en quelque sorte, fait partie d'eux et du groupe lui-même. Nous en revenons donc à l'attachement au sol qui semble bien être la cause essentielle de l'importance qu'on doit reconnaître aux deux autres motifs : attachement à la famille et, dans un village par exemple, attachement aux familles voisines. C'est toujours le sol, la terre, qui passe ici au premier plan.

Certes, lorsqu'un travailleur de l'industrie, venu depuis quelque temps de la campagne, se représente son milieu d'origine, il éprouve un peu le même sentiment qu'aux États-Unis l'émigrant qui s'est fait place dans un pays neuf, et qui songe avec un mélange d'orgueil, de dédain et de compassion au vieux continent, où il n'a connu à vrai dire que la misère, mais sur lequel il n'en porte pas moins un jugement total. L'ouvrier raille et plaint le campagnard, parce qu'il lui paraît être en retard et hors du mouvement, immobilisé dans les ornières de vieilles routines, incapable d'utiliser des méthodes et dispositifs modernes qui épargnent à la fois le temps et la peine. Les

1 La Capacité politique des classes ouvrières, un des derniers ouvrages publiés par PROUDHON, p. 18 [CEuvres complètes, éd. Bouglé et Moysset, annotées par Maxime Leroy, p. 67.]

2 Essais sur les groupements sociaux, Paris, 1929. 
ouvriers, à cet égard, se considéraient comme plus avancés que les paysans, et mêlés plus étroitement aux formes supérieures de la vie technique et économique.

Mais le paysan n'a pas le sentiment que le travail de la terre soit une occupation inférieure. C'est que l'agriculture se heurte à des difficultés que ne connaît pas l'industrie. Elle ne peut, pour des raisons qui tiennent non pas aux hommes, mais à la terre et à ses produits, réduire le travail et accélérer la production au même degré. L'industrie opère toujours sur une matière inerte. Le caractère commun à toutes les branches et les subdivisions de la production agricole, c'est, au contraire, qu'elle opère sur des êtres, animaux et végétaux, qui sont de nature organique. Or l'organique, jusqu'à présent, s'oppose à l'inorganique, en ce qu'il échappe beaucoup plus à l'action modificatrice des hommes ${ }^{1}$.

A vrai dire, la terre sur laquelle travaille le paysan n'est pas le sol en son état primitif. Il a fallu choisir les terrains qui se prêtaient le mieux à la culture. Il a fallu défricher, dessécher, irriguer, défoncer, amender, fumer. Il a fallu trouver les méthodes d'assolement qui donnaient le meilleur rendement. D'autre part le paysan se sert bien, lui aussi, d'instruments, de machines. Elles n'ont pas jusqu'ici révolutionné les conditions techniques de travail. Mais nous savons qu'aux États-Unis, par exemple, elles ont permis d'économiser beaucoup de main-d'œuvre. Enfin, ce qui correspond le mieux au machinisme, dans l'agriculture, c'est peut-être la distribution et la disposition de plus en plus rationnelle des terres en vue d'obtenir les croissances des organismes les mieux adaptés à la nature du sol et aux autres conditions naturelles ${ }^{2}$.

Mais, cela dit, il n'est pas moins vrai que l'homme doit se borner, après les semailles, à attendre que les semences enfouies dans le sol aient germé, que la plante se charge d'épis ou porte des fruits, sous l'action d'agents naturels, chaleur, humidité, etc., qui sont en rapport avec les saisons. Il ne peut se substituer à la nature, pousser aussi loin que dans l'industrie la division du travail. Et il en est de même de l'élevage, de la basse-cour, etc. Imaginons qu'on parvienne à doubler, tripler, quadrupler et même quintupler le rendement, en utilisant les engrais, en employant des semences, faucheuses, batteuses mécaniques, et tous les moyens modernes de transport automobile. On reste loin des accroissements de production et des économies de main-d'œuvre réalisés dans l'industrie depuis un demi-siècle : ici il faudrait multiplier les résultats anciens par 10, par 100, par 1.000 et plus. Bêtes et plantes ne se laissent pas « forcer » comme les choses inertes.

Ainsi la technique agricole est, en somme, ce qu'elle doit être, étant donnée la nature des objets et produits auxquels elle s'applique. Si le paysan paraît routinier, c'est qu'il a le sentiment, assez juste, qu'on n'a pas trouvé jusqu'ici, dans son domaine, des méthodes nettement supérieures aux vieux procédés. Il faut juger les pratiques paysannes par rapport à la campagne et non pas par rapport à la ville, car la campagne n'est pas la ville. Il y a bien des métiers et des industries qui pourraient paraître aussi retardataires. Les ouvriers qu'on y emploie ne s'estiment pas inférieurs aux autres. De même les paysans ne se mettent pas au-dessous des ouvriers.

SIMIAND, op. cit., p. 336.

Maurice Halbwachs, La Classe ouvrière et les niveaux de vie, recherches sur la hiérarchie des besoins dans les sociétés industrielles contemporaines, Paris, 1913, p. 17. 
Mais d'autre part, un émigrant, même s'il participe à une civilisation qu'il estime plus haute, parce que plus complexe et sujette à de plus rapides transformations, songe, au moins de temps en temps, à ce qui lui manque et qu'il avait autrefois, de vieilles traditions, à l'ombre desquelles il se sentait indépendant du reste du monde, un milieu où il se trouvait l'égal des autres dit moins en ce due tous étaient d'un même pays, parlaient la même langue et vivaient dans la même atmosphère morale. Entre l'ouvrier et le paysan, n'y a-t-il pas aussi une différence essentielle en ce que le premier est un salarié soumis au patron, qui ne possède point ses instruments de travail, qui n'a même aucun droit de propriété sur le produit, tandis due, dans notre pays ait moins, le second, qu'il soit petit propriétaire ou fermier, règle lui-même les conditions de son travail, dispose du produit de la terre comme il l'entend, est son maître, ou jouit, en tout cas, d'une large part d'indépendance ?

Pour juger des raisons qu'a le paysan d'être ainsi attaché à la terre, il convient de prendre, comme représentant le mieux la condition paysanne, celle qui comprend le plus grand nombre, de beaucoup, des travailleurs de la terre. En France, que nous apprennent les statistiques a cet égard ?

SIMIAND a distingué, dans l'agriculture, les personnes « de catégorie plutôt ouvrière » et les personnes « de catégorie plutôt patronale ». Nous réunissons, dit-il, sous la première catégorie d'une part les domestiques agricoles (qui se distinguent cependant de l'ouvrier, puisqu'ils sont souvent embauchés à l'année et qu'ils vivent dans le ménage de l'agriculteur), et d'autre part les travailleurs que l'on appelle journaliers agricoles, qui se différencient de l'ouvrier industriel en ce que souvent ils sont en même temps propriétaires.

Même ainsi étendue, cette catégorie plutôt ouvrière présente, entre 1851 et 1921 , sur l'ensemble de la population active agricole (masculine), une proportion d'un ordre de grandeur assez modéré, entre 30 et $45 \%$, au lieu de $78 \%$ actuellement pour les employés et ouvriers de l'industrie par rapport à l'ensemble de la population active masculine correspondante ${ }^{1}$.

Mais ajoutons que tous ces travailleurs agricoles ne restent pas toute leur vie dans la même condition. Ceux qui restent toujours ouvriers ne représentent que 10 à $20 \%$ de l'ensemble, au lieu de 40 à $60 \%$ dans l'industrie. Ainsi les ouvriers de l'agriculture qui ne deviendront pas propriétaires indépendants sont très peu nombreux, moins de $15 \%$ de l'ensemble.

À côté des propriétaires, il y a, il est vrai, beaucoup de fermiers, et un plus petit nombre de métayers. Le fermier et le métayer ne possèdent pas proprement la terre qu'ils exploitent. Ils dépendent du propriétaire en ce qu'ils se sont engagés à lui payer, à intervalles réguliers, des sommes déterminées, à exécuter des travaux d'entretien et des amendements. Mais les baux sont de longue durée et souvent renouvelés. Le propriétaire, en général, habite au loin, il n'exerce pas sur le paysan la surveillance à laquelle l'ouvrier est constamment soumis par les directeurs et contremaîtres : c'est le paysan qui occupe, et c'est lui qui exploite. D'autre part, comme son revenu résulte de ce qu'il ne donne pas au propriétaire, que la part de celui-ci et la sienne proviennent de son travail, que la sienne d'ailleurs est plus indéterminée et plus variable, il est facilement conduit à penser qu'il travaille pour son compte, et à considérer la rente comme une taxe prélevée sur le produit de son travail, de même que l'ancienne dîme

1 Cours d'économie politique, 2e année (1928-1929) p. 449. 
ou le vingtième. Ainsi, fermiers et métayers sont à peu près propriétaires de fait, sinon de droit, et se comportent comme tels.

C'est un fait assez remarquable, que la prédominance dans notre pays de la petite propriété paysanne. D'après M. TRUCHY, il y a près de la moitié des établissements

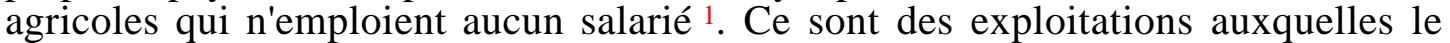
travail en famille du paysan propriétaire, du fermier ou métayer, suffit. Quant aux établissements qui ont des ouvriers, ils n'en occupent pas, en moyenne, plus de deux par exploitation.

Pourquoi ne trouve-t-on pas plus souvent de grands biens cultivés par beaucoup d'ouvriers sous la direction d'un régisseur ? C'est, sans doute, en raison de la nature de la production agricole. Elle ne se prête pas aussi bien que l'opération industrielle aux méthodes mécaniques et à la division du travail. Dans l'usine, l'enchaînement des travaux et le rythme des machines obligent l'ouvrier à donner toujours le même effort et avec la même rapidité. D'autre part, l'ensemble et le détail de la production peut être prévu et fixé d'avance. Le contrôle et la surveillance est une fonction distincte dont les ouvriers n'ont pas à s'occuper. Dans l'agriculture, c'est le travailleur lui-même qui doit choisir le temps et régler l'allure de son travail. Il lui faut tenir compte de la saison et de beaucoup de circonstances naturelles imprévisibles. La qualité de son effort dépend de lui et de lui seul. Il faut qu'il pense toujours à son champ, à ses bêtes, et qu'en quelque sorte il s'identifie et se confonde avec son exploitation. On n'obtiendra de lui de tels résultats que s'il y est pleinement intéressé, c'est-à-dire s'il est propriétaire, ou s'il a, à peu près, le sentiment de l'être.

Le voyageur anglais, Arthur YOUNG, observant autrefois, en France, « la propreté, le bien-être et l'aisance qu'évoquent les maisons, les étables fraîchement construites, les petits jardins, les clôtures, les mues de volailles et les toits à pores », concluait : "La possession du sol est le stimulant le plus énergique à un travail rude et incessant, et je ne sais pas de moyen plus sûr de mettre en valeur le sommet des montagnes que de le partager entre les paysans. »

Cet amour de la terre n'est-il, en réalité, qu'une duperie ? Certes, il y a bien des différences quant à la richesse des hommes et au rendement du sol entre les diverses régions. Dans les grasses campagnes de la Normandie, de la Beauce, de l'Anjou, du Poitou, dans la plaine du Nord, en Picardie, et dans tout le bassin de la Seine, la terre récompense le travail des hommes. Mais ailleurs, il faut peiner dur, pour peu de résultat. Le paysan évoque encore, en plus d'un endroit, ces animaux farouches, dont parle LA BRUYÈRE, noirs, livides, tout brûlés du soleil, attachés à la terre qu'ils fouillent et remuent avec une opiniâtreté invincible, qui se nourrissent d'eau, de pain noir, de racine, se retirent le soir dans des tanières, et ont à peine la face humaine. Nous le retrouvons, nous découvrons toutes ses misères physiques et morales, son labeur toujours renouvelé, et si mal payé, à travers les sèches notations d'un Jules Renard.

C'est un fait, cependant, que les paysans s'attachent aux régions même ingrates, même arides et tristes, peut-être en raison même de la peine qu'ils ont à y vivre. Les montagnards, par exemple. Les populations de la Bretagne. " La lande, dit VIDAL DE LA BLACHE, les bois, les champs de culture, les espaces vides se fixent dans un

1 Cours d'économie politique, tome 1er, p. 256. 
ensemble inséparable dont l'homme emporte le souvenir avec lui ${ }^{1}$. » Isolés dans leurs fermes perdues dans les sentiers fangeux et sous les arbres, les Bretons n'éprouvent pas le besoin de solliciter plus loin une nature moins ingrate.

Complexité, donc, de ce sentiment qui retient le paysan au lieu où il est accoutumé de vivre, qu'il y vive largement des produits du sol, d'ailleurs, ou qu'il y trouve à peine de quoi subsister, malgré un travail exténuant. Au reste, même sur les bonnes terres, le paysan sait bien qu'il dépend du marché, des mouvements de prix, qui se forment quelquefois bien loin, en d'autres continents, et qui viennent déferler sur lui comme une tempête.

En période de baisse, de dépression, cependant, le paysan réussit à vivre. C'est qu'à la différence des métiers industriels, le travail de la culture peut, en tout cas, nourrir son homme, qui, sans intermédiaire, sans avoir à rien débourser, fait sortir du sol le peu de blé, les quelques pommes de terre qui lui suffisent pour s'alimenter. Cette fois, les hommes de la campagne ont recouvré leur indépendance. Ils ne dépendent plus du marché, n'ont pas besoin d'acheter les services des artisans et des marchands. Ils en sont revenus à l'économie domestique, directe, sans échange, à l'économie naturelle. De pouvoir y retourner quand l'échange ne serait qu'à perte, c'est une garantie suprême, une sauvegarde précieuse, et l'on comprend qu'ils éprouvent le bienfait de cette sécurité, que telle soit peut-être la raison principale pour laquelle ils tiennent à la terre, et y restent groupés, tout près d'elle. C'est une nourrice, et quand bien même elle devient marâtre, elle n'abandonne jamais ses enfants.

C'est bien là qu'il faut chercher la racine de cet attachement au sol chez nos paysans. Bien différent a été, tout au cours du XIXe siècle et jusqu'à présent, l'état d'esprit de ces fermiers américains, dont SIMIAND nous dit (à propos de la période de 1790 à 1820) : ce ne sont pas comme en Europe, des paysans à travail acharné, prudents, économes, niais plutôt des fermiers spéculateurs, qui croient que la terre doit sans cesse augmenter de valeur ${ }^{2}$. C'est, pour eux, la forme la meilleure d'épargne ou de placement. On s'endette pour acheter de la terre. On achète ce dont on a besoin moyennant des avances, qui sont consenties par le marchand sur le résultat de la vente de la récolte, avec, éventuellement, report et emprunt nouveau. Dès lors, ils traitent la terre à peu près comme un autre objet d'échange. S'ils la désirent, s'ils la recherchent avidement, c'est comme les chercheurs d'or aux temps héroïques se disputaient les emplacements, comme plus tard on s'efforcera d'obtenir des titres, des valeurs mobilières privilégiées ou qui sont à la hausse. Ils la revendront, dès que cette vente sera une bonne opération. Bien souvent ils ne l'exploitent pas eux-mêmes, s'en éloignent, n'en connaissent que ce qu'ils apprennent par un homme d'affaires. Qu'une occasion s'offre, ils cesseront vite d'être fermiers, oublieront la culture, s'occuperont d'industrie, de commerce, de ventes d'immeubles, comme M. Babbitt, qui n'éprouve le besoin de se retrouver dans la campagne que pour s'y distraire et y faire du sport.

Par contre, dans nos pays, la terre n'est pas pour eux, pour les paysans, une sorte de valeur abstraite, qui passe dans leurs mains, mais n'y restera pas. Au contraire. Certes, nous connaissons aussi des marchands de biens qui spéculent, mais, pour la plupart, ce ne sont point des paysans. Toute la vie et toute la pensée du campagnard

Tableau de la géographie de la France, dans : Histoire de la France depuis les origines jusqu'à la Révolution, par Ernest LAVISSE, tome 1er, 1re partie, Paris, 1903.

2 Inflation et Stabilisation alternées : le développement économique des États-Unis (des origines coloniales au temps présent), Paris, 1934. 
est au contraire liée indissolublement au sol, et c'est ce qui explique d'autres mobiles encore, d'autres sentiments collectifs, par exemple l'attachement à la maison qui est sans doute à la base de la famille paysanne et de son unité. Tandis que les hommes des villes choisissent leurs appartements, les lieux où ils habitent, en tenant compte du confort, de la facilité d'accès, de la situation dans un quartier tranquille ou animé, populaire ou riche, pour un villageois, la maison est avant tout le centre de l'exploitation ${ }^{1}$. Il faut qu'elle soit à proximité du lieu où il travaille, c'est-à-dire des parcelles ou de la terre qu'il possède. La maison villageoise est, le plus souvent, la propriété de celui qui l'habite. Elle lui a été transmise par ses parents et elle évoque à ses yeux bien des souvenirs et des conditions où se confondent les hommes et les lieux. Par ses dimensions, son importance, elle représente le mieux l'étendue et la valeur de ses biens ; si le paysan est fier d'avoir une maison vaste, importante, relativement luxueuse, c'est qu'il songe qu'elle enferme une famille opulente et se rattache à des biens importants.

Ajoutons que non seulement la situation de la maison paysanne est déterminée par l'emplacement du bien, mais sa disposition intérieure dépend des occupations habituelles du propriétaire. Voici encore un trait par où la vie campagnarde se distingue nettement de la vie urbaine. A la ville, le logement de l'ouvrier est presque toujours séparé de l'atelier où il travaille (ou, s'ils se confondent, c'est pour, des raisons accidentelles). Il est même rare qu'on y trouve ses instruments et ses outils. Au contraire, à la campagne, il n'y a pas de séparation tout à fait nette entre les pièces, les meubles, les produits, suivant qu'ils se rattachent à la vie domestique ou à la profession. L'étable, la grange font souvent corps avec la maison, et, en tout cas, c'est la maison qui leur est d'ordinaire subordonnée. On mange, on dort près des animaux, des sacs de grain. La basse-cour pénètre presque dans les chambres où l'on habite. C'est ce que nous apercevons dans plus d'un intérieur paysan peint jadis par les peintres hollandais, et que nous retrouvons encore aujourd'hui dans plus d'un de nos villages. Ainsi les préoccupations du métier dominent et pénètrent toute l'existence campagnarde.

Il en résulte que la famille paysanne doit être à la fois plus étendue el plus solidement constituée que dans les milieux urbains. Dans ceux-ci, en effet, toute la partie de la vie qui est consacrée aux occupations professionnelles se déroule hors du cercle domestique, à l'atelier, dans les banques, dans les bureaux. Il n'en était pas ainsi autrefois. Avant de se laisser enfermer dans des locaux d'affaires ou de travail, dans des magasins, des bureaux, des usines, ceux qui allaient devenir les employés du commerce et les ouvriers de l'industrie sont demeurés aussi longtemps qu'ils l'ont pu dans leurs boutiques, leurs échoppes et leurs ateliers domestiques, où l'on sentait la famille toute proche, où les rapports de maître à compagnon gardaient l'aspect patriarcal. Les coutumes de métiers ne regardaient pas seulement le côté technique de la vie professionnelle. Tous les événements qui se produisaient au sein de la famille, les réunions de voisins et d'amis, les mariages, les deuils en recevaient l'empreinte. A présent les deux domaines de l'activité professionnelle et de la vie familiale se sont dissociés. Non seulement les lieux où l'on travaille sont distincts et d'ordinaire éloignés dans l'espace des maisons qui constituent le cadre matériel de la vie domestique, mais encore les périodes consacrées à ces deux modes d'existence se trouvent nettement séparées et n'empiètent pas l'une sur l'autre. La famille est maintenant détachée de l'atelier, de la boutique et doit se suffire à elle-même. C'est pourquoi elle est souvent plus fragile et plus instable.

1 Maurice Halbwachs, La Classe ouvrière, etc. (op. cit.), pp. 40 et 73. 
A la campagne, au contraire, le travail s'accomplit dans le cadre du groupe domestique, dans les champs et les prés qui lui appartiennent, aux environs immédiats de la maison bien souvent. Lorsque des paysans se rencontrent, qu'ils échangent des réflexions, se communiquent des nouvelles, lorsque des sentiments divers les unissent ou les opposent, les deux ordres de préoccupations se rapprochent et s'enchevêtrent, alors même qu'il n'y a point entre eux de rapports de parenté, puisque le village est, en un sens, une famille élargie.

La vie du groupe paysan est profondément engagée, et tout entière, dans la nature. De là une saveur et une âpreté particulières, plus de spontanéité, d'élan primitif et même de sauvagerie. Mais elle s'y alourdit de tout le poids de la terre, elle s'y déroule suivant le rythme ralenti des travaux campagnards. C'est une vie collective à la fois très forte et très simple, ou très simplifiée. Les coutumes y puisent leur force à la fois dans les sentiments de parenté et dans les occupations communes. C'est ce qui fait leur stabilité et leur continuité.

Il est d'ailleurs assez difficile, pour cette raison même, de reconnaître quelle influence exercent sur les paysans les deux grandes puissances collectives : la famille et la religion. Elles paraissent y avoir conservé plus qu'ailleurs leur intégrité. Mais ne le doivent-elles pas surtout aux coutumes en général, telles qu'elles se maintiennent à la campagne ? Les cérémonies religieuses périodiques sont une occasion pour eux de se réunir. Mais souvent les hommes restent le dimanche à la porte de l'église ou sur la place. Aux coutumes religieuses comme aux autres ils paraissent attachés surtout par esprit traditionnel, parce qu'elles font partie d'un genre de Vie qui est le leur depuis longtemps, et qui se conserve parce que les petites communautés villageoises sont repliées sur elles-mêmes, et échappent dans une large mesure à l'influence des courants de pensée, de croyance, et des habitudes collectives qui se forment et se développent dans les villes.

De l'attachement au sol, à la terre, qui fait qu'un paysan, s'il sort de son village, s'il fait un parcours long ou court en chemin de fer, s'intéresse aux champs, aux cultures, distinguons l'attachement au pays. Ils forment en effet des communautés de fait, parce que leurs maisons sont groupées, plus ou moins d'ailleurs. Vidal DE LA BLACHE opposait l'Ouest et l'Est de la France comme les paysans et les villageois ${ }^{1}$. Dans l'Ouest, les fermes sont disséminées entre les closeries, pâturages, étangs et flaques, et isolées les unes des autres : les habitants ne se rencontrent guère qu'aux jours de fête ou de foire, mais vivent chacun à part durant de longues saisons pluvieuses. Dans l'Est, au contraire, en Lorraine, en Bourgogne, en Champagne, en Picardie, la population rurale est agglomérée autour du clocher. Si borné qu'y soit l'horizon si affaiblis qu'y parviennent les bruits du dehors: le village compose une petite société accessible aux influences générales. Pourtant, cette agglomération, qui s'explique en général par le morcellement de la terre ou la rareté de l'eau, n'est pas une organisation. Si les maisons sont voisines, les hommes demeurent séparés par leurs intérêts et leurs préoccupations, qui ne se rattachent point aux mêmes parties du sol et n'ont en général rien de solidaire.

Certes, les paysans se réunissent, aux veillées pendant l'hiver, les jours de fête encore, et de marché. Ils travaillent en commun aux moissons, à la vendange, mais le reste du temps, ces familles vivent isolées. Chacun ne pense qu'à soi ou aux siens. De

1 Tableau de la géographie de la France (op. cit.). 
même qu'un village, parfois, ignore, envie, déteste un village voisin, de même aussi il arrive trop souvent que les familles se jalousent d'une maison, d'une ferme à l'autre, ignorent l'entraide.

Âpreté et égoïsme, individualisme à la base comme au sommet. On est économe, frugal. On cherche à arrondir sa terre. Mais on ne se soucie pas des autres. Il n'y a pas une tendance naturelle à s'associer, même entre les habitants d'un même village, d'une même région, dans une pensée d'intérêt commun.

N'exagérons pas, cependant ; si telle est la tendance naturelle, il s'est produit, il est vrai, depuis quelques dizaines d'années, une évolution notable, qui ne s'explique pas seulement par les relations malgré tout plus fréquentes avec les villes petites, moyennes et grandes, par les écoles, par la presse, par le service militaire, par le progrès des moyens de transport, automobile, etc. Mais des raisons économiques sont intervenues, qui résultent des besoins mêmes de la production agricole développée.

Le type de l'exploitation paysanne moyenne et petite, de la petite propriété, s'est maintenu en France (comme en d'autres pays), parce qu'il est bien adapté aux conditions de la production agricole. Cependant il se heurtait à des limitations, à des difficultés, lorsqu'il s'agissait de vendre sur un marché assez étendu, et aussi dans le cadre de certaines productions spécialisées. Il fallait s'occuper alors du côté commercial de l'exploitation, et se procurer des avances, ce qui dépassait les moyens et possibilités de l'exploitant isolé. De là le développement considérable de la coopération agricole, en certaines régions et pour certaines cultures ; les paysans ont réussi à s'organiser et à mettre leurs efforts en commun ; motif social qui s'est révélé très efficace ${ }^{1}$.

Voici, d'abord, des associations déjà anciennes qui sont des coopératives de vente : les fruitières du Jura. Elles produisent un fromage, le gruyère, qui par son volume demande une quantité de lait supérieure à la production d'un paysan isolé, et qui oblige les producteurs à se mettre en rapport avec un marché plus étendu aussi que celui que chacun d'eux peut atteindre. D'où les communautés de village, peut-être faisant suite à d'anciennes communautés pastorales, et qui ont passé par plusieurs étapes. D'abord, dans la période héroïque, les exploitations groupées font ce travail pour toutes, tour à tour; puis elles prennent un spécialiste, un fromager, qui va dans les diverses fermes opérer la transformation commune. Enfin, on choisit un local commun, avec une installation spéciale, et le produit est fabriqué par un employé du groupe. Souvent, le groupement de paysans se borne à réunir le lait et à le vendre pour les fermes, et le fromager est un industriel ou un commerçant indépendant. Ce qui vise surtout en somme ici l'organisation coopérative, c'est l'opération commerciale d'écoulement du produit de chacun.

De même dans les beurreries coopératives. La quantité de lait obtenue par un exploitant paysan n'est pas assez grande pour que, chaque jour, il puisse utilement battre le beurre. Il fabrique moins de beurre, de moins bonne qualité. Il n'a la possibilité ni d'abaisser les prix, ni d'utiliser les moyens de production qui sont à la portée d'un gros éleveur, ni d'utiliser les sous-produits (petit-lait pour l'engraissement

François SIMIAND, Cours d'économie politique, 1930-1931, p. 672. 
des pores, fromage sec, caséine) obtenus avec les résidus. Ici, donc, le petit exploitant aurait été éliminé sur le marché par le grand producteur, s'il n'avait pas eu recours à l'association. Première étape - elle réunit le lait, en fixe le prix, et c'est un entrepreneur indépendant qui le transforme en beurre, et vend le beurre à ses risques. Seconde étape : c'est la coopérative qui fabrique le beurre, en fait un produit de qualité homogène, se constitue des débouchés réguliers, fixe sa marque et la fait connaître.

On trouverait, hors de France, des exemples remarquables d'organisations coopératives agricoles pour la vente ; le Danemark, qui, ainsi, a développé son exportation de produits agricoles et dominé le marché anglais par la qualité de ses produits ; l'Irlande, un peu plus tard (restée longtemps fidèle aux modes d'exploitation individualistes). Avant-guerre, on citait comme exemple de ce genre de réalisation celles de Sibérie. Avant et après la guerre, bien d'autres pays encore, Belgique, Allemagne, Tchécoslovaquie, etc.

Or, sans doute on a pu observer que la coopération, pour obtenir des produits de qualité, a dû se préoccuper des conditions d'élevage, d'alimentation et de couchage, de formation de la race aussi, de sélection des animaux employés, des vaches laitières, a créé même des inspections d'étables. Par là, elle a exercé une influence certaine sur la conduite des producteurs. Mais, jusqu'à présent, la coopération agricole ne va pas plus loin. Elle ne va pas jusqu'à intégrer. les exploitations paysannes, qui demeurent séparées et indépendantes.

Il en a été de même des coopératives vinicoles, établies parmi les propriétaires vignerons qui avaient l'habitude et le goût de la production individuelle, de la vente individuelle avec. ses aléas, notamment ses chances de bons prix et de bonnes ventes. L'extension même des vignes, l'expérience des méventes prolongées, la nécessité d'atteindre la clientèle, surtout urbaine, voilà ce qui explique les groupements pour la vente. Ceux-ci ont également réagi sur la production, de façon à répondre aux besoins des consommateurs, qui réclament d'une année à l'autre "le même vin » (mélange de divers vins naturels). On est même passé, de là, à un stade plus intégré. Les viticulteurs apportent à la coopérative leur récolte à l'état de raisins : c'est elle qui opère la vinification. Ainsi se sont développés les chais coopératifs. Cependant, ici encore, on s'associe, on coopère pour toute la partie de la transformation qui se rapproche de l'industrie : mais l'esprit coopératif n'atteint pas les opérations proprement agricoles, qui s'accomplissent toujours dans le cadre des exploitations indépendantes.

Nous pourrions prendre d'autres exemples - les grands « élévateurs » coopératifs du Canada, dans la production du blé, qui ont même tenté de prendre la forme de cartels ou de pools, - et encore dans la production des fruits, de la viande, etc. Toujours il apparaît que la coopération de vente est en quelque sorte imposée aux paysans par les nécessités commerciales (nécessité, surtout, d'atteindre un marché étendu, de créer parmi les consommateurs une certaine régularité et fixité de besoins, par la qualité des produits). Elle les a même obligés à améliorer leur technique. Mais elle n'a pas été au delà, et n'a pu intégrer leurs exploitations. En d'autres termes, les paysans, par l'association, ont utilisé tous les moyens qui étaient à leur portée, en vue d'améliorer les conditions du commerce, quant à la vente de leurs produits. Mais ils n'en sont pas moins demeurés des petits propriétaires.

Même remarque pour ce qui est de l'achat des matières premières et des moyens de production. Pendant longtemps l'agriculture a pu, en grande partie, tirer ses 
matières premières d'elle-même et fabriquer ses instruments. Mais, de plus en plus, elle a besoin d'instruments achetés (outils, machines), d'autant plus qu'ils sont plus perfectionnés ; elle doit acheter des semences, des engrais, des fertilisants, etc. Or, le petit exploitant isolé est, pour toutes ces coopérations, en état d'infériorité : défaut de connaissances, défaut de moyens pour discerner où et comment acheter dans les conditions les meilleures d'espèces, de prix, de qualité, enfin difficultés de paiement, de crédit. Là est donc intervenue l'association, en France, sous la forme -des syndicats agricoles, sous d'autres formes dans d'autres pays. Quand il s'agit de moyens de production importants et coûteux, par exemple une batteuse, qui ne peut être utilisée simultanément par tous les participants, ou encore, de l'emploi de la force électrique, on adopte une organisation collective, mais limitée à l'emploi de tels moyens ${ }^{1}$.

Enfin, quant aux associations coopératives de crédit, elles ont apparu d'abord dans les pays de l'Europe centrale et de l'Europe orientale, c'est-à-dire dans des pays agricoles plus pauvres et moins évolués, et elles résultaient d'ailleurs d'interventions extérieures, de l'État ou philanthropiques (caisses Raiffeisen et Schultze Delitzsch). En France, c'est assez récemment que le crédit agricole s'est étendu, avec des résultats importants, mais cependant qui ne correspondent pas à l'ensemble des opérations de prêt et de remboursement effectuées par la totalité des agriculteurs. Dans ce domaine les paysans, quand ils le peuvent, évitent de recourir à des institutions de caractère officiel : signe qu'ils restent encore attachés aux coutumes de crédit et d'emprunt traditionnelles liées au régime de l'exploitation indépendante ${ }^{2}$.

Ainsi, il y a bien eu dans la masse paysanne, depuis quelque temps, une tendance assez forte à utiliser certaines formes d'organisation coopérative, syndicale et d'association, mais dans la mesure où elles n'empiètent pas sur la propriété indépendante, sur l'autonomie de l'exploitation.

Certes, dans l'histoire, il y a des périodes, étendues sur plusieurs siècles, durant lesquelles l'esprit communautaire a dominé les milieux d'agriculteurs. M. Marc BLOCH a montré que la disposition des champs en longues bandes, et la façon dont les parcelles étaient réparties, s'explique par une organisation collective de la culture qui n'a fait place que peu à peu au régime des exploitations indépendantes ${ }^{3}$. Mais, aujourd'hui, le motif dominant du paysan, au moins dans nos pays, est bien l'attachement à la terre, le désir de conserver et d'accroître son bien, sa propriété.

Ce n'est pas seulement, comme nous l'avons montré, parce que le travail agricole doit être stimulé par le sentiment qu'on en est pleinement responsable et que son rendement conditionne le revenu du cultivateur. Ajoutons que les plantes, les bêtes, à la différence des matières premières et des produits de l'industrie, ne peuvent pas être transportées et que la croissance n'en peut pas être dirigée et surveillée ailleurs que là où elles poussent et se nourrissent. Elles doivent être distribuées et fixées à la surface du sol. C'est pourquoi, en même temps qu'à la terre, ils sont attachés à tout ce qui fait corps avec elle, à la maison qui est en même temps l'habitation et le centre de l'exploitation, au village, et surtout au genre de vie qui s'y développe, en rapport avec la richesse du sol et la nature de ses produits, aux coutumes ainsi qu'aux traditions qui expriment et renforcent la stabilité du groupe paysan.

Op. cit., p. 680.

Ibid., p. 681.

Les Caractères originaux de l'histoire rurale française, Paris, 1934. - Voir aussi : Note sur la notion de civilisation agraire, par Jules Sion, dans : Annales sociologiques, série E, fasc. 2, 1937. 
Ce cadre ne laisse pas de s'ouvrir à quelques influences générales qui s'exercent du dehors, avec l'école, la presse, les moyens de transport, la T.S.F., etc. D'autre part, à mesure que la production agricole est davantage en rapport avec les besoins des habitants de la ville, elle s'industrialise et prend une forme plus commerciale : quelques parties de l'activité rurale se prêtent à l'organisation : par là pénètre peu à peu, dans leur masse, un esprit d'entr'aide mutuelle et de coopération.

Mais l'individualisme subsiste, dans toute la partie de leur vie et de leur activité qui les laisse en contact avec la terre, c'est-à-dire dans ce qui est proprement la culture et le genre d'existence paysanne telle qu'elle lui est adaptée. Certes, il y a des riches et des pauvres parmi eux, des différences de classe. La préoccupation de se maintenir à son rang, à Son niveau, et même de s'élever dans l'échelle sociale, explique toute une partie de leur conduite. Mais ils ont surtout le sentiment d'être paysans, en face des habitants des villes, et ce qu'il y a de spécifique dans les motifs qui les guident s'explique, en définitive, par l'opposition qui subsiste entre deux types de civilisation. 


\title{
III
}

\section{LES MILIEUX URBAINS ET LA CIVILISATION INDUSTRIELLE}

\author{
PREMIÈRE PARTIE \\ Les entrepreneurs, la bourgeoisie
}

Retour à la table des matières

C'est dans les villes, surtout dans les grandes villes modernes, que la vie sociale se présente sous ses formes les plus complexes. Au reste, dans ces milieux urbains ${ }^{1}$, il y a une partie de la population qui détermine les. directions, les objets principaux de l'activité commune, et qui manifeste mieux que les autres aussi les tendances communes à tous. C'est la classe la plus élevée, la plus riche, celle qui exerce les fonctions les plus importantes. Elle peut être dite dirigeante non point seulement parce qu'elle possède le plus de puissance et d'autorité matérielle, politique et économique, mais par ses façons de penser, qu'on imite et dont on s'inspire dans les classes moins élevées. Nous allons fixer d'abord notre attention sur les motifs principaux de la conduite, dans les milieux de la bourgeoisie.

Le mot bourgeois signifie, étymologiquement habitant d'un bourg. C'est dans les villes petites et moyennes, par rapport à nos cités d'aujourd'hui, de l'ancien régime, du régime corporatif, que la bourgeoisie a pris naissance. Pour comprendre ce qu'elle est aujourd'hui, et le chemin qu'elle a parcouru, prenons d'abord une idée de la psychologie collective des milieux de bourgeois et d'artisans d'autrefois.

Quel était le motif dominant des bourgeois de l'ancien régime ? Essentiellement, le souci de sécurité. Sécurité matérielle d'abord. Le bourgeois est pacifique. Il s'oppose au noble, comme le civil au militaire. Mais il sait s'armer, se protéger par des murailles. Il a besoin de la paix, et H. PIRENNE a bien montré que, pour que le commerce pût se développer, il fallait que marchands et artisans fussent protégés

1 [Voir dans Villes et Campagnes, op. cit., p. 9, le graphique de la proportion de la population urbaine dans la population totale, de 1846 à 1946.] A.C. 
contre l'exploitation des seigneurs, contre les incursions des pillards et des bandes armées ; au bord de la mer et dans le commerce maritime, contre les pirates ${ }^{1}$.

Surtout, c'est la sécurité économique qui les préoccupait. D'après Adam SMITH, le régime réglementaire des villes corporatives tendait surtout à fournir aux villes le moyen d'acquérir, avec une moindre quantité de leur travail, le produit d'une plus grande quantité de travail des campagnes. Il tendait à fixer les prix et les salaires des produits fabriqués dans les villes de telle manière que les bourgeois pussent obtenir en échange non seulement les denrées agricoles qui suffisaient à les faire vivre, mais encore un bénéfice qui leur permît de s'habiller, de se loger mieux que les paysans, et de disposer en outre d'un certain nombre d'avantages auxquels ceux-ci ne pouvaient prétendre ${ }^{2}$.

Mais comme l'a montré SOMBART, ce qu'ils désiraient surtout, c'était non pas d'améliorer leur condition, mais de la maintenir telle qu'elle avait été jusqu'alors ${ }^{3}$. Artisans, marchands, ils étaient habitués à un genre de vie fixé par la coutume, par l'opinion, et ils estimaient que leur métier devait le leur garantir ; rien de moins, mais rien de plus.

C'est pourquoi ils étaient attachés aux méthodes traditionnelles et n'en voulaient pas changer. Ils tenaient à ce que le travail fût bien fait, à ce que le produit portât la marque personnelle de l'artisan, parce qu'à cette condition seulement ils étaient assurés de conserver leurs clients. Chacun d'eux avait en effet son cercle de clientèle, et les règlements fixaient le nombre des maîtres, des compagnons, des apprentis, de façon que chaque artisan et chaque 'marchand pût compter sur un nombre suffisant d'acheteurs. Pas de nouveauté, pas de concurrence. On n'essayait pas d'accroître ses affaires en abaissant le prix de revient, en faisant de la réclame. C'est pourquoi régnait dans ce groupe un esprit de communauté et d'entraide.

En d'autres termes, le gain en argent, le gain à tout prix et l'accroissement indéfini du gain, n'était pas le mobile de ces hommes qui se contentaient de gagner leur vie, de façon à rester au même niveau social que leurs parents et que leurs voisins. La doctrine de l'Église sanctionnait ces règlements et cette conduite. Elle condamnait l'usure, et si elle tolérait le commerce, c'était à la condition qu'on vendît au juste prix, à celui qui laissait un bénéfice raisonnable, tel qu'il devait suffire pour que les vendeurs demeurassent dans leur condition.

Il est vrai que ce tableau correspond à un état ancien et relativement idéal ; qu'il y avait, dès cette époque, des commerçants plus aventureux que les autres, qui n'hésitaient pas à risquer pour gagner. "Il s'est toujours trouvé des artisans, dit SOMBART, qui ne se sont pas contentés de leur « subsistance », qui ont agrandi leurs affaires et intensifié leur activité économique, afin d'augmenter leurs gains..., des personnes animées de la passion de l'argent », même dans le moyen âge européen. Mais, ajoute-t-il, « ces personnages n'ont pas réussi à ébranler, dans ce qu'il avait d'essentiel, l'esprit de la vie économique précapitaliste ». Ce qui prouve à quel point,

1 Les Villes au moyen âge, Paris, 1932. H. PIRENNE a bien montré qu'en particulier, tant que la mer Méditerranée fut fermée aux navires européens, c'est-à-dire depuis la conquête mahométane jusqu'aux croisades, il n'y eut pas de commerce véritable à l'intérieur de l'Europe. Le commerce reprend, au contraire, quand la mer redevient libre.

2 An Inquiry into the Nature and Causes of the Wealth of the Nations, 1776, Book I, Chapter X, Part Il: Inequalities occasioned by the Policy of Europe.

3 Der moderne Kapitalismus, 2 vol., 1902. 
d'après lui, la recherche du gain pur et simple était étrangère aux hommes de ce temps, c'est le fait que « toute passion du gain, toute rapacité cherche à se satisfaire en dehors du domaine de la production, du transport et même, en grande partie, du commerce des biens. On court vers les mines, on fouille dans l'espoir de trouver des trésors, on pratique l'alchimie et d'autres arts magiques, et cela précisément parce qu'on ne peut gagner autant d'argent qu'on en voudrait dans le cadre de l'économie de tous les jours ${ }^{1} \gg$.

En somme, et en ce sens, les exceptions confirment la règle. Il y a, en tous temps, des natures d'exception, des brigands, des flibustiers, comme dit SOMBART, des charlatans (tels que beaucoup d'alchimistes) qui faisaient des dupes, et encore des inventeurs (mais qui viennent trop tôt, dans une société où l'on est hostile de parti pris à toute nouveauté technique dans les métiers), des joueurs, des spéculateurs. Mais si nous considérons l'ensemble des motifs qui animent la plupart des artisans et des marchands de cette époque, il faut bien reconnaître que l'esprit d'entreprise et la recherche du gain pour lui-même étaient incompatibles avec les tendances et l'organisation économique d'alors.

Aussi n'est-ce pas sans un étonnement profond que l'historien, lorsqu'il envisage ce qu'on a pris l'habitude d'appeler l'économie capitaliste, telle qu'elle apparaît en son plein essor dès la fin du XVIIIe siècle et jusqu'à nos jours, découvre dans les milieux d'industrie et de commerce une psychologie toute différente. Énumérons les motifs de leur conduite, tels qu'ils nous apparaissent alors, en tant qu'ils s'opposent aux précédents :

$\left.1^{\circ}\right)$ Préoccupation du gain en argent et de l'accroissement indéfini du gain. Aristote considérait que l'acquisition de capitaux dépassant les besoins naturels était incompatible avec l'activité économique ${ }^{2}$. La richesse en argent, loin de servir à des fins économiques (c'est-à-dire à assurer la subsistance nécessaire), ne se prête qu'à des usages extra-économiques immoraux. Toute économie connaît limites et mesures ; l'acquisition des richesses se soustrait aux unes et aux autres. Certes, l'amour de l'or ou de l'argent, auri sacra fames, est de toutes les époques. Mais autrefois, on ne recherchait l'argent que pour les biens qu'il permettait d'acquérir. L'avare qui accumule pour le plaisir d'accumuler, qui meurt de faim sur un tas d'or, n'a jamais été qu'une exception, qu'une sorte de malade mental. Dans une société où on ne peut gagner de l'argent que par l'exercice d'un métier, où d'ailleurs les règlements et la coutume fixent la quantité d'argent qu'on peut gagner ainsi d'après ce qui est nécessaire pour vivre suivant sa condition, où l'argent ne peut être employé qu'à acquérir des biens de consommation, on travaille pour gagner sa vie, on ne recherche pas l'argent pour lui-même.

Il en est tout autrement du jour où l'argent peut être employé à gagner plus d'argent encore, où l'argent rapporte un intérêt. Certes, il y a eu toujours des prêteurs, mais qui prêtaient à des personnes qui voulaient de l'argent pour le dépenser en biens

1 Werner SOMBART, Le Bourgeois, Contribution à l'histoire morale et intellectuelle de l'homme économique moderne, traduction française, Paris, 1926, p. 23.

2 ARISTOTE, Politique livre 134. 
de consommation, à des prodigues ou à des joueurs. Le métier de prêteur était d'ailleurs un métier comme un autre, où le gain était limité par les lois contre l'usure, et qu'exerçaient en réalité ceux qui n'en avaient pas d'autre. Ce qui est nouveau, ce qui caractérise le régime capitaliste, c'est le prêt à la production, les avances qui ont pour objet de financer une exploitation productive.

On recherche dès lors, dans l'argent, le pouvoir de créer de l'argent. Mais tel désir, dès qu'il est né, est destiné à s'accroître -indéfiniment chez celui qui l'éprouve. Où trouverait-il une limite ? L'argent désiré pour les biens de consommation qu'il procure disparaît dans ces biens, dans la consommation qu'on en fait. Quant au désir des biens, il disparaît dès qu'on est satisfait et, s'il reparaît ensuite, c'est avec la même intensité qu'auparavant, précisément parce qu'on n'a plus d'argent pour le satisfaire. Mais l'argent qu'on place pour produire de l'argent, d'abord, ne disparaît pas, il s'accroît au contraire. On le replace, et en même temps ce dont il s'est accru, pour la même raison qu'on a placé d'abord, et qui n'a pas disparu non plus. Ou encore : il n'y a pas de limite où on puisse s'arrêter, puisque ce qu'on recherchait au début n'était pas un bien concret, une satisfaction définie, mais la possession d'une chose qu'on désire, en raison de ce qu'elle n'existe que pour s'accroître, que sa nature et sa raison d'être est de grandir sans cesse.

De ce que l'argent a ce pouvoir, il résulte qu'il passe au premier plan. Désormais on évalue tout en monnaie, les biens, les quantités, les services, le temps lui-même. Autrefois on songeait aux biens en eux-mêmes. L'attention ne se portait sur leur valeur monétaire que lorsqu'on voulait les échanger contre d'autres, c'est-à-dire pour peu de temps, puisqu'on se préoccupait surtout des biens. A présent, puisque le marchand n'acquiert les biens que pour gagner plus d'argent (et non se procurer d'autres biens), pour faire produire des intérêts à l'argent qu'il a, les biens ne sont que, la forme sous laquelle se présente l'argent. Toute la vie économique et même la vie sociale est dominée par des représentations monétaires. Quand on mange, quand on porte des vêtements luxueux, la question se pose : si j'avais retranché sur mon alimentation, sur mon vêtement, mis de côté la somme correspondante, j'aurais pu payer cette somme comme intérêt pour tel capital, qui, placé, m'aurait rapporté davantage.

Comme le disait FRANKLIN : « Le temps est de l'argent. Celui qui pourrait gagner six shillings chaque jour par son travail et qui va se promener ou demeure dans sa chambre la moitié du temps, alors même qu'il ne lui faut que six pences pour son plaisir, doit songer qu'il a dépensé cinq shillings de trop ${ }^{1}$ », et ailleurs : "Pour six livres Par an tu peux disposer de 100 livres, pourvu due tu sois un homme d'une prudence et d'une honnêteté reconnues. Celui qui, chaque jour, dépense un groschen inutilement, dépense inutilement six livres par au, ce qui est le prix qu'on paie pour disposer de 100 livres. Celui qui, chaque jour, gaspille une partie de son temps qui vaudrait un groschen (peut-être deux minutes), perd, l'un dans l'autre, la disposition de 100 livres par an ${ }^{2}$. » Ainsi, l'homme est subordonné au gain, et non le gain aux satisfactions de l'homme. Le devoir de s'enrichir, non pour jouir de plus de biens que l'on consommera, mais pour avoir plus de moyens de s'enrichir encore : tel est le nouveau devoir, qui, comme un impératif catégorique, est à la base de la morale capitaliste.

Advice to a Young Tradesman, 1748, Oeuvres, éd. Sparks, vol. II, p. 87.

2 Necessary Hints to those that would be rich, 1736, ibid. Ce texte, comme le précédent, est 'reproduit par Max Weber, dans l'essai cité plus bas. 
$\left.\mathbf{2}^{\mathbf{o}}\right)$ L'esprit d'entreprise. - L'ancien régime était hostile à toute nouveauté, dans le domaine de la production et du commerce. Certes, en dehors des cadres corporatifs, de -nouvelles activités étaient apparues, qui visaient à étendre les relations économiques dans l'espace, à faciliter aussi les règlements par la banque, par le crédit. Mais l'ancien système n'était guère modifié par ces initiatives qui lui demeuraient extérieures et presque étrangères.

Au contraire, dans le système moderne, l'esprit d'extension, de renouvellement, de transformation agit de l'intérieur. Un des plus vigoureux théoriciens économistes d'à présent, SCHUMPETER, a expliqué comment les sociétés ont passé de ce qu'il appelle le système statique, où la production et la consommation sont réglées par la tradition, où chaque période répète exactement la période antérieure, au système dynamique, qui représente au contraire le changement et le progrès ${ }^{1}$. C'est que sont apparues des personnalités fortes, qui portent en elles et ne tirent pas du milieu les règles de leur action, qui sont surtout sensibles à la joie de créer. Leur rôle est, essentiellement, d'inventer des combinaisons nouvelles, qui permettent d'augmenter le rendement. Ce sont les entrepreneurs modernes. L'entrepreneur est d'ailleurs aidé par le banquier, qui lui avance du capital par les moyens du crédit. Quelquefois les deux fonctions sont réunies dans la même personne.

L'ancien artisan ne se souciait pas de perfectionner sa technique et d'en accroître le rendement. Il se conformait, dans son métier, à des règles traditionnelles, qui avaient fait leurs preuves, puisqu'elles assuraient la bonne qualité du produit. Il en est tout autrement, lorsqu'il s'agit de faire en sorte que le prix de vente s'élève de plus en plus au-dessus du prix de revient, ou que celui-ci s'abaisse de plus en plus au-dessous de celui-là. Alors, il faut à toute force introduire dans l'industrie et dans le commerce des méthodes nouvelles.

L'entrepreneur va de l'avant, sans tenir compte des traditions, en leur tournant le dos. Il n'est jamais satisfait de ce qui existe, de ce qui n'est que reproduction et continuation des conduites antérieures. Sans doute, toute innovation comporte un risque. Mais ce qu'on poursuit, ce n'est plus la sécurité, c'est l'accroissement du gain. L'entrepreneur est toujours inquiet, agité, fiévreux, à l'affût de nouvelles inventions, de combinaisons qui n'ont pas encore été éprouvées. Ce n'est point là, d'ailleurs, chez lui, un état d'esprit exceptionnel, momentané. On ne fait point leur part aux inventions. Dès qu'on s'est engagé dans cette voie, il faut continuer. Dès qu'on s'arrête, en effet, l'ancien système reparaît. On n'accroît son capital, on ne réalise des bénéfices suffisants pour l'augmenter, qu'à la condition d'améliorer encore les procédés de fabrication et de vente. Le premier succès obtenu est une raison d'en chercher d'autres. Sinon, pourquoi aurait-on commencé ?

Ce n'est pas seulement dans le domaine technique que cet esprit de transformation incessante se manifeste, niais aussi dans l'organisation économique, commerciale, financière, de l'entreprise, dans les rapports avec les ouvriers, avec les clients. L'entrepreneur considère que, de 'tous ces éléments, il doit tirer le maximum d'avantages

Theorie der wirtschaftlichen Entwickelung, Leipzig, 1912. Traduction française : Théorie de l'évolution économique, recherches sur le profit, le crédit, l'intérêt et le cycle de la Conjoncture, avec une introduction par François Perroux. - Voir nos comptes rendus : Année sociologique, tome XII, 1913, p. 574, et Annales sociologiques, série 1), fasc. 2, 1937, p. 126. 
pécuniaires, et qu'il le peut s'il ne se repose jamais sur ses positions, s'il applique sans cesse sa pensée a la recherche de simplifications et d'extensions dont il sera le premier à avoir l'idée et à tirer le bénéfice. D'oit un effort constant et sans répit, une tension perpétuelle de tous les ressorts spirituels, un déploiement continu de volonté et d'énergie, qui contraste avec l'activité régulière, sereine et sans fièvre dont on se contentait autrefois.

L'esprit d'entreprise, enfin, est avant tout rationnel, et c'est bien le mot : rationalisation, retrouvé si souvent dans la littérature - économique récente, qui exprime le mieux les tendances profondes du régime moderne de la production. D'abord, dans la mesure où il s'oppose à la coutume, à la tradition, à l'instinct et à l'habitude, à l'inertie naturelle des hommes qui craignent ce qui est nouveau, parce que tout ce qui est nouveau exige d'eux un effort plus ou moins pénible d'adaptation. D'autre part, l'organisation moderne tend à uniformiser les travaux, les gestes, les genres de vie, les habitudes de dépenses et de consommation, alors que la nature humaine comporte une grande diversité suivant les individus, suivant les groupes. Enfin l'esprit d'entreprise s'inspire de la mesure, du calcul, s'efforce de découvrir, dans la réalité économique, tout ce qui se prête à la précision et à l'organisation. Il tend à éliminer progressivement des relations entre patron et ouvrier, entre vendeur et acheteur, ce qui relève encore de la fantaisie et du libre choix, tout ce qui répond aux diversités de lieu, de temps, aux liens familiaux, aux rapports de familiarité ou de voisinage, et à introduire partout, dans le travail comme dans la satisfaction des besoins, des règles uniformes. Organisation scientifique des usines, standardisation des besoins, comptabilité, administration, bureaucratisme : tels sont bien les derniers mots d'ordre de ce qu'on appelle le progrès économique ${ }^{1}$.

$\left.3^{\circ}\right)$ L'esprit de lutte et de concurrence. - Sous le régime capitaliste a été posé le principe de l'entière liberté économique : liberté pour tout homme d'exercer le métier qu'il veut et d'accroître, d'étendre son entreprise dans les limites qui lui conviennent. La concurrence entre marchands ou entre artisans, que les règlements corporatifs écartaient ou limitaient, est devenue la loi de la production et de la vente. Cela, d'autant plus que, par leur extension même, par l'importance de leur capital, par une division du travail plus poussée, les grandes entreprises obtiennent souvent un rendement meilleur.

Certes, la grandeur d'une exploitation comporte bien des inconvénients aussi et des risques, expose à des difficultés particulières. C'est ce qui explique que, suivant les branches d'industrie, les métiers, les régions aussi, et les conditions économiques (prospérité et dépression), la part des petites et moyennes entreprises soit sujette à bien des variations, qu'elle augmente parfois, et qu'elle reste, en tout cas, considérable. Mais entre celles-ci également, et même entre les petits artisans modernes, entre les petits commerçants, la lutte pour la vie est quelquefois plus intense encore qu'entre les grandes entreprises. Chaque entreprise, sous le régime actuel, doit compter sur ses propres moyens pour subsister, doit souvent attaquer pour se défendre, et en tout cas, n'étant plus protégée, doit sans cesse lutter.

Sur la rationalité économique et le bureaucratisme, voir : Max WEBER, Wirtschaft und Gesellschaft, section III du Grundriss der Sozialökonomik, 1922 ; - sur la rationalisation et les méthodes scientifiques dans l'industrie, voir Sombart, Das Wirtschaftsleben im Zeitalter des Hochkapitalismus, 2 vol., 1928 ; traduction française : L'Apogée du capitalisme, 1932. 
Individualisme et libéralisme, tels sont les deux mots d'ordre de tous les théoriciens qui ont présenté l'apologie de ce système. L'individualisme, école d'énergie, qui assure une heureuse sélection par le triomphe des mieux doués. Le libéralisme, le laissez-faire, sans intervention de l'État, qui porte en lui-même son correctif, puisque, en vertu de la loi de l'offre et de la demande, l'équilibre se rétablit de luimême, dès qu'il est rompu quelque part. Cependant ce sont là des conditions de guerre, et d'une guerre dans laquelle tous les moyens sont bons, s'ils assurent le succès.

Qu'on lise l'histoire de quelques-uns de ceux qui passent pour les pionniers du capitalisme, d'Astor, par exemple, - qui sut s'assurer d'abord le monopole de la vente des fourrures, en livrant bataille à main armée à ses concurrents, 'en vendant de l'alcool aux indigènes, en corrompant les pouvoirs publics, qui arma des navires pour la contrebande, et termina par des spéculations sur les terrains à New-York, en profitant de la détresse et de l'inexpérience de beaucoup de propriétaires ${ }^{1}$, - et de beaucoup d'autres, magnats du pétrole, des chemins de fer, etc. On ne sera pas très édifié sur la source de la plupart des grandes fortunes bâties ainsi sur la chance, sur la ruine des concurrents malheureux, avec beaucoup d'audace, sans doute, mais aussi, bien souvent, avec beaucoup d'improbité.

C'est, souvent, la loi de la jungle. Celui qui ne dispose pas d'appuis financiers suffisants, qui ne sait pas tirer parti de la publicité et de la réclame, qui n'est pas au courant des combinaisons de ses concurrents, est facilement étranglé.

En tout cas, un des motifs essentiels auxquels obéit l'industriel moderne est l'esprit de lutte. Le commerce, si on le considère en lui-même, en sa réalité brutale, oppose le vendeur et l'acheteur comme deux ennemis. Il n'en est pas tout à fait ainsi dans de petites sociétés traditionnelles, dominées par la coutume. Alors, acheteurs et vendeurs sont, en même temps, membres de groupes locaux, familiaux, religieux, à l'intérieur desquels ils se rapprochent. Ainsi se trouve atténuée et voilée la dureté des relations purement de commerce. Mais dans des communautés plus vastes et plus mêlées, où ces liens traditionnels sont moins puissants, on se retrouve de nouveau dans l'état de guerre. Les individus, les sociétés de commerce et de finance, se disputent la clientèle, comme les pays luttent entre eux pour la conquête des débouchés. D'OÜ ces dispositions réalistes, égoïstes, qu'on reproche souvent aux entrepreneurs et qui ne correspondent pas toujours à leur nature individuelle, niais qui ne sont chez eux qu'une réaction nécessaire et comme une arme dans la lutte pour la vie et surtout pour le gain.

Qu'il y ait, d'ailleurs, une évolution à cet égard depuis quelques décades que le régime capitaliste, à mesure qu'il s'étend et se complique, développe chez les agents de la production une tendance inverse, les oblige à s'organiser, à s'assurer des garanties mutuelles, que les groupes de producteurs s'efforcent de se discipliner, de fixer les limites de leurs domaines, concluent entre eux des traités de paix et d'entente, c'est une réalité contemporaine qui est sans doute dans la nature des choses.

Ainsi de nouveaux motifs prennent naissance chez les entrepreneurs, des sentiments de solidarité, le sens de l'intérêt général, et de leur responsabilité sociale. Mais

John Jacob Astor Businessman, 2 volumes, Cambridge (Mass.), 1931 ; - voir notre étude : Un grand marchand d'Amérique : John Jacob Astor, dans Annales d'Histoire économique et sociale, 1933. 
c'est comme une autre période qui s'ouvre, et les traits que nous avons dégagés, au cours des siècles révolus, n'en gardent pas moins, jusqu'à présent, tout leur relief.

Les dispositions psychologiques que nous venons de décrire sont-elles nées du système capitaliste lui-même ? Certes, le système les a renforcées. Il faut aussi, pour expliquer l'ébranlement des anciennes coutumes et les intérêts nouveaux qui sollicitent les hommes, tenir compte de l'afflux de l'or et de l'argent en Europe, après la découverte de l'Amérique, dans le cours du XVIe siècle. N'est-il pas naturel que l'argent et l'or, le métal précieux, n'ait pas été recherché pour lui-même, qu'on ne l'ait pas davantage accumulé, en une période où il était très rare et suffisant à peine aux besoins des échanges ? Lorsqu'il arriva en grande abondance et que, par son moyen, industrie et commerce grandirent vite, rien ne dut exciter plus de convoitises et encourager à plus d'efforts. Avec la monnaie, la richesse s'est répandue dans les villes ; ceux qui y possédaient des maisons, des fonds de terre, en ont vu hausser la valeur ${ }^{1}$ ; la population s'est accrue : artisans et marchands ont dû satisfaire une plus grosse clientèle, d'autant plus que des besoins nouveaux naissaient, et qu'on s'attachait aux objets de luxe ${ }^{2}$. Ainsi les hommes se seraient progressivement adaptés aux nouveaux courants économiques, de même que chez ceux qui passent de la campagne à la ville, goûts et préférences se transforment et la pensée comme la volonté se plie à un nouveau genre de vie.

Il est vrai que l'esprit nouveau s'est manifesté avec une intensité très inégale, suivant les pays. La France était en rapport direct de voisinage avec l'Espagne, par où passait tout l'or de l'Amérique : des artisans français travaillaient, en grand nombre, pour les Espagnols et chez eux. L'Allemagne, l'Italie ont pu profiter de cet afflux de métal précieux en Europe autant que tout autre pays. C'est cependant en Angleterre, dans les grandes villes anglaises commerçantes et manufacturières, que les dispositions qu'on appellera plus tard capitalistes, que les motifs bourgeois peuvent être signalés le plus tôt : à la fin du XVIe siècle, au commencement et dans le cours du XVIIe siècle, premier élan industriel, dans un pays encore peu peuplé, qui avait dans la Hollande et les villes du Nord de l'Europe des concurrents redoutables pour le commerce maritime et pour plus d'une branche du commerce. Au XVIIIe siècle, des groupes, principalement anglo-saxons, s'inspirent encore de cet esprit, sont à l'avantgarde du nouveau régime les colonies de l'Amérique du Nord, d'où sortirent les ÉtatsUnis.

Certes, le mouvement gagnera bientôt les autres pays, niais avec un retard, quelquefois un retard considérable ; la révolution industrielle ne se produit en France qu'au début et, en Allemagne, qu'à la fin du XIXe siècle : jusqu'au règne de LouisPhilippe, ce n'est que timidement que le bourgeois français obéit à l'esprit d'entreprise, et les habitudes féodales et corporatives, le morcellement de l'ancien régime, paralyseront bien plus longtemps encore l'activité économique dans les pays d'outreRhin. Dès la fin du XVIIIe siècle, au contraire, l'industrie anglaise est en plein essor,

C'est là-dessus qu'a insisté surtout Karl Bücher, Die Entstehung der Volkswirtschaft, Tübingen, 1893 ; 2e éd., 1898 ; traduction française [sous le titre Études d'histoire et d'économie politique], Paris, 1901.

2 Adam SMITH, An Inquiry, etc., op. cit., Book III, Chapter IV. 
elle a pris une avance qu'elle ne perdra plus. Quant aux commerçants et hommes d'affaires américains, il semble de bonne heure qu'ils obéissent à la même impulsion.

Est-ce, comme l'ont cru quelques sociologues, parce que dans ces pays la masse de la population et tout au moins ses premiers artisans appartiennent à la race anglosaxonne, et que celle-ci serait plus énergique à la fois et plus positive que les autres ${ }^{1}$ ? Les hommes de cette race, tournés plus tôt que les autres vers les activités de l'industrie et du commerce, dégagés des croyances magiques et religieuses, appliquent à l'analyse de la réalité une pensée toute pratique et même scientifique. Le capitaliste, alors, se serait distingué des autres hommes, et aurait pris le pas sur les autres, seulement parce qu'il découvrait d'un regard plus lucide les conditions d'une entreprise efficace. Les ingénieurs techniques (efficiency engineers) et ce qu'on appelle l'organisation scientifique des usines, se placeraient bien dans la ligne d'une telle activité positive et tenace.

Mais on a soutenu qu'il y a eu autre chose encore à l'origine de l'esprit capitaliste. N'oublions pas, en effet, qu'il s'agissait alors non point surtout de modifier la technique matérielle de l'industrie, ni les divers procédés appliqués an commerce, ni les cadres mêmes de la production. Cela s'est fait à la longue, petit à petit. Il fallait d'abord changer l'esprit, les dispositions des artisans et marchands. C'était là un monde de croyances, de coutumes, à la fois morales et religieuses, auxquelles il était nécessaire d'opposer des forces de même nature, si l'on voulait engager dans une direction économique nettement différente tous ces agents de la production.

En effet, le but de l'activité économique, et aussi son intensité, ne pourra changer que si l'homme change aussi tout entier, s'il estime, par exemple, que lui est permis et même commandé ce qui lui était autrefois interdit, par Dieu, par l'Église, par la morale, et s'il est capable, par volonté, par conviction que tel est son devoir, de développer un effort qui fait violence, aussi bien qu'à ses habitudes enracinées, à ses inclinations naturelles. La transformation des motifs économiques que nous envisageons s'expliquerait donc par un changement d'attitude morale et religieuse.

Tel est bien le point de vue auquel s'était placé Max WEBER ${ }^{2}$. D'après lui, si la grande industrie et le capitalisme sont apparus et ont grandi d'abord en Angleterre et en Amérique du Nord, c'est que ces pays ont été gagnés de bonne heure aux doctrines morales du puritanisme protestant, qui leur enseignait à aimer J'effort pour l'effort, si bien que l'activité capitaliste reproduisait dans le domaine économique ce que fut l'activité puritaine dans le domaine religieux. De ces pays, dans les milieux protestants en général, le même esprit aurait pénétré dans d'autres pays encore. Max WEBER étudiant, de nos jours, les statistiques professionnelles des pays où les confessions religieuses sont mélangées, ne trouvait-il pas qu'elles concordent d'une façon tout à fait remarquable en ce que les protestants sont proportionnellement les

1 Thorstein VEBLEN, The Instinct of Workmanship and the State of the Industrial Arts, New-York, 1914, 21 éd., 1918. - Voir notre article : L'Instinct ouvrier dans l'art industriel (Revue philosophique, mars-avril 1921, pp. 214-233).

2 Gesammelte Aufsätze zur Religionssoziologie. I. Die protestantische Ethik und der Geist des Kapitalismus, Tübingen, 1920, pp. 17 à 236, rééd. 1927 (publié pour la première fois sous forme d'article dans Archiv für Sozialwissenschaft und Sozial politik, 1904-1905, et reproduit sans changement, mais avec un grand nombre de notes nouvelles très étendues. Non traduit en français. Nous l'avons assez longuement analysé dans notre article : Les origines puritaines du capitalisme (Revue d'histoire et de philosophie religieuses publiée par la Faculté de théologie de l'Université de Strasbourg, mars-avril 1925, pp. 132 à 157). 
plus nombreux parmi les possesseurs de capital et les entrepreneurs, aussi bien que parmi les ouvriers de l'industrie, et qu'ils ont aussi une part prépondérante dans le personnel technique et commercial supérieur ? Ce n'est pas parce qu'ils sont ou ont été une minorité, comme si les minorités exclues des fonctions de l'État, se tournaient naturellement vers l'industrie. Les catholiques, minorités en Allemagne, en Hollande et en Angleterre, n'y ont jamais fait preuve de dispositions particulières pour l'industrie. C'est donc bien la morale religieuse du milieu puritain qui aurait été favorable au développement de l'esprit d'entreprise.

Bien des entreprises de forme capitaliste, banques, grand commerce d'exportation, gros magasins de détail, furent longtemps gérées dans un esprit traditionnel (non capitaliste). Florence, au XIVe et au XVe siècle, a été le théâtre d'un développement industriel déjà capitaliste, dans des milieux dominés cependant par une morale hostile à toute activité dirigée vers le gain.

Jusque vers le milieu du XIXe siècle, sur le continent du moins, tel a été le cas de l'industrie textile. Elle réclamait des capitaux : les entrepreneurs, les commerçants, lorsqu'on envisage la nature de leurs opérations, leur comptabilité, etc., rentrent bien dans la définition du capitalisme. Mais la plupart d'entre eux vivaient modestement et travaillaient sans fièvre, comme on vivait et travaillait autrefois dans leur classe. Ils attendaient les paysans qui venaient chercher les commandes, et écoulaient les produits par des intermédiaires.

Ceux qui modifièrent ces méthodes durent au contraire employer à plein tout leur temps, aller jusqu'au bout de leurs forces, et se priver de toutes distractions et de tout repos superflu. Ils allèrent trouver les paysans, les sélectionnèrent, en firent des travailleurs d'usine. Ils organisèrent la vente directe aux magasins de détail, se préoccupèrent de la clientèle, s'efforcèrent de tenir compte très exactement de ses besoins et de ses goûts. Pour gagner la confiance des paysans et des ouvriers, pour tenir tête aux obstacles de toute nature qui se dressaient et qu'on dressait sur leur route, et surtout pour donner un tel effort d'une façon continue, il fallait une maîtrise de soi et une confiance en soi exceptionnelles. Ce n'est pas l'argent tout seul, les réserves d'argent dont ils pouvaient disposer, qui leur eussent donné ces qualités. Mais ces qualités, plutôt, les rendirent capables de trouver les fonds nécessaires pour les mettre en œuvre. Ce n'étaient point des spéculateurs, des aventuriers sans scrupules, ou simplement des riches, mais des hommes de mentalité bourgeoise, qui prenaient la vie comme un devoir difficile et comme une lutte de tous les instants.

Mais comment de tels dons personnels se rattachent-ils à des convictions religieuses ? Aujourd'hui surtout, qu'on interroge un de ces hommes acharnés au travail en vue du gain, qu'on leur demande quelle est la raison de leurs efforts. Ils ne diront pas qu'ils travaillent pour gagner le ciel. Leur regard est fixé sur la terre, et ne la quitte pas. Si quelques-uns prétendent qu'ils veulent assurer la vie de leurs enfants et de leurs petits-enfants, le plus grand nombre laisseront entendre que les affaires sont pour eux une nécessité, et le travail une raison de vivre. De fait, le grand entrepreneur capitaliste ne tient souvent ni aux jouissances, ni aux distractions que peut lui procurer sa fortune. Il veut avant tout se rendre à lui-même cette justice qu'il a fait sa tâche.

En tout cas, ce respect de la profession industrielle, cette haute idée du travail de l'artisan ou du marchand ne se reflète pas dans l'opinion, à l'époque où naît le capitalisme. l'Église atténue sa doctrine qui condamne le prêt et le commerce, par 
égard pour les grands manieurs d'argent des villes italiennes. Elle n'en considère pas moins toute activité mercantile comme déshonorante (turpitudo). Telle est bien alors l'opinion générale. L'inquiétude des commerçants eux-mêmes se révèle comme dans des témoignages posthumes : dons par testament à des établissements ecclésiastiques, restitutions à des débiteurs pour cause d'usure.

Si l'esprit nouveau ne s'expliquait que par les formes capitalistes de l'industrie moderne, comment se fait-il qu'à Florence, qui était au XIVe et au XVe siècle le théâtre d'un développement industriel déjà capitaliste, une telle hostilité de principe vis-à-vis des activités orientées vers le gain se soit maintenue, alors qu'au XVIIIe siècle, en Pensylvanie, où il n'y avait pas de grandes entreprises, à peine des banques, mais des artisans et de petits commerces, l'évangile capitaliste (chez Franklin et dans son milieu) était déjà né ? Ici, une âme sans corps, là un corps sans âme. Mais c'est l'âme qui devait organiser le corps.

Qu'est donc cet esprit capitaliste, et quelles sont ses racines ? SOMBART a soutenu qu'il se confondait avec l'esprit rationnel. Sans doute le capitalisme substitue partout la réflexion et le calcul à l'intérêt et à la routine. Mais entre ces méthodes de production industrielle et ce qu'on appelle communément le rationalisme, il n'y a guère de rapport. C'est dans les pays latins, en France et en Italie, que la philosophie voltairienne s'est épanouie, qu'elle a répandu partout ses «lumières ». Mais c'est ailleurs que la révolution capitaliste s'est d'abord accomplie. Au reste, si les méthodes de l'industrie moderne sont rationnelles, il y a, dans l'abnégation d'hommes qui se dévouent entièrement à une profession lucrative non par amour du gain pour les biens 'utiles qu'il procure, niais par sentiment du devoir, quelque chose qui heurte la raison.

D'après Max WEBER, c'est le protestantisme, c'est la Réforme, qui aurait, sinon créé l'esprit capitaliste, du moins qui l'aurait stimulé et marqué de son empreinte. Non la réforme luthérienne en Allemagne. LUTHER pensait que chacun devait faire son devoir dans la place que le Seigneur lui avait assignée. Que chacun se contente de ce dont il a besoin pour vivre, et laisse les impies s'égarer à la poursuite du gain. Fils de paysan, LUTHER avait le même préjugé que les paysans contre le prêt à intérêt. Il n'admettait pas qu'on pût faire valoir de l'argent. Il pensait que l'avidité qui pousse à gagner plus que ce dont on a besoin, est le signe qu'on n'est pas en état de grâce.

C'est dans le calvinisme, au contraire, et dans les sectes qui s'inspirèrent du même esprit, que la profession lucrative se trouvera rehaussée en dignité et rattachée à une source religieuse intérieure. Bien plus : ce qui creuse comme un abîme entre luthériens et catholiques d'un côté, calvinistes de l'autre, c'est l'idée qu'on se fait ici et là de la morale, c'est-à-dire de la vie terrestre et de la façon dont il convient de l'apprécier et de la régler.

Il faut comprendre la vie pratique et professionnelle avant tout comme un devoir, peut-être comme le seul devoir, plus important que la contemplation oisive de Dieu. Les calvinistes ont été jusque-là. C'est pourquoi après la Réforme s'est établi un contraste si marqué entre la manière d'être et de penser des Anglais et des Allemands. En Angleterre même, depuis la Réforme jusqu'à nos jours, il n'exista pas une différence moins tranchée, d'abord entre les Cavaliers et les Têtes rondes, ensuite entre les squires qui gardent la tradition de la merry old England, et la bourgeoisie commerçante marquée par les influences puritaines, et qui vivait entre la Bible et le comptoir. La bonhomie (Gemütlichkeit) et le naturel un peu vulgaire des Allemands font contraste avec la contrainte des Anglo-Saxons, dont les visages mêmes sont plus 
fermés et les traits plus tendus. Tant la méthode puritaine a mis son empreinte sur les esprits et sur les corps.

L'évangile du travail, de l'effort aimé pour lui-même, l'orgueil un peu pharisien des riches qui doivent leur richesse à leurs privations, leurs économies, leur activité sans relâche, le conformisme qui rapproche ceux qui se reconnaissent dignes d'entrer dans l'élite des hommes dont le travail a été récompensé par la richesse, et ainsi consacré par Dieu, tels sont les traits qui permettraient de définir une morale marchande et puritaine, la morale de la bourgeoisie traditionnelle. Ne cherchons pas ici de trop près quelle a pu être l'influence, à cet égard, du dogme calviniste de la prédestination, comme si le fait de la réussite temporelle était le seul signe qui révèle les élus, qui les distingue de la foule à leurs yeux et aux yeux de la foule.

On a reproché, sans doute à juste titre, à cette thèse de ne pas tenir assez compte du grand mouvement économique qui s'est produit en Hollande et en Angleterre aux XVIe et XVIIe siècles, non plus que des découvertes (bien que, d'ailleurs, les idées aient pu réagir sur les conditions matérielles). Il faut faire une part aussi, dans l'explication de l'esprit capitaliste, à la pensée politique de la Renaissance : Machiavel a contribué, autant que Calvin, à supprimer les restrictions morales traditionnelles, à créer un milieu intellectuel favorable à l'individualisme économique.

TAWNEY, tout en voyant dans la conception de Max WEBER « une des théories les plus pénétrantes et les plus fécondes qui aient été présentées quant aux rapports entre la religion et les idées ou les théories sociales », pense cependant qu'il simplifie à l'extrême le calvinisme lui-même ${ }^{1}$. C'est une erreur de croire que les puritains anglais du XVIe et ceux du XVIIe siècle avaient les mêmes vues sur les devoirs sociaux et les raisons d'opportunité (expediency). En réalité, les calvinistes du XVIe siècle, y compris les puritains anglais, croyaient en une discipline rigoureuse, et l'individualisme qu'on a raison d'attribuer à la dernière phase du mouvement puritain leur eût fait horreur. Il y avait d'ailleurs, parmi les puritains du XVIIe siècle euxmêmes, une certaine diversité de point de vue en matière de politique sociale. Cromwell ne trouva pas une formule qui pût rassembler les aristocrates puritains et les Levellers (niveleurs), les propriétaires du sol et les laboureurs, les marchands et les artisans.

Ce qu'il y a de solide et de juste dans la thèse de WEBER, conclut TAWNEY, c'est l'idée que les classes commerçantes du XVIIe siècle en Angleterre ont représenté un opportunisme social (dans le sens d'une conception très progressive et très large des méthodes dans le commerce et l'industrie), très différente de ce qu'on rencontre parmi les éléments plus conservateurs de ce pays - paysans, maîtres, artisans et noblesse terrienne -et que cette conception religieuse et politique s'est exprimée aussi dans leur conduite économique et sociale.

Quoi qu'il en soit, c'est bien dans ces milieux protestants anglo-saxons que paraissent s'être formés, sous des influences en partie religieuses, un ensemble d'habitudes et de croyances morales qui subsisteront longtemps, qui sont loin d'avoir disparu. Malgré les exemples démoralisants de fortunes trop vite et trop facilement acquises, malgré ce que les moralistes appellent l'action corruptrice de la richesse, certains riches réalisent encore le type du marchand qui tient les comptes de ses

1 Religion and the Rise of Capitalism, Londres, 1926 [traduction française, La Religion et l'essor du capitalisme, Paris, M. Rivière, 1951.] 
bonnes et de ses mauvaises actions avec autant d'exactitude que les comptes de ses dépenses et de ses recettes, et qui transporte d'ailleurs dans sa vie privée le sentiment du devoir développé en lui dans l'exercice de sa profession.

Ce à quoi l'on obéit, dans les milieux soumis à cette morale, c'est ce que nous pouvons appeler le motif individualiste. Comment une société a-t-elle pu se construire sur la base de l'individualisme ? Comment l'individu a-t-il pu être considéré comme la valeur par excellence, la valeur absolue, et comment a-t-on tiré une morale de cette croyance d'où semblait découler l'égoïsme le plus immoral ? C'est que, d'une manière ou de l'autre, cette croyance a pris la forme religieuse. De fait, Max WEBER encore, après un voyage en Amérique, décrivait les vestiges qu'il y avait trouvés de l'ancienne organisation des sectes, à présent laïcisées en partie, c'est-à-dire remplacées par les clubs et les sociétés exclusives dont il faut être membre pour obtenir un certain degré de considération et de crédit. La secte, formée uniquement entre des hommes pieux, avec des conditions de noviciat, et l'obligation de justifier par sa conduite soumise à un contrôle incessant qu'on faisait partie vraiment des justes, fut comme le terrain où purent prendre racine et se développer les qualités ascétiques et l'esprit individualiste, qui sont l'âme de l'organisation capitaliste. «Tandis que l'enrichissement excessif d'un membre d'une corporation, au moyen âge, agissait sur l'esprit corporatif comme un dissolvant, la réussite capitaliste d'un « frère », parmi les baptistes ou les quakers, pourvu qu'elle fût obtenue légalement, était une preuve de son état de grâce et augmentait les chances de succès de la secte ${ }^{1}$. »

En tout cas, dès le XIXe siècle, celte morale nouvelle paraît subsister désormais par elle-même. Elle a pénétré d'ailleurs dans les milieux catholiques hostiles à l'individualisme protestant. Elle s'y est heurtée certainement à des résistances. l'Église catholique qui, traditionnellement, opposait les riches aux pauvres comme les méchants aux bons, ou du moins ceux qui sont plus exposés au péché à ceux que leur pauvreté préserve de beaucoup de tentations, a dû admettre cependant que l'activité de l'industriel et du commerçant peut ne pas être sans mérite.

«Vie plus dure, plus pénible et aussi mortifiée que celle que les plus grands serviteurs de Dieu mènent dans le cloître et dans le désert », dit, au milieu du XVIIIe siècle, le père Croiset, en parlant de l'existence tourmentée de la plupart des hommes d'affaires. Ce sont des ascètes, et quels que soient les motifs qui les font renoncer aux plaisirs du monde, il semble bien que la « gênante assiduité » qu'ils s'imposent, et jusqu'à l'opiniâtreté dont ils font preuve dans leur travail, devraient leur assurer certains avantages, aux yeux de la foi, sur les mondains qui ne travaillent pas, ne fûtce que parce que, en travaillant comme ils le font, ils semblent bien à leur manière se conformer à l'ordre de Dieu, et. expier le péché originel que l'homme du inonde, oisif et jouisseur, paraît toujours vouloir ignorer ${ }^{2}$.

Pourtant, il n'y a en définitive qu'un moyen de justifier sa richesse et les efforts qu'on a faits pour l'acquérir : ce sont les bonnes oeuvres, l'aumône, la charité. l'Église

Article paru en 1906, reproduit également dans sa Religionssoziologie [tome I, pp. 207-236] sous le titre: Les Sectes protestantes et l'esprit du capitalisme.

2 B. GROETHUYSEN, origine de l'esprit bourgeois en France. I. l'Église et la Bourgeoisie, 1927, p. 243. 
s'accommode tant bien. que mal du capitalisme, qu'elle ne peut ignorer ; mais elle reste solidaire d'une société ancienne qui lui était foncièrement hostile.

NIETZSCHE ${ }^{1}$ remarque quelque part que la vie religieuse suppose avant tout beaucoup de loisir et que, dans nos sociétés affairées, où l'activité laborieuse qui les absorbe a, depuis des générations, détruit lentement en eux l'instinct religieux, la plupart des gens ne savent plus à quoi la religion est utile, et se contentent d'enregistrer son existence avec un profond étonnement : "Pris par leurs affaires et par leurs plaisirs, ils n'ont plus de temps à lui consacrer, d'autant plus qu'ils ne savent pas très bien s'il s'agit là d'une affaire ou d'un plaisir. » Quelle que soit en effet l'influence qu'exerce encore la religion sur les commerçants, les industriels, les hommes d'affaires, on peut bien dire que le motif de leur activité et de leurs efforts n'est généralement pas religieux. Alors, quel est-il ?

Ici, il faut sans doute observer que le régime économique moderne, par le fait seul qu'il existe, crée et entretient un ensemble de représentations collectives auxquelles les agents de la production, en particulier ceux qui exercent des fonctions de direction, doivent bien obéir. Là où ils sont placés, dans l'organisation industrielle, certains d'entre eux au moins sentent qu'ils ont une tâche à remplir, qu'ils sont chargés de responsabilités : il est naturel qu'ils tiennent à justifier, par la qualité de leur effort, le rang social, où l'hérédité, la chance, les circonstances, les ont élevés.

Individualisme encore, bien que ce sentiment résulte de, la pression qu'exerce sur eux leur milieu, parce qu'ils veulent se rendre surtout à eux-mêmes cette justice qu'ils ont bien rempli leur tâche et leur destinée. Ce motif prend davantage forme sociale, lorsque passe au premier plan l'opinion des autres. Membres d'une classe élevée, il leur apparaît que "bourgeoisie » (de même que noblesse) oblige. Et ils veulent apporter devant les autres la preuve qu'ils sont dignes de faire partie de cette classe. Souci de respectabilité bourgeoise, qui leur commande d'agir suivant les règles de la morale courante dans leur milieu, où il est admis que l'homme doit faire tout ce qu'il peut pour accroître sa richesse, mais en se conformant aux usages et traditions sur lesquelles repose le prestige de la classe elle-même.

Au reste le commerce, l'industrie, les méthodes et organisations économiques ont évolué, en même temps que se transformait la société et en particulier te monde bourgeois. Déjà au moyen âge, si les corporations réglementaient le commerce et l'industrie à l'intérieur de la ville, elles ne pouvaient imposer exactement leurs coutumes ni leur morale aux étrangers qui s'occupaient à mettre en rapport les divers marchés urbains. Il y a, à chaque époque, des méthodes lucratives traditionnelles, et d'autres qu'on peut appeler modernes. En particulier, en toutes les périodes de transformation économique, des couches nouvelles de bourgeoisie surgissent, enrichies par des méthodes qu'elles ont été les premières à mettre en œuvre ${ }^{2}$.

D'autre part, dans toute société un peu développée, on distingue des régions où l'activité des producteurs et des marchands s'exerce dans des cadres depuis longtemps fixés, et d'autres où les cadres sont nouveaux et se modifient sans cesse : milieux de

Jenseits von Gut und Böse, 3. Hauptstïck, 758.

SIMIAND, Cours d'économie politique, 2, année, 1928-1929, p. 478 : Les grandes poussées de classes bourgeoises : médiévales, des XVIe et XVIIe siècles, en Espagne, Portugal, Hollande. Poussée de la "Révolution industrielle », en Grande-Bretagne ; l'ère victorienne (portrait du bourgeois anglais vers la fin du XIXe siècle par SCHIILZE-GÄVERNITZ), du XIXe siècle à la fin du XXe, de la période de guerre et d'après-guerre. 
bourse et de finance, industries et commerces nouveaux, ou formes nouvelles de groupements et d'association d'industries anciennes ${ }^{1}$.

Or, ces commerçants et industriels d'un nouveau type apportent avec eux des idées et des habitudes empruntées à des milieux où ne règnent pas les conceptions bourgeoises traditionnelles : sociétés d'artistes, groupes politiques, monde des théâtres, de la bourse, des journaux, des sports, groupes étrangers et cosmopolites, collectivités plus mêlées et plus ouvertes, où, comme en terrain neutre, se rencontrent, se côtoient des hommes de toutes provenances. Qu'on se reporte aux romans de Balzac, miroir fidèle d'une société économique en pleine transformation, où les deux types de commerçants et d'hommes d'affaires présentent un si vif contraste. Qu'on songe encore à ces industriels saint-simoniens qui entrent, au début du règne de Louis-Philippe, dans les carrières bourgeoises. Avant de créer les premiers chemins de fer, d'organiser financièrement la publicité et la réclame, de construire des canaux internationaux, de spéculer sur les immeubles et sur les terrains des grandes villes, de développer les banques, c'est au contact de philosophes, de savants, d'artistes, et même de représentants des classes populaires, que leur pensée a pris l'habitude des vastes projets, des méthodes complexes, qui répondent à un type de société plus évolué et sans doute plus étendu que le monde occidental de leur temps ${ }^{2}$.

C'est dans un milieu différent de la société bourgeoise traditionnelle, et moins fermé, que ces bourgeois d'un nouveau type se sont formés. Les conceptions morales y sont différentes aussi. On y juge et on y apprécie les hommes moins sur des qualités d'énergie et d'obstination au travail de commerce et d'affaires, d'honnêteté et de tenue individuelle, que d'après leur esprit social, tel qu'il se développe dans une classe élargie, en perpétuel renouvellement, et où, l'homme est plus considéré dans la mesure où il a le sens des réalités collectives, où il est capable de s'adapter vite aux mœurs et aux institutions, suivant le rythme de leurs transformations.

Ainsi naît une conception nouvelle de l'entrepreneur : non plus une personnalité forte, qui considère l'entreprise comme une chose à lui, subordonne à ses fins propres les agents de la production, et aussi les consommateurs, la clientèle : mais plutôt, l'homme chargé d'une fonction sociale importante, qui en prend conscience, et se subordonne à sa fonction, se confond avec l'entreprise, cherche à s'identifier avec elle.

Après tout, la réussite industrielle ou commerciale implique chez les chefs des qualités très spéciales, qui peuvent se présenter extérieurement sous des formes plus ou moins pittoresques, mais qui doivent être définies principalement sur le plan économique : faculté de coordonner les divers éléments d'une entreprise, d'en assurer l'orientation générale, d'en apercevoir les liaisons avec d'autres et avec le milieu des affaires en général. Mais cela suppose que l'entrepreneur pense et agit en tant que personne collective, représentant une fonction impersonnelle, quelle que soit d'ailleurs l'intensité de ses motifs intéressés. Sous ce rapport, d'ailleurs, il n'y a qu'une

C'est par là que SOMBART explique la situation particulière et les formes d'activité des Juifs sous l'ancien régime (exclus des corporations, des corps administratifs, partout étrangers, d'où une morale commerciale qui leur était propre). Die Juden und dos Wirtschaftsleben, Leipzig, 1911, traduction française : Les juifs et la vie économique, Paris, 1923. - Voir notre compte rendu, Année sociologique, XII, 1913, p. 623.

2 Voir dans l'École saint-simonienne, son influence jusqu'à nos jours, par Georges WEILL, Paris, 1896, le système de la Méditerranée, pp. 112-113, et les chapitres V des saint-simoniens en Afrique) et VII des saint-simoniens sous Louis-Philippe), et, dans L'Histoire du Saint-Simonisme, par S. CHARLÉTY, Paris, 1896, le livre IV de Saint-Simonisme pratique). 
différence de degré et de complication entre l'entreprise privée d'ancien type et l'exploitation moderne, soit d'une société qui se rattache à un cartel ou à un consortium, soit d'un type où te caractère publie est encore plus marqué et plus important ${ }^{1}$.

Faut-il croire, avec SOMBART, que « dans une entreprise moderne, c'est-à-dire dui répond -aux exigences de la direction capitaliste de l'économie, il n'y a pas place pour l'âme »? Il reproduit ce mot de Ford : «Une entreprise gigantesque est trop grande pour être humaine. A mesure qu'elle grandit, elle étouffe les personnalités. Dans une grande entreprise, l'individualité de l'employeur et celle de l'ouvrier se perdent dans la masse. » En d'autres termes la rationalisation, les méthodes scientifiques auraient peu à peu substitué l'esprit (c'est-à-dire le calcul abstrait) à l'âme, dans l'entreprise, et déshumanisé celle-ci. SOMBART oppose la personnalité individuelle de l'entrepreneur du type ancien et l'entreprise moderne, oeuvre de raison abstraite et technique, qui réduirait l'entrepreneur comme l'ouvrier à n'être qu'un rouage ${ }^{2}$.

Mais une entreprise n'est presque jamais simplement un mécanisme. Sans doute on peut dire qu'autrefois, et souvent encore aujourd'hui, elle tire en partie ce qui fait d'elle comme un être personnel du chef qui est à sa tête. Mais elle tend à acquérir une vie et comme une conscience propre qui s'impose à celui même qui la dirige.

A propos des sociétés anonymes modernes, SIMIAND remarquait que, lorsqu'elles ont réussi, en remboursant leur capital, à ne plus être dépendantes des actionnaires, tout se passe comme si elles se possédaient elles-mêmes. « A ce point de développement, ajoute-t-il, une telle société est comme un être collectif, de caractère privé, mais qui en réalité se rapproche des êtres collectifs de caractère publie, tels que les communes, les États, qui ont aussi ce caractère d'être indépendants des personnes et d'avoir une vie continue, distincte de celle des personnes. Même on peut dire qu'assez souvent cette entreprise arrive à constituer ou posséder une certaine âme qui se caractérise, se différencie et se préoccupe d'aboutir à des réalisations où l'on voit sa raison même. »

Certes un tel caractère ne se dégage pleinement que dans des organismes industriels très évolués et différenciés. Mais il semble qu'il se retrouve, sous des formes plus enveloppées, à toutes les étapes de l'évolution. La réussite économique suppose, avant tout, et a dû toujours supposer, chez le chef, la faculté de s'identifier avec son entreprise, elle-même être collectif, et de se pénétrer de son esprit.

Certes, on aperçoit bien des obstacles au développement de dispositions sociales véritables dans la bourgeoisie, même d'un simple esprit d'entraide entre ses membres. C'est d'abord que cette classe se décompose en quelques grandes catégories qui, pour le maintien et l'augmentation de leurs revenus, se trouvent dans des conditions trop différentes pour recourir aux mêmes types d'organisation.

La partie supérieure du fonctionnariat a un statut, fixé par la loi. Dans les professions libérales, c'est d'après la coutume en vigueur dans les milieux bourgeois que se fixent les honoraires des médecins, des avocats, etc. Ici et là, il y a bien des

\footnotetext{
1 Voir notre Revue critique des travaux sur l'évolution récente du « capitalisme », dans les Annales sociologiques, série D, fasc. 1, 1934, pp. 141 et suivantes.

2 L'Apogée du capitalisme op. cit. (3• partie : La déshumanisation de l'entreprise, II, p. 409).
} 
associations, mais limitées au cadre de chaque profession, et qui ne s'inspirent pas d'un esprit de classe plus général ${ }^{1}$.

Quant aux industriels et aux commerçants, la loi prévoit pour eux la possibilité de former des syndicats patronaux. Il s'en est constitué. D'autre part, il y a une tendance bien notable, dans l'industrie et le capitalisme modernes, à réunir les entreprises d'une même industrie, d'une même branche, dans le cadre national et même dans le cadre international, comptoirs de vente, centrales, concerns, etc. Même il se forme, entre les syndicats et associations de ce genre, des unions plus larges, des fédérations. Mais l'objet de tels groupements d'industriels est surtout de favoriser la production, d'étendre, d'aménager les marchés nationaux et internationaux. Ils se constituent surtout sur le plan de la production, et non de la répartition ou de la fixation des gains. C'est que les gains des industriels et des commerçants sont des bénéfices qui résultent de l'effort et des conditions propres de chaque entreprise, et ne peuvent être déterminés par des règles collectives.

Ainsi, entre ces catégories en lesquelles se décompose la bourgeoisie, il n'y a pas communauté d'organisation, parce que chacune a des méthodes particulières en vue de maintenir et élever la situation de ses membres.

Ajoutons qu'à l'intérieur de chacune d'elles règne une concurrence très forte. C'est par son effort et ses chances personnelles qu'un fonctionnaire s'élève aux plus hauts degrés de la hiérarchie, qu'un médecin améliore sa clientèle en quantité et qualité, et surtout qu'un entrepreneur élargit ses débouchés et augmente ses bénéfices. Certes, cet individualisme, qui se trouve à la base du régime industriel moderne, est plus ou moins développé suivant les phases qu'on peut distinguer dans l'histoire de cette classe. A la fin de l'ancien régime, la classe bourgeoise naissante s'est organisée contre la noblesse, d'abord dans les Parlements et autour d'eux, dans le Tiers État et les assemblées qui l'ont préparé, dans les assemblées révolutionnaires. Puis, ses droits reconnus, entrée dans la période d'essor, elle a trouvé dans son élan même un principe d'unité suffisant, et dans la pleine liberté, l'absence de tous liens conventionnels entre ses membres, la condition nécessaire de son ascension. Depuis quelques décades, plus sensible aux inconvénients de la concurrence qu'aux profits qu'elle en tire, elle essaie de nouveau de s'organiser. Mais il y a une contradiction latente entre l'esprit d'association et l'esprit bourgeois. Il manque à cette classe une idée, une conception commune de son rôle, de sa fonction dans la société.

Écoutons cependant un grand industriel, s'adressant à des ingénieurs, à des hommes d'affaires, et qui dénonce la fin du libéralisme : "Si l'ordre doit être changé, il faut que ce soit nous, tous ceux qui, à des degrés divers, sommes des chefs, qui en prenions l'initiative... La recherche doit être tendue à résoudre par l'esprit collectif, par l'entente, dans tous les domaines, les problèmes - avant que l'État ne s'en saisisse... Le libéralisme nous a donné de bien mauvaises habitudes. Il a sanctifié l'égoïsme... Jusqu'ici l'entente s'est développée, mais elle n'a été conçue que comme une défense, comme une association sans sacrifices sensibles, destinée seulement à accroître les bénéfices ou à diminuer les pertes... Elle a résolu un certain nombre de problèmes personnels ; elle laisse en suspens les problèmes généraux... Ce qui est nécessaire, c'est l'entente pour l'intérêt publie... Il faut que nous fassions disparaître peu à peu Vidée et la réalité des classes sociales, par l'éducation et par la facilité

1 Simiand, Cours d'économie politique, 1930-1931, p. 572. 
d'accès de tous aux postes les meilleurs. Il faut que nous pensions tous comme si nous étions le peuple ${ }^{1}$. »

Ce n'est pas là une voix isolée. Les motifs sociaux ont prise dès maintenant sur une partie des chefs de l'industrie, sur une partie de la bourgeoisie. C'est bien autour de la notion d'intérêt général que pourrait se constituer une classe des «producteurs » au sens où l'entendait SAINT-SIMON, une classe des chefs temporels, suivant le mot d'Auguste COMTE, qui prendrait conscience du caractère social de sa fonction.

1 Conférence de M. A. DETOEUF, La fin du libéralisme (Bulletin du Centre polgtechnicien d'études économiques : X - Crise), nos 31-32, mai-juin, août 1936, pp. 48, 49 et suivantes. 


\title{
LES MILIEUX URBAINS ET LA CIVILISATION INDUSTRIELLE
}

\author{
DEUXIÈME PARTIE
}

Les ouvriers de la grande industrie

$\underline{\text { Retour à la table des matières }}$

En France, la population industrielle et commerciale (patrons, employés, ouvriers) - (personnes travaillant à leur compte ou au compte d'autrui) s'approche de $50 \%$ de toute la population active (49\%, décomposés en : industrie $38 \%$, commerce $11 \%$ ). Ceci, au recensement de 1921. Tenons-nous à l'industrie. On peut compter que, de ces $38 \%$, les quatre cinquièmes environ sont ouvriers au sens du recensement, c'est-àdire travaillant au compte d'autrui et étant d'ailleurs occupés à un travail manuel, - soit près du tiers de la population active tout entière.

Considère-t-on de façon séparée les ouvriers de la grande industrie (cinq personnes et plus par entreprise), par rapport au total des ouvriers de l'industrie : nous trouvons $32 \%$ au milieu du siècle dernier (sensiblement moins auparavant), pour atteindre ensuite $50 \%$, sans d'ailleurs dépasser ce pourcentage. C'est la catégorie ouvrière la plus caractéristique, l'ouvrier d'établissement : soit le sixième de la population ${ }^{1}$. Elle comprend en particulier presque tous ceux qui sont occupés dans l'industrie chimique, la métallurgie, les mines et minières, et aussi la plupart des ouvriers dans les terrassements, la construction, les industries textiles, les fers et aciers ${ }^{2}$.

1 [Cf. Villes et Campagnes, op. cit., p. 130 (rapport de M. Pierre COUTIN) : « Sur 4368598 salariés travaillant dans des établissements industriels en 1936 [contre 1.200.000 ouvriers agricoles], 941.941 (soit 21,6 p. 100) travaillaient dans des établissements occupant de 1 à 10 salariés ; - 1.251 .478 (soit 28,6 p. 100) travaillaient dans des établissements occupant de 11 à 100 salariés ; - 1.043 .752 (soit 23,9 p. 100) travaillaient dans des établissements occupant de 101 à 500 salariés ; - 1.131 .427 (soit 25,9 p. 100) travaillaient dans des établissements occupant plus de 500 salariés. » - Il est remarquable qu'en totalisant les trois derniers chiffres, on arrive presque exactement en effet au sixième de la population active.] A.C.

2 Simiand, Cours d'économie politique, 21 année, 1928-1929, pp. 448 et 450. Ajoutons quant aux autres pays : en Norvège, Tchécoslovaquie, Suède, Danemark, où la population agricole est, comme en France, de près de $40 \%$, en proportion la catégorie ouvrière (industrielle), est peu étendue elle l'est beaucoup plus en Angleterre, Écosse, Belgique plus que dans la première catégorie, moins que dans la seconde, aux Pays as, en Allemagne, en Suisse ; en revanche, elle est nettement plus faible que dans la première, dans les pays à forte proportion de population agricole : Grèce, Irlande, Italie, Portugal, Hongrie. Dans 1'Union Soviétique, en 1927, la proportion de population agricole était de $87 \%$. Dans l'industrie, la proportion des ouvriers s'élevait à $41 \%$ de la population industrielle, mais représentait sensiblement moins de $5 \%$ de la population active totale. 
Qu'on s'en tienne à cette catégorie plus restreinte, aux ouvriers de la grande industrie, ou aux ouvriers en général, il s'agit d'ensembles considérables et d'ailleurs d'une importance relativement stable. A travers des fluctuations, plus notables sans doute qu'on ne le croit, son extension se retrouve à peu près la même dans des conditions économiques comparables (d'une période de prospérité à une autre), depuis un demi-siècle.

Ces chiffres nous donnent une idée de l'extension qu'a prise, dans la civilisation moderne, cette classe qui existait à peine aux XVIIe et XVIIIe siècles. Sous le régime corporatif, en effet, les artisans étaient des maîtres et des compagnons dont le plus grand nombre étaient assurés de devenir maîtres à leur tour. A présent, SIMIAND encore, d'après les résultats des recensements, quant à la répartition des âges dans les diverses catégories de la population, nous dit : en France, sur 100 personnes actives de chaque groupe, on peut prévoir que la proportion de ceux qui resteront toute leur vie dans la condition d'ouvrier d'établissement, c'est-à-dire d'ouvrier proprement dit, au sens étroit, est dans l'agriculture, de $10 \%$ seulement, dans l'industrie, de $40 \%$ en 1901, de $43 \%$ en 1921. Si nous y comprenons les ouvriers à domicile, les ouvriers irréguliers (qui ne travaillent pas de façon suivie chez le même patron), les demifaçonniers, demi-producteurs indépendants, nous trouverons : dans l'agriculture, $30 \%$ en 1901, $20 \%$ en 1921 (qui restent ouvriers toute leur vie) ; dans l'industrie, $60 \%$ en 1901, $66 \%$ en 1921. Ainsi de 60 à $65 \%$ des ouvriers, en moyenne, resteront ouvriers toute leur vie, c'est-à-dire ne seront occupés qu'à un travail d'exécution, n'auront aucune part aux opérations de direction, de contrôle, d'achat des matières premières, de vente, de crédit, etc., dont s'occupera seulement le patron ${ }^{1}$.

Dès lors, nous pouvons tout de suite prévoir que le désir d'être à son compte, de posséder son entreprise ou son affaire, de ne point se trouver en une situation de dépendance, qui nous paraissait si général dans les milieux paysans, ne sera ressenti que par une fraction restreinte de la classe ouvrière avec assez de force pour que ses membres préfèrent l'échoppe, le petit atelier domestique, la petite boutique, aux vastes ateliers et chantiers, aux grandes usines, à la grande industrie.

Observons cependant, comme il résulte encore des recherches méthodiques poursuivies par SIMIAND, que les passages de la condition d'ouvrier à celle de travailleur indépendant sont plus nombreux en période de prospérité économique que lorsque les prix baissent ou se stabilisent et que les revenus se resserrent. «Avec les phases de grand développement, quant aux valeurs globales et aussi quant aux quantités produites, mais surtout de forte hausse de prix, nous voyons que la proportion des ouvriers proprement dits et de grande industrie ne va pas tellement croissant. Dans les phases, au contraire, de restriction ou du moins d'atténuation des valeurs, mais avec augmentation des quantités et baisse de prix, la proportion des ouvriers, spécialement de grande exploitation, augmente davantage ${ }^{2}$. » C'est que, quand la situation est favorable, tout se développe, aussi bien les petites et moyennes exploitations que les grandes, il y a des facilités de crédit, les ventes sont assurées.

Aux États-Unis, la proportion de population industrielle dépasse $44 \%$ en 1920 (elle était de $40 \%$ en 1910) ; la population agricole, $35 \%$. Constatations comparables pour l'Australie, l'Argentine.

1 SIMIAND, ibid., p. 454 (durabilité de condition sociale - recherche originale, et qui ne pouvait être tentée jusqu'à ce jour).

2 SIMIAND, ibid., p. 451. 
Il en est autrement en période de crise : alors nombre d'artisans sont obligés de travailler à l'usine (comme il s'agit d'ouvriers assez qualifiés, ils trouvent du travail malgré le chômage), et les ouvriers eux-mêmes ne sont point tentés de s'installer à leur compte, alors qu'ils constatent combien les indépendants souffrent de la dureté des temps. Bien entendu, l'ouvrier préférerait être son maître, et, dès que les occasions se multiplient, et que l'exemple des autres qui réussissent sous ses yeux l'encourage, il cherche à acquérir « une affaire ». Mais le plus souvent, lorsqu'il met en balance les perspectives de risques sérieux, d'une lourde responsabilité et la sécurité d'une situation qui lui apporte régulièrement les moyens de vivre et d'entretenir les siens, la sécurité l'emporte sur le goût de l'indépendance.

Rassemblés dans les mines, réunis en équipes autour des machines, les ouvriers se présentent comme des groupes soumis à une discipline. Ils exécutent et ne commandent pas. Toutes les décisions, quant à l'agencement technique de la production, à plus forte raison quant à la fixation des prix, à la marche économique de l'entreprise, c'est en dehors d'eux qu'elles sont prises. Sans doute leur est-il donné de choisir dans une certaine mesure le métier particulier, l'industrie dans laquelle ils veulent travailler. Chaque homme désire occuper un emploi où ses qualités et aptitudes personnelles soient le mieux utilisées. Tel est le principe de l'orientation professionnelle. Mais, d'une part, ces méthodes sont jusqu'ici assez imparfaites et incertaines. D'autre part elles se heurtent aux conditions mêmes de l'industrie. On ne peut pas adapter les tâches aux aptitudes et aux goûts de la main-d'œuvre. Il faut, plutôt, que la main-d'œuvre s'adapte aux tâches disponibles. L'hérédité, plus exactement l'exemple des parents, joue en somme un rôle limité dans le choix des professions. Ce qu'on constate, c'est que l'ouvrier, à cet égard, s'inspire surtout des circonstances.

En tout cas, lorsque des ouvriers, en particulier des ouvriers qualifiés, exercent depuis quelque temps un métier, ils répugnent à en changer. Ainsi s'explique que dans des industries anciennes, telle que celle de la laine, en Angleterre, aux débuts de la révolution industrielle, le progrès ait été très lent, parce que les ouvriers se contentaient de salaires inférieurs pourvu qu'ils pussent demeurer dans le même métier ${ }^{1}$. On a vu aussi, récemment, des ouvriers réduits au chômage et qui préféraient demeurer dans la catégorie des sans-travail, plutôt que de paraître déchoir en entrant dans une autre profession moins considérée. Il se développe pour cette raison, ou pour ces raisons, habitude, amour-propre professionnel, dans certains milieux ouvriers, une force d'inertie caractéristique.

Le travailleur, engagé dans une profession, a-t-il du moins la liberté de régler luimême la marche et le rythme de Non travail ? Il semble, par exemple, que, suivant les modes de rémunération du travail, suivant que le travail est au temps ou aux pièces, sa situation à cet égard ne soit pas la même. On pourrait croire que le travail aux pièces laisse à l'ouvrier deux libertés : liberté d'accroître (ou de limiter) son gain, d'augmenter (ou de ne pas augmenter et même de diminuer) l'intensité de son effort; il peut, s'il le veut, travailler plus et augmenter d'autant son gain.

Le travail au temps, au contraire, ne lui laisserait qu'une de ces libertés : travailler plus ou moins, dans le même temps, sans que le gain soit changé. En tout cas,

Paul Mantoux, La Révolution industrielle au XVIIIe siècle. Essai sur les commencements de la grande industrie moderne en Angleterre, Paris, 1906. 
l'ouvrier, dans l'un comme dans l'autre cas, serait relativement libre quant à l'effort qu'il fournit ${ }^{1}$.

Mais on sait que, dans nombre de métiers, les ouvriers sont hostiles au travail aux pièces, et on en voit bien la raison. Quand le salaire est. au temps, rien ne prouve au patron que l'ouvrier donne tout l'effort dont il est capable. Instituant le travail aux pièces, il stimule le travailleur qui va jusqu'au bout de ses forces pour accroître son gain. Une fois l'expérience ainsi faite, rien n'empêche le patron soit de rétablir le travail au temps, et de renvoyer ceux qui n'adoptent pas le rythme de travail qui a été reconnu possible, soit, en maintenant le travail aux pièces, d'abaisser le salaire à l'unité, de façon qu'en moyenne le salaire reçu par l'ouvrier soit le même que quand il travaillait au temps. Ainsi, entre le salaire au temps et aux pièces, il n'y a guère de différence sous ce rapport. Le salaire au temps implique un minimum d'intensité de travail, et le salaire aux pièces un maximum de travail journalier.

Dans ces conditions l'ouvrier n'est pas libre de régler la marche et le rythme de son travail. Cette marche et ce rythme sont fixés hors de lui. Assez récemment, même, ont été introduites des méthodes nouvelles, méthodes d'organisation scientifique du travail, méthode Taylor, qui visent à former des contremaîtres et chronométreurs aptes à indiquer aux ouvriers comment ils doivent procéder dans le détail, quels sont les temps de repos qu'ils doivent mettre entre leurs gestes, etc., en vue d'obtenir le rendement maximum. Ces méthodes nouvelles, qui répondent à certaines nécessités industrielles, tendent en somme à réduire la part d'initiative personnelle dans le travail des ouvriers ${ }^{2}$.

Jusqu'ici, nous avons envisagé les ouvriers dans leur comportement individuel. Mais c'est l'attitude des groupes ouvriers, en face des patrons ou des groupes patronaux, ce sont leurs démarches collectives qui expliquent en réalité comment se déterminent les conditions les plus importantes de la vie du travailleur, le montant du salaire, la quantité de travail qu'ils donnent en échange. Le contrat de travail n'est individuel qu'en apparence. Les ouvriers obéissent ici à des volontés, à des coutumes, à des tendances qui prennent naissance dans leurs groupes. C'est sous forme collective que se présentent les motifs qui règlent leur action.

SIMIAND s'était placé à ce point de vue, et il en venait ainsi à distinguer plusieurs tendances collectives qu'il formulait ainsi, les rangeant suivant l'ordre décroissant de leur intensité ${ }^{3}: \mathbf{1}^{\mathbf{0}}$ tendance à conserver le même gain ; $\mathbf{2}^{\mathbf{0}}$ tendance à maintenir le même effort ou, si l'on veut, à ne pas augmenter l'effort ; $\mathbf{3}^{\mathbf{o}}$ tendance à augmenter le gain $; \mathbf{4}^{\mathbf{0}}$ tendance à diminuer l'effort. Il constatait, en effet, qu'en règle générale, la première l'emporte sur la deuxième, et sur les suivantes, la deuxième sur la troisième, etc., c'est-à-dire, par exemple, que, afin de conserver le même gain, les ouvriers accepteront dans certains cas d'augmenter l'effort, qu'afin de ne pas augmenter l'effort ils renonceront à obtenir un accroissement de leur gain (possible avec une augmentation de l'effort), etc. Ce sont bien là les motifs essentiels de la

Maurice Halbwachs, La Classe ouvrière, etc., op. cit., p. 105.

Voir notre article Matière et société, dans la Revue philosophique, juillet-août 1920, pp. 98 et suivantes.

3 Le Salaire, L'Évolution sociale et la Monnaie, essai de «théorie expérimentale du salaire, 3 volumes, Paris, 1932, vol. 11, pp. 478 et suivantes. - Voir notre article : Une théorie expérimentale du salaire (Revue philosophique, novembre-décembre 1932, p. 353). 
conduite ouvrière en ce domaine, et nous pouvons, maintenant, les analyser l'un après l'autre ${ }^{1}$.

$1^{0}$ Tendance à conserver le même gain. - Que ce soit bien là l'objet essentiel poursuivi par les ouvriers, c'est ce qui résulte du mouvement même des salaires, tel qu'on peut le suivre en France pendant plus d'un siècle, à travers des périodes alternatives et de longue durée, d'expansion, de hausse des prix, d'augmentation des revenus et de resserrement, de baisse des prix, d'arrêt dans l'augmentation et même de fléchissement temporaire des revenus. En période de prospérité, en même temps que les prix s'élèvent, on voit augmenter aussi les revenus qui s'imputent sur les prix, non seulement les bénéfices des patrons, mais aussi les salaires des ouvriers. Cela est assez explicable.

Ce qui le paraît moins, c'est ce qui se passe après une crise, quand les prix baissent. On pourrait s'attendre à ce que les bénéfices et les prix baissent aussi. Mais, pour les patrons aussi, l'essentiel est de maintenir leurs bénéfices au même niveau. C'est pourquoi ils s'efforcent de réduire les salaires, et ils y réussissent en partie au début. Mais les salaires résistent. Alors les patrons sont obligés de recourir à d'autres méthodes ; ils cherchent à obtenir un meilleur rendement du travail ouvrier, à introduire des perfectionnements techniques dans l'entreprise, à exercer un contrôle plus serré sur tous les éléments du prix de revient. En fait, dans ces périodes, le salaire se stabilise à peu près.

C'est ce qui explique qu'à travers toutes les phases il augmente au total, que les augmentations obtenues se conservent, que la situation ouvrière s'améliore dans l'ensemble. Mais cela suppose de la part des ouvriers un effort considérable, à certains moments, en vue de ne pas laisser remettre en question les avantages acquis.

Comment s'explique cette tendance ? Est-ce parce que les ouvriers tiennent à satisfaire les mêmes besoins ? Il semble bien que ce qu'ils défendent alors, c'est moins le salaire réel, c'est-à-dire la puissance d'achat du salaire, comme s'ils pensaient aux denrées alimentaires qu'ils doivent acheter, aux services qu'ils doivent payer, que le salaire nominal, c'est-à-dire le montant monétaire du salaire ${ }^{2}$. En effet, dans une société économique dominée par les représentations monétaires, le prix du travail en argent passe au premier plan. Le salaire atteint mesure aux yeux des ouvriers les progrès qu'ils ont pu réaliser au cours du temps, en faisant reconnaître par l'opinion quelle est la valeur non pas seulement de leur travail, mais de la personne humaine engagée dans la production. C'est pourquoi, au besoin, ils acceptent de donner un effort plus grand, si c'est la condition pour que le taux du salaire soit maintenu. Alors qu'il y a beaucoup de chômage, on pourrait penser à le réduire en enrôlant un plus grand nombre d'ouvriers à un salaire plus bas. Mais les ouvriers au travail s'y opposent. Ils préfèrent accorder, par leurs syndicats, des allocations aux chômeurs de la profession, pour les tenir à l'écart du marché du travail.

Ils ne veulent pas admettre que le travail soit une marchandise comme les autres, soumise à la loi de l'offre et de la demande. Ils pensent que le contrat de travail n'est

Simiand ajoutait que lorsque ces tendances entrent en conflit, de la catégorie patronale à la catégorie ouvrière, c'est la tendance de rang plus élevé dans une des deux catégories qui l'emporte sur la tendance de rang moins élevé dans l'autre.

2 Op. cit., vol. 11, p. 390, et vol. Il, p. 156 (salaire dit réel et salaire nominal). 
pas une opération commerciale comme les autres. Le salarié n'est pas comme un commerçant qui vend un produit, un produit qu'il a acheté, car le salarié n'a pas acheté sa force de travail, et il n'a pas d'autres règles pour en déterminer la valeur que de se référer à ce qu'elle a valu jusqu'à présent, en argent. De là le principe, souvent invoqué : à travail égal, salaire égal.

$2^{\circ}$ Tendance à ne pas augmenter l'effort. - L'effort, la dépense de force dans le travail manuel, est un des termes du rapport établi entre la prestation ouvrière et le salaire. Si, sans modifier le salaire, les patrons augmentent la durée de la journée de travail, c'est encore le prix du travail qui est remis en question, et peut-être abaissé par cette voie indirecte. C'est pourquoi les ouvriers tiennent à ce que la durée normale ne soit pas dépassée.

Certes, il est possible, par diverses méthodes de fixation du salaire, d'obtenir un accroissement du travail en durée et en intensité : par des systèmes de primes, progressives à partir de tel rendement ou de telle durée. Mais les ouvriers ont le sentiment que ces primes sont calculées sans qu'il soit tenu un compte exact du sacrifice que représente pour eux, à partir d'un certain moment, tout travail supplémentaire. C'est pourquoi ils sont en principe hostiles, au moins collectivement, à ce qui est imaginé en vue d'accroître le rendement, soit par allongement de la journée de travail, même avec sursalaire, soit par ces méthodes d'organisation scientifique mentionnées plus haut, qui consistent souvent à déterminer entre eux une véritable concurrence fondée sur l'émulation.

Il faut des circonstances exceptionnelles, pour qu'ils acceptent de donner un plus grand effort, soit la crainte d'une diminution du salaire habituel, soit la nécessité d'exploiter à plein une situation favorable (ce qui a été le cas aux États-Unis dans la période des hauts salaires). En Russie soviétique, ce qu'on appelle le stakhanovisme, c'est-à-dire l'esprit de sport transporté dans le travail industriel, la préoccupation de battre un record, était en rapport avec les conditions toutes particulières qui répondaient au plan quinquennal : enthousiasme et dévouement collectifs, qui s'inspirent d'un idéal à la fois social et politique ${ }^{1}$. Mais on a pu dire qu'au fond c'était, sous une autre forme, l'application du système Taylor, par sélection des plus aptes, obtenue d'ordinaire de l'individu (non du groupe) par l'attrait d'un relèvement de salaire, qui l'est, ici, par d'autres moyens (propagande, publicité, reproduction de l'exploit accompli dans toute la presse, etc ... $)^{2}$.

L'action des Trade-Unions en Angleterre a eu toujours pour objet de bien spécifier la quantité de travail qui devait correspondre à un salaire unitaire donné, et s'est exercée, suivant les métiers, tantôt en faveur du salaire au temps, tantôt du salaire aux pièces, parce qu'ainsi il était le mieux possible de vérifier cette correspondance ${ }^{3}$.

Mais, dans la revendication des trois huit, avant la guerre, et, après la guerre, dans l'effort développé par le B.I.T. en vue d'assurer dans tous les pays la fixation de la

1 Georges FRIEDMANN, Un aspect du « mouvement stakhanoviste » (Annales d'histoire économique et sociale, mars 1936, p. 166, bibliographie, note 3, même page).

2 U.R.S.S. Réflexions, par Ernest MERCIER. Éditions du Centre polytechnicien d'études économiques, janvier 1936, p. 60.

3 Beatrice et Sydney WEBB, Industrial Democracy, 2 vol., Londres, 1897 des méthodes, le taux étalon du salaire, 21 partie). 
journée de travail à huit heures, il y a autre chose encore que le souci d'empêcher que, par des moyens détournés, le salaire ne soit abaissé. Les travailleurs industriels réclament plus de repos et plus de loisirs.

Non qu'ils jugent que le travail à l'usine et sur les chantiers soit, de toute nécessité, dégradant et pénible. Beaucoup d'ouvriers s'intéressent passionnément à leur tâche, à leurs outils, aux difficultés qu'il faut surmonter, à la matière sur laquelle ils opèrent, à ses propriétés, à ses formes. Le reflet des hauts fourneaux danse, comme un mirage nostalgique, devant les yeux de l'ouvrier métallurgiste condamné au chômage. Le travailleur des cuirs et peaux renifle avec satisfaction l'odeur du tan. Il arrive souvent qu'on entende les ouvriers de la mécanique, ou même les maçons et terrassiers, s'entretenir longuement en dehors des heures de travail des machines qu'ils ont montées, des chantiers où ils ont passé, des tunnels qu'ils ont percés, des ponts qu'ils ont édifiés, etc. Pour eux, leur travail n'est pas contre nature, il ne leur paraît pas faire violence à la nature humaine.

Il n'est guère douteux, en effet, que toutes les activités ouvrières soient à base d'instincts ou de dispositions humaines. Acuité sensorielle, sûreté des mouvements, résistance nerveuse, force musculaire, ingéniosité, agilité, c'est là tout un ensemble de facultés actives et sensibles qui nous semblent développer simplement des tendances faisant partie de la nature humaine, et qui étaient en elle avant de se manifester dans un métier, à l'état embryonnaire. Ainsi, l'attachement au métier et à la tâche pourrait être, est certainement dans beaucoup de cas un motif puissant qui aide l'ouvrier à supporter bien des efforts et des privations.

Mais, d'autre part, le travail ouvrier présente aussi bien des aspects rebutants, par sa monotonie souvent, parce qu'il spécialise l'homme dans un genre d'activité mécanique étroitement limitée et tournée vers un seul aspect de la matière.

Il est vrai que, par la spécialisation, nous pénétrons en quelque sorte mieux au fond des choses, et que l'homme d'un métier, d'une fonction, est supérieur à l'amateur superficiel qui prétend embrasser tous les aspects de la nature, exercer toutes les facultés de l'être humain, et ne réussit qu'à s'éparpiller et se disperser. Mais la condition ouvrière se caractérise surtout par le fait que le travail oblige, pendant la plus grande partie de la journée, de rester en contact avec la matière inerte, avec des matières malléables et fragiles, comme les ouvriers du textile, filateurs, tisserands, avec des matières dures et résistantes, comme les mineurs, avec des métaux solides ou en fusion, avec du bois, avec des matières dangereuses, avec des matières malpropres, etc. Il en résulte que le travailleur de l'industrie est isolé du monde, la plupart du temps, à la différence de tous les autres agents de la vie économique, commerçants, employés, contremaîtres, caissiers, etc., que leur travail met en rapport avec des personnes, et n'oblige pas à sortir des groupes humains ${ }^{1}$.

Certes l'ouvrier travaille en équipes, associe ses efforts à ceux de ses camarades, coopère avec eux. Mais cette coopération est toute technique. Ce que les hommes associent, ce sont leurs forces et leurs mouvements physiques. Il s'établit entre eux des rapports machinaux qui n'intéressent ni la pensée, ni le sentiment. Or, l'homme, en général, a besoin du contact et de la société des autres hommes. C'est pourquoi

Maurice Halbwachs, La Classe ouvrière et les niveaux de vie, etc., op. cit., pp. 55 et suivantes et pp. 74 et suivantes. 
l'ouvrier trouve longue la journée de travail, quand elle le retient en face d'un établi, ou aux prises avec la tâche matérielle.

$3^{\circ}$ Tendance à augmenter le gain. - On a souvent cité ce mot de TURGOT : « En tout genre de travail, il doit arriver et il arrive que le salaire de l'ouvrier se borne à ce qui est nécessaire pour lui procurer sa subsistance », et cet autre de Ricardo : «Le prix naturel du travail est celui qui fournit aux ouvriers en général les moyens de subsister et de perpétuer leur espèce sans accroissement ni diminution. » Ainsi les salaires doivent assurer la subsistance de l'ouvrier. Seulement tout dépend de ce qu'on entend ici par subsistance. Supposez une population ouvrière dont les exigences soient extrêmement réduites, par exemple comme dans beaucoup de régions industrielles à la fin du XVIIIe siècle et tout au début du XIXe siècle. On pourra dire que les salaires se règlent sur les besoins ${ }^{1}$. Mais alors comment expliquer que les salaires se soient élevés ? C'est que la subsistance n'est plus réduite à la satisfaction des besoins élémentaires. Les besoins se sont développés et multipliés. Est-ce pour cette raison que les salaires ont augmenté ? On pourrait soutenir aussi bien que ce sont les augmentations successives de salaires réalisées par d'autres causes, qui ont permis l'apparition et la satisfaction de besoins nouveaux.

Quoi qu'il en soit, ce motif est bien plus faible que la tendance à maintenir le gain, parce que celle-ci résulte de l'attachement au niveau social atteint, celui-là, de l'idée d'un niveau social plus élevé, qui n'est en partie qu'une idée. Il est même plus faible que la tendance à ne pas augmenter l'effort. Il intervient, en somme, dans les périodes où les prix haussent, où les ouvriers se rendent compte de ce que le produit de leur travail est vendu de plus en plus cher. Il intervient encore quand les ouvriers s'aperçoivent que les salaires ne sont pas au même niveau, dans la même profession, en des régions différentes. Dans ces deux cas, on peut dire que ce qu'ils reprochent aux patrons, c'est de vouloir profiter seuls, en période de prospérité, d'une différence en augmentation dans le prix du produit de leur travail commun, ou bien de vouloir profiter seuls d'une différence interrégionale de salaires.

De cette constatation il résulte que, pour les ouvriers, il y a un rapport entre le salaire et le prix du produit, qui est un rapport quantitatif ${ }^{2}$. Mais on peut aller peutêtre plus loin. Il y a un rapport quantitatif entre les prix et les salaires. Or, les salaires représentent la valeur du travail. Un rapport quantitatif est un rapport établi entre deux quantités. D'un côté, nous avons les prix, qui sont des quantités. Il faut donc, de l'autre côté, celui du travail et de la valeur du travail, quelque chose qui soit aussi une quantité. Par conséquent les ouvriers se représentent que leur travail est une quantité, c'est-à-dire quelque chose de mesurable et d'homogène.

$\mathrm{Au}$ fond. et en soi, il ne semble pas que le travail soit une quantité. Il ne l'est que quand on envisage l'agent humain sous J'aspect mécanique ou physique. Mais le travail suppose tout autre .chose, c'est une réalité psychologique et humaine. Plaçonsnous dans l'hypothèse d'une économie naturelle, familiale, de l'économie telle qu'elle existait avant le développement des sociétés modernes, avant l'introduction de la monnaie dans les communautés agricoles. On ne peut pas dire que le travail était alors calculé en quantité. Peut-être régnait-il un certain régime communautaire. Peut-être les gens étaient-ils récompensés également, quel que fût leur travail. Peut-être tenait-

Maurice Halbwachs, L'Évolution des besoins dans les classes ouvrières, Paris, 1933, p. 136.

Maurice Halbwachs, La Classe ouvrière, etc., op. cit., p. 110. 
on compte de leur bonne volonté et de leur zèle, c'est-à-dire de qualités psychologiques, morales. Le travail n'a pas changé de nature du fait que nous sommes dans une économie monétaire. Le travail reste toujours un élément qui n'est pas une quantité.

Pourquoi, cependant, le représente-t-on comme une quantité ? La condition d'une économie monétaire, c'est le calcul des produits et des services en argent. Pour que le travail puisse être introduit dans une économie fondée sur l'échange, il faut qu'il revête le vêtement monétaire qui est celui de tous les produits, de toutes les marchandises. C'est une illusion, si l'on veut, une apparence, une représentation, mais ce n'en est pas moins une représentation réelle. A cette condition, on peut établir des tarifs de salaires et réclamer leur augmentation, s'il apparaît que les prix en général, avec lesquels on admet qu'ils sont en rapport, ont haussé. Mais cela en période de hausse et sans que la durée de la journée de travail soit modifiée.

$4^{\text {o }}$ Tendance à diminuer I'effort. - Plus faible que les précédentes, elle existe cependant, elle se manifeste par des résultats. il faut voir quelles raisons expliquent qu'elle soit relativement peu intense, et qu'elle ne soit cependant pas négligeable.

Il n'a sans doute pas été facile, aux débuts de la grande industrie, d'obtenir de ceux qui les premiers travaillèrent comme ouvriers dans les fabriques, une application et un effort continu, sans autre perspective que de recommencer le lendemain ce qu'ils avaient fait la veille. Lorsque des entrepreneurs, des chefs d'exploitation essaient, aujourd'hui, dans les colonies d'Afrique, d'Asie, de dresser les indigènes au travail industriel, ils se heurtent aux habitudes traditionnelles de populations qui ont peu de besoins, et sont habituées à de tout autres conditions que la discipline des ateliers ${ }^{1}$. Des sociologues ont observé que si l'on a introduit l'esclavage dans certaines régions, c'est que les produits naturels de la terre suffisaient aux besoins des habitants; comme ils n'étaient point disposés à travailler librement pour un salaire, il a fallu les y contraindre ${ }^{2}$. C'est ce qui explique aussi les méthodes de travail forcé qui ont été appliquées en plus d'une de ces contrées.

Toujours est-il que, dans nos sociétés occidentales, la loi du travail et de l'activité régulière, ininterrompue, intense parfois et qui oblige l'homme à aller jusqu'au bout de ses forces, s'est de plus en plus imposée. Il en résulte que le temps qu'on n'emploie pas et qu'on attrait pu employer à son travail professionnel semble du temps perdu. On ne sait même plus très bien ce qu'on ferait du temps si on l'utilisait à d'autres fins. Toute réduction de la durée du temps de travail pose un problème très difficile à résoudre: continent utiliser les loisirs ? C'est que la vie est organisée en vue du travail et non du reste. Les hommes ont perdu, n'ont jamais pu développer, peut-être, d'autres goûts et d'autres besoins.

Certes, il arrive que des ouvriers envient les hommes des autres classes qui ne sont pas obligés de se rendre à l'usine dès le matin, lorsque siffle la sirène, pour y rester toute la journée jusqu'au signal du départ. Mais comme ils se trouvent le plus souvent en contact avec d'autres ouvriers, il leur paraît plutôt naturel que leur vie s'écoule dans l'accomplissement des tâches auxquelles ils sont habitués. D'autant plus que toute interruption, toute réduction accidentelle du temps de travail, se traduit pour

J. C. Greaves, Modern Production among backward peoples, Londres, 1935.

Nieboer (Or. H.J.), Slavery as an industrial system, La Haye, 1900. 
eux par une diminution de leur salaire. Dans les périodes où il $\mathrm{y}$ a beaucoup de chômage, total ou partiel, toute leur ambition est de travailler aussi long temps que par le passé, si c'est la condition nécessaire pour que leur salaire reste à peu près au même niveau.

Il en est autrement lorsqu'ils aperçoivent la possibilité, pour eux, de travailler moins en conservant le même salaire, alors. qu'ils n'ont d'ailleurs pas le moyen d'obtenir un salaire plus élevé en travaillant autant. La situation ouvrière, en effet, est définie, elle occupe un rang qui est fixé dans l'échelle sociale, par deux éléments : le montant du salaire, qui est le plus important, et la durée du travail. Quand ils ne peuvent plus la relever par un accroissement de salaire, il reste qu'un homme qui dispose de plus de loisirs se sent rehaussé à ses propres yeux comme à ceux des autres. C'es, une question de considération sociale, de « standing ». D'abord, et indirectement, ils obtiennent ainsi que leur travail soit plus apprécié, puisqu'il coûte plus à l'unité. Mais, surtout, ainsi se trouve augmenté le temps durant lequel ils participent à la vie sociale telle qu'elle est organisée hors de l'usine, hors des locaux de travail.

Ces possibilités résultent surtout du machinisme, du progrès de la technique. Les ouvriers ne s'en sont pas rendu compte au début. Ils n'ont été sensibles qu'au fait que l'introduction des machines permettait de réduire la main-d'œuvre dans les fabriques qui existaient alors, et n'ont pas prévu l'accroissement considérable de la production qui a entraîné l'emploi d'une main-d'œuvre plus nombreuse. Mais, surtout, la conséquence du machinisme et du progrès économique en général, c'est d'obtenir un rendement bien plus grand par ouvrier, ou le même rendement avec un temps de travail très diminué. Il était donc possible, sans réduire la production, et même en l'augmentant pour une même dépense en capital et en main-d'œuvre, de réduire la durée de la journée de travail. D'où non seulement la journée de huit heures, mais la semaine anglaise, la semaine de quarante heures, les congés payés. Mais comme ces réformes n'ont pu être obtenues que par l'action collective des ouvriers, cela nous conduit à parler de leurs organisations.

Le degré de solidarité ou d'esprit social dont sont capables les groupes ouvriers occidentaux se manifeste par l'étendue et la forme des associations qu'ils ont créées. Et d'abord, des syndicats.

La Révolution française, en supprimant tous les corps de l'ancien régime, par la loi Le Chapelier (1791), interdisait à l'avenir aux ouvriers aussi bien qu'aux patrons de s'associer, soit de façon durable, soit même temporairement, et, par suite, de se concerter en vue de faire grève. Le droit de coalition, c'est-à-dire le droit de suspendre le travail par une décision prise en commun, n'a été reconnu en France qu'en 1864. Les grèves n'en éclataient pas moins, mais sous forme de mouvements confus, désordonnés, parfois violents. C'est cependant sous cette forme que les ouvriers ont d'abord manifesté le besoin de s'entendre et d'agir en commun. C'est que, si leur condition s'est beaucoup améliorée depuis un siècle, il n'y a rien eu là d'automatique. Ils ont dû lutter, et, par exemple, chaque augmentation des salaires s'est accompagnée de mouvements ouvriers plus ou moins nombreux, plus ou moins prolongés. Si la grève représente ainsi comme l'exercice d'une fonction nécessaire dans la société, à la longue la fonction a créé l'organe. Dès 1884, en France on a reconnu aux ouvriers, 
en même temps qu'aux patrons, le droit de foriller des organisations professionnelles. doi Waldeck-Rousseau).

On peut définir le syndicat (Trade-Union en Grande-Bretagne, Gewerkschaft en Allemagne), « une association permanente d'ouvriers, ayant pour objet le maintien ou l'amélioration de la condition ouvrière ${ }^{1}$ ». Il est certain qu'à diverses époques, dans les milieux ouvriers, des aspirations plus étendues sont apparues dans le mouvement syndical, tendant non seulement à améliorer la condition des ouvriers dans le cadre présent, mais, beaucoup plus, à modifier l'organisation économique totale, à en changer les bases, et à assurer aux travailleurs une partie sinon la totalité de la direction dans les entreprises. Un théoricien célèbre du syndicalisme révolutionnaire, avant la guerre, disait alors que l'essentiel pour les ouvriers syndiqués n'est pas d'obtenir quelques succès limités dans la lutte pour le relèvement des salaires, mais, par la lutte elle-même, surtout lorsque l'ensemble de la classe ouvrière est appelée à y prendre part, d'exalter sa conscience de classe par la création de mythes, mythe de la révolution, mythe de la grève générale, etc. ${ }^{2}$.

Sans ignorer ou négliger de telles aspirations et les démarches qui ont pu s'en inspirer, constatons que, dans le développement d'ensemble du mouvement ouvrier, nombre des fédérations et syndicats les plus importants, et qui représentent les ouvriers types de la grande industrie, n'y ont aucunement participé. D'autre part, là même où on pourrait croire que cette tendance existe, pour en juger il faut voir non pas ce que disent les syndiqués, mais ce qu'ils font. Sans doute, dans certains cas plus ou moins récents, pendant quelques mois en Italie, plus longtemps en Union Soviétique. il y a eu des tentatives de direction complète de la production par les syndicats ouvriers : expériences exceptionnelles, un peu troubles, et qui n'ont pas beaucoup duré. Par contre des organisations ouvrières aussi développées que les syndicats allemands ont été pleines de réserves, en présence de la loi sur les conseils d'entreprise qui semblaient cependant leur garantir une participation à la conduite d'ensemble de l'entreprise, de même les Trade-Unions britanniques, vis-à-vis du mouvement des guildes qui devaient assurer l'exploitation dans son ensemble par les syndicats ouvriers ${ }^{3}$.

En France, il y a bien eu des associations ouvrières ou coopératives de production qui visaient à supprimer le salariat, en appelant les ouvriers à diriger eux-mêmes l'entreprise et à s'en partager les bénéfices. Mais d'abord, ces associations n'englobent qu'une petite fraction de la masse ouvrière. Au cours d'une enquête faite sur elles par l'Office du travail, en 1897, il apparaissait qu'elles comprenaient moins de $1 \%: 0,25$ $\%$ du nombre total des ouvriers, et aujourd'hui moins encore. Or en Grande-Bretagne, actuellement, il y a 5 millions et demi de syndiqués (8 millions et demi en 1920, 4 millions au début de la Grande Guerre), soit, avant-guerre, $20 \%$ de la population masculine, et, par rapport à la population industrielle masculine, une personne sur deux : $50 \%$. En France, on évaluait les effectifs syndiqués, avant la guerre ${ }^{4}$, à $20 \%$ de la population industrielle masculine, soit un million ; leur nombre s'est élevé à 2 millions et demi en 1920, c'est-à-dire près de $50 \%$, et à présent cette proportion paraît être très dépassée. En Allemagne, on a été jusqu'à 10 millions en 1920, depuis il y a eu une baisse notable, qui ramenait ce nombre, en 1920, à 4 ou 5 millions, soit

Beatrice et Sydney Webb, Industrial Democracy, Op. cit.

Georges Sorel, Réflexions sur la violence [Paris, 1908].

Simiand, Cours d'économie politique, 2e année, 1928-1929, p. 491.

[Il s'agit, bien entendu, de la guerre de 1914.] 
environ $35 \%$ par rapport à la population industrielle masculine. Aux États-Unis, environ $20 \%$. Donc, quant au nombre, il n'y a pas de comparaison à établir, même de loin, entre le personnel des syndicats et celui des coopératives de production ${ }^{1}$.

D'autre part, bien que beaucoup de ces coopératives aient été fondées à la suite de grèves, par des ouvriers syndiqués, l'expérience semble indiquer que l'association de production ne réussit qu'à condition d'être administrativement et financièrement indépendante du syndicat auquel elle se rattache. Enfin, c'est un fait encore que le mouvement syndical proprement dit s'est surtout développé depuis qu'il s'est distingué du mouvement pour la coopérative de production.

Ainsi, c'est l'amélioration de l'état où se trouve l'ouvrier, et non la suppression de la condition ouvrière elle-même, que se propose le syndicat, qui exprime bien sans doute ici les tendances des milieux de travailleurs. Signe que ceux-ci, dans leur ensemble, reconnaissent que leur condition est bien définie et qu'elle est durable.

Pour qu'un syndicat se forme et fonctionne, il faut qu'il y ait une séparation nette et durable entre patrons et ouvriers. D'autre part le machinisme et les concentrations industrielles peuvent aider au développement des syndicats, mais ils n'en sont les conditions ni nécessaires, ni suffisantes. Aux États-Unis, c'est-à-dire dans un pays économiquement très avancé, avec une industrie très concentrée et beaucoup de machines, le syndicalisme est souvent moins développé que dans les industries correspondantes en France. Que faut-il donc de plus et d'autre ${ }^{2}$ ?

Au début, soit en Grande-Bretagne, soit en France, il ne se rencontre pas d'association de caractère permanent et d'activité soutenue dans les milieux ouvriers de conditions misérables. Dans ces régions les plus basses de la classe ouvrière, ou bien on observe une passivité qui dépasse parfois les limites du vraisemblable : dans l'industrie à domicile, dans l'industrie textile durant la première moitié du XIXe siècle, où l'on ne trouve pas d'associations véritables ; ou bien ces travailleurs réagissent à l'exploitation et à la misère par des révoltes brusques accompagnées de violences irréfléchies, bris de machines, destructions, etc., après quoi la passivité et l'oppression reprennent. D'une manière générale, et même à un niveau un peu plus. élevé, dans les professions non qualifiées, l'organisation syndicale ne s'est introduite qu'assez récemment. Elle n'est pas toujours solide. Elle résulte d'ailleurs de l'action et de l'influence exercée par des ouvriers d'autres professions, et notamment des professions qualifiées correspondantes.

Au contraire, les syndicats se sont constitués d'abord et le plus efficacement dans des catégories ouvrières d'un niveau relativement élevé, par exemple chez les typographes, les verriers, les ouvriers qualifiés du fer, etc. C'est ainsi qu'on a pu reprocher au syndicalisme anglais de l'époque victorienne d'être un aristocratisme ouvrier, de chercher (et d'obtenir) pour ses membres des conditions privilégiées, plutôt que des droits généraux s'étendant à l'ensemble de la classe ouvrière. De fait, ce sont surtout des ouvriers qualifiés qui se sont groupés en Trade-Unions pour exclure de leur profession les non affiliés et maintenir ainsi les hauts salaires. Telle est d'ailleurs la raison pour laquelle ils sont restés attachés à l'institution désuète qu'est l'apprentissage.

SIMIAND, ibid., p. 500.

SIMIAND, ibid., pp. 496 et suivantes. 
Plus nettement encore, aux États-Unis, les premiers syndicats, constitués par des ouvriers très qualifiés et de revenus assez élevés, s'inspiraient d'un esprit corporatif, et interdisaient l'accès de leur métier à la main-d'œuvre inférieure ${ }^{1}$. Cette tendance a subsisté longtemps, même au sein de la Fédération américaine du travail, à laquelle Samuel Gompertz a imprimé une autre direction. Elle se manifeste encore par l'hostilité vis-à-vis de certaines catégories jugées indésirables, par exemple les immigrants chinois et japonais, et ceux qui débarquent venant de régions européennes où l'on est habitué à un bas niveau de vie. C'est pour une raison du même genre que, par exemple, la Fédération typographique, en France même, n'a pendant longtemps pas admis les femmes dans ses syndicats ${ }^{2}$. D'où un certain exclusivisme qui répond au niveau plus élevé qu'occupent ces groupes.

Cela, d'ailleurs, ne suffit pas. Il faut encore qu'ils aient le sentiment de ce que comporte et de ce qu'entraîne ce niveau de vie, ou, comme on dit, ce « standing » sentiment d'une communauté non seulement de condition, mais aussi de besoins, de traditions et de tendances, soit dans le cadre local, soit dans le cadre de la profession ou de l'industrie. C'est alors, dit SIMIAND, une réalité sociologique qu'exprime la formule souvent mal comprise de « l'ouvrier conscient et organisé », c'est-à-dire conscient de remplir, ainsi que ceux qui l'entourent, toutes les conditions nécessaires à l'organisation ${ }^{3}$. Inversement, quand ces groupements veulent s'élargir à l'extrême, si bien qu'il ne peut se constituer et s'entretenir en eux un meilleur esprit collectif, ils perdent de leur force, alors même qu'ils conservent leur existence, mais une existence très réduite.

C'est un fait bien remarquable que le syndicat, l'organisation ouvrière par excellence, ait été ainsi construit à partir des éléments les plus élevés de cette classe. Nous avons dit que les conditions de leur travail rendent les ouvriers impropres aux formes évoluées de la vie sociale. Mais il y a des parties de la classe ouvrière où ces conditions s'atténuent, soit que le travail soit moins absorbant moins mécanique et moins monotone, qu'il puisse même être l'occasion d'un exercice de la pensée, soit que les revenus plus hauts permettent des dépenses propres à mieux réparer l'usure de l'homme dans sa nature non seulement physique, mais sociale, soit enfin et peut-être surtout que les conditions plus complexes dans lesquelles s'établit le salaire et la tâche les incitent à un effort de réflexion qui appelle ]a communauté, car on ne réfléchit bien dans ces circonstances qu'en réunissant et confrontant les avis. Dans de tels groupes on sentirait d'abord le besoin de s'organiser, et on en serait le mieux capable.

Mais si l'élite de la masse des travailleurs s'organise ainsi, pour se distinguer de tous ceux qui ne sont pas l'élite, que devient la conscience de classe, et peut-on parler d'une classe ouvrière vraiment une ? Certes, on oppose couramment les ouvriers qualifiés et les manœuvres, et, alors qu'il s'agit de cas extrêmes ou éloignés, l'opposition parait nette, en effet. Seulement, il y a en réalité une quantité de stades de transition, où le manœuvre, peu à peu, acquiert des habiletés qui rendent son travail plus rapide, plus facile et plus sûr, où l'ouvrier qualifié doit dépenser autant de force musculaire que d'ingéniosité. N'y a-t-il pas des groupes considérables d'ouvriers tels

Robert Marjolin, L'Évolution du syndicalisme aux États-Unis de Washington à Roosevelt, Paris, 1936, p. 100 (domination des ouvriers qualifiés).

Maurice Halbwachs, La Classe ouvrière, etc., p. 95, note 1.

SIMIAND, ibid., p. 499. 
que les mineurs, dont on ne peut pas dire précisément s'ils sont qualifiés, et leur activité ne se rapproche-t-elle pas plutôt de celle des terrassiers ou des manœuvres ${ }^{1}$ ?

Mais ce qui tranche la question, c'est qu'en fait l'organisation syndicale s'est étendue à l'ensemble des ouvriers, et que, de plus en plus, elle s'est efforcée d'être une image et comme le décalque exact et complet de la classe ouvrière dans son ensemble. Telles se présentent en France la Confédération générale du Travail et les Confédérations, Fédérations, Unions dans les autres pays. L'organisation se réalise dans les cadres mêmes de la production. Dans le syndicat, chaque ouvrier prend conscience du groupe particulier auquel il se rattache : c'est l'association élémentaire, qui est près de ses membres et à l'intérieur de laquelle ils se sentent le plus solidaires. Dans la fédération de métier ou d'industrie, ces divers groupes producteurs se rapprochent en une association plus vaste, et le progrès de ce genre d'organisation exprime le sentiment croissant d'une unité de la classe ouvrière dans la société.

L'essentiel est, cependant, au delà et au-dessus de la structure, l'esprit dont s'inspire le mouvement syndical, qui dépasse le cadre du métier aussi bien que de l'industriel, et qui prend son point d'appui dans des représentations non point techniques, niais sociales, dans une conception humaine et bien définie de la condition des ouvriers en général. Tout se passe comme si chaque progrès réalisé par une catégorie, située plus haut ou plus bas dans l'échelle des salaires, devait profiter à l'ensemble. Non qu'on se propose de fixer un niveau identique pour tous. Mais plutôt il s'agit d'assurer à tous des garanties identiques, la possibilité pour chaque catégorie d'échapper à l'arbitraire et à l'exploitation dans les limites des conditions économiques, diverses d'ailleurs d'un métier ou d'une industrie à J'autre.

Le salaire est fixé, en principe, par une série de contrats individuels, librement consentis. Il n'en était pas de même autrefois, sous le régime des corporations. Les maîtres, dans leurs rapports avec les compagnons, devaient se conformer à des coutumes, à des règles communes qui reposaient sur la tradition. Ni le montant du salaire, ni les conditions du travail, ne dépendaient du patron considéré individuellement non plus que du compagnon pris à part des autres. Or, l'ouvrier isolé, dans la période pré-syndicale, ne trouvait autour de lui à cet égard aucun appui, aucun conseil.

Au patron, il ne pouvait opposer que son point de vue individuel, c'est-à-dire une information très réduite et des besoins qu'on pourrait toujours discuter, puisqu'ils étaient, en apparence au moins, non pas ceux d'un groupe, mais d'une personne. C'est pourquoi l'action syndicale, dès que les ouvriers ont pu s'associer, s'est opposée non pas à la liberté des contrats comme telle, niais à leur individualité. Les syndicats ont essayé de substituer une détermination collective des conditions du travail à une fixation individuelle, mais en restant d'ailleurs dans le cadre de la liberté des relations économiques ${ }^{2}$.

Cette attitude des organisations syndicales vise ainsi à rétablir l'égalité réelle, en tant que contractants, entre patrons et ouvriers. Mais, d'autre part, elle est pleinement conforme à la réalité économique, et, de cette réalité, de leur situation réelle dans la société industrielle, les ouvriers prennent mieux conscience lorsqu'ils adoptent une telle tactique.

Maurice Halbwachs, La Classe ouvrières etc., p. 94

Simiand, ibid., p. 506. 
En effet, on ne comprendrait qu'il y eût un contrat individuel de salaire que dans deux cas, dont ni l'un ni l'autre n'est réalisé. Ou bien il s'agirait de la vente d'une marchandise, ici le travail ou la force de travail, par libre débat entre le patron qui est l'acheteur, et l'ouvrier qui serait le vendeur. Mais l'ouvrier ne vend pas son travail, comme un commerçant, puisqu'il ne l'a pas acheté auparavant et n'en saurait assigner le prix pour lui. L'idée se précise de plus en plus, dans les milieux ouvriers comme dans les autres, que le travail n'est pas une marchandise dont le prix serait simplement fixé par l'offre et la demande.

Ou bien il s'agirait d'un contrat portant sur un service ou des services qu'une personne s'engage à rendre à une autre, services relatifs à la personne qui les rend comme à celle qui les reçoit, c'est-à-dire portant en quelque sorte la marque de cette personne même. Débat individuel alors, et de personne à personne. Mais nous avons vu que le travail ouvrier n'a point ce caractère, qu'on ne tient pas compte de ce qui est proprement qualités de la personne : plus grand effort pour le même résultat, meilleure volonté, dévouement à l'entreprise, zèle, honnêteté, etc.

L'opération ouvrière se présente, dans notre système économique, non comme un effort individuel, mais comme une partie d'un ensemble collectif homogène, dont les unités sont substituables les unes aux autres, et qu'on n'envisage que sous l'aspect de la quantité.

C'est en s'inspirant de ce point de vue que les associations syndicales ouvrières s'efforcent d'établir des conditions collectives dans la mesure et pour autant que le travail ouvrier tel qu'il se présente réalise une communauté de conditions entre les travailleurs individuels. Ainsi s'explique, d'ailleurs, que l'action syndicale, contrairement peut-être à ce qu'on aurait pu attendre, bien loin de vouloir en réserver ]p bénéfice aux membres du syndicat, en vient de bonne heure à réclamer des stipulations qui, aussitôt et d'emblée, s'appliquent à l'ensemble des ouvriers de la catégorie, qu'ils soient ou non syndiqués.

La règle commune est la protection de l'individu ou de groupes isolés. D'où le principe - a travail égal, salaire égal, dans l'espace et dans le temps (au moins comme moyen de défense). D'où l'établissement de tarifs, tantôt aux pièces, tantôt au temps, suivant les industries, suivant que l'un ou l'autre mode permet le mieux de constater que c'est bien le même travail qui est rémunéré de la même façon. D'où aussi, l'action en vue de limiter la durée du travail par journée, semaine, afin d'empêcher qu'en allongeant le temps de travail les patrons ne réussissent à abaisser le salaire par unité de travail précise. D'où, encore, la lutte contre le chômage, comme partie essentielle de l'activité syndicale : si le syndicat attribue des allocations aux chômeurs, c'est que ceux-ci menacent dans leur emploi et leurs conditions de travail les ouvriers occupés. D'où, enfin, l'effort syndical en vue d'obtenir la fixation du salaire et des conditions du travail par des contrats collectifs ${ }^{1}$.

D'une manière générale, l'objet de toutes ces règles, c'est de faire profiter les ouvriers moins bien situés, ou qui risquent pour quelque raison que ce soit d'être moins bien traités que les autres, des avantages obtenus par le plus grand nombre, c'est de consolider ainsi les progrès réalisés. Les syndicats s'attachent à des formules telles que le minimum d'existence, le salaire nécessaire, le salaire vital. Ils s'inspirent

$1 \quad$ Simiand, ibid., pp. 509 et suivantes, 520. 
de l'idée que la situation ouvrière dépend surtout de la valeur du travail humain, et du travailleur en général, telle qu'elle est reconnue par l'opinion et consacrée par le niveau qu'il sait avoir atteint. Ils s'appuient sur l'opinion sociale, mais surtout sur l'opinion que la classe ouvrière a d'elle-même, de la place qu'elle a conquise dans la société. En ce sens ils sont bien, dans ces groupes, l'organe par excellence de la conscience de classe.

Nous ne ferons que signaler ici l'existence des mutualités, groupements d'intéressés constitués par efforts privés, comportant une libre adhésion, et qui se proposent de donner à leurs membres une aide mutuelle dans le cas de certains événements qui entraînent une diminution de ressources, tels que tout spécialement la maladie et aussi l'invalidité et la vieillesse, ou encore le décès, du moins dans certaines de ses conséquences. Elles ont eu un développement assez grand au cours du XIXe siècle, mais surtout dans les périodes d'expansion, Au reste, en France, les ouvriers paraissent y avoir une participation assez faible. D'une manière générale, l'épargne joue un rôle secondaire dans la classe ouvrière. C'est par la législation des assurances sociales que cette classe a obtenu d'être garantie contre les accidents, la maladie, le chômage, l'invalidité et la vieillesse.

Les coopératives de consommation représentent au contraire une réalisation sociale considérable, et, après les syndicats, sont la manifestation la plus notable d'un esprit de solidarité et d'organisation, tel qu'il se développe dans certaines parties de la classe ouvrière. « Non pas plante de serre, dit SIMIAND, mais plante de plein vent, qui n'a pas été favorisée par les pouvoirs publics, surtout dans les commencements, qui n'a pas toujours eu même l'appui de l'opinion, notamment au début, qui a rencontré et rencontre encore de fortes concurrences, et qui cependant a atteint le succès, un succès économique, qui est arrivée à un développement très étendu et encore croissant ${ }^{1}$. »

Quelques données numériques nous fixeront sur cette évolution depuis 1880. Dans le Royaume-Uni, 500.000 coopérateurs en 1880, 1 million dix ans après, 2 millions vers 1905 , près de 3 millions en 1914 , près de 5 millions après la guerre. En Allemagne, une centaine de mille vers 1880 , près de deux millions dans l'avantguerre, davantage après. En France, 200.000 vers 1895, près d'un million dans l'avantguerre, plus de 2 millions après. En Grande-Bretagne cela doit représenter (en multipliant par 3 ou 4 pour représenter les familles) plus de $30 \%$ de la population, en Allemagne $15 \%$, en France un peu moins. Accroissement supérieur quant aux chiffres d'affaires. Par tète de coopérateur, 1.000 francs, 1.500, 2.000 et plus, dans la période récente. Ce n'est là qu'une moyenne. Pour l'épicerie, l'alimentation, la boulangerie, la charcuterie, et même la bonneterie, la lingerie, les chaussures, la quincaillerie, les articles de ménage, il y a déjà un nombre considérable de familles dont la plus grande part des dépenses correspondantes, sinon presque la totalité, dans certaines villes, dans certains pays, est assurée par la fourniture de la coopérative ${ }^{2}$.

Cours d'économie politique, 1930-1931, p. 639.

[Chiffres récents d'après : B.I.T., Le mouvement coopératif et les problèmes actuels, Montréal, 1945. Nombre des membres des coopératives de consommation : Grande-Bretagne, 8.703.314 (plus 69.911 pour l'Irlande) en 1941 ; Allemagne, 2.010 .911 (en 1937) ; France, 1.800 .000 (en 1937). Nombre des membres individuels de l'Alliance coopérative internationale GrandeBretagne, 7,852.000 ; France, 3.636.000 (en 1938) Allemagne, 2.901 .000 (1932). Ouvrage cité, tome 1 , p. 117 et 1671 A. C. 
Si maintenant nous recherchons les motifs pour lesquels les ouvriers (car c'est parmi eux que se recrutent surtout les coopérateurs) se sont attachés à cette forme d'association, il faut distinguer, entre les promoteurs, ceux qui sont le plus étroitement mêlés au mouvement et la masse des autres. Pour ce qui est des premiers, reportons nous à la déclaration initiale des pionniers de Rochdale (29 pauvres tisserands qui eurent en 1843 l'idée de se réunir pour fonder une société de ce genre), telle qu'elle est reproduite dans le « text-book » de l'enseignement coopératif anglais.

Ils donnent pour objet, à leur société, de former des arrangements pour le bénéfice pécuniaire et pour l'amélioration de la condition sociale et -familiale de ses membres, en levant un montant suffisant de capital en parts d'une livre sterling pour mettre en oeuvre les plans suivants : l'établissement d'un magasin de vente de denrées, de vêtements ; ensuite la construction ou l'achat de maisons ; puis la création de manufactures pour donner du travail à leurs membres; puis des achats de terres pour les mettre en culture et constituer des colonies intérieures ; puis mettre en train un hôtel de tempérance. Aspiration à une reconstruction sociale qui porte la marque de l'époque, associée cependant (malgré le caractère ambitieux d'un tel programme) à un esprit pratique, positif, visant des réalisations immédiates. On peut bien dire que ce mélange de foi et de calcul, d'esprit social hardi et de prudence commerciale se retrouve chez beaucoup de ceux qui sont à la tête des coopératives.

Quant à la masse des membres, s'ils obéissent eux aussi obscurément à de telles tendances, ce qui les attire et les retient dans ces associations, ce sont les avantages à la fois matériels et moraux qu'ils en retirent. Au moyen d'une organisation qui est bien à eux, -qui est indépendante aussi bien des pouvoirs publics que des entreprises de commerce privées du type ordinaire, ils sont assurés d'abord d'obtenir les produits à un prix qui n'est pas, sans doute, le prix de revient, mais qui s'en rapproche. Mais, surtout, ils participent aux bénéfices au prorata de leurs achats. C'est là une règle fondamentale, parce qu'elle intéresse les individus au résultat de l'activité sociale, et parce que la répartition, la ristourne, est souvent assez considérable pour leur donner le sentiment d'être possesseurs d'un capital. Ce capital, ils le laissent, au moins en partie, dans la société, et c'est là une forme d'épargne bien adaptée aux habitudes et dispositions des ouvriers parce qu'elle se réalise automatiquement, sans qu'ils aient à consentir un effort ou un sacrifice particulier. Enfin, ce n'est pas l'homme seul, c'est la femme, bonne ménagère, c'est la famille tout entière qui y contribue et y est intéressée.

Ajoutez que ce capital (auquel s'ajoutent les souscriptions par versements échelonnés et les dépôts des membres) se distingue de tous les autres en ce qu'il n'a point un dividende, mais seulement un intérêt, et que, quel que soit son apport en capital, quelle que soit l'importance de ses dépôts, un membre n'a pas plus de voix dans la société qu'un autre : «Un homme, une voix », tel est le principe qui fait que la prédominance du capital ne peut pas s'exercer ${ }^{1}$.

Voir G. FAUQUET, Le Secteur coopératif, essai sur la place de l'homme dans les institutions coopératives et sur la place de celles-ci dans l'économie, Bruxelles, s.d. (1935) : « Par le caractère personnel ou familial des unités qu'elle groupe, l'association coopérative n'est pas un groupement impersonnel de capitaux, mais, au sens fort du terme, une association de personnes. Dans l'institution coopérative, c'est la personne humaine tout entière qui entre en jeu, l'homme social, lié à ses semblables par toute une série de liens autres que les purs rapports économiques. » Ainsi s'expliquent la règle d'égalité des sociétaires entre eux, la dévolution désintéressée, la pratique habituelle de consacrer une partie des excédents annuels à des oeuvres d'éducation et de solidarité. 
Il n'y a pas de privilèges, de luttes d'influences, de concurrences dans ces sociétés démocratiques. Indépendamment des raisons de programme, de propagande et de foi coopérative, les sociétaires ont intérêt à susciter et favoriser de nouvelles entrées dans la société. Plus augmente le chiffre d'affaires dans l'ensemble des sociétés, plus il est possible d'obtenir de nouveaux avantages, par la création, notamment, de magasins de gros, de services de production (minoteries, fabriques de chaussures, etc.), services financiers, services bancaires, plus aussi les coopérateurs ont le sentiment de soustraire aux prélèvements du capital privé l'ensemble des consommateurs, et de leur assurer la pleine disposition de leur pouvoir d'achat qui, avec leur force de travail, représente tout ce qu'ils possèdent et qu'ils tendent autant que possible à se réserver.

Syndicats et coopératives, telles sont donc les deux formes d'associations les plus développées dans les milieux ouvriers, et par lesquelles se manifeste le mieux jusqu'à présent leur esprit proprement social.

Traitant des sociétés coopératives, nous nous sommes déjà engagés dans cette zone de la vie sociale extérieure à l'usine où les ouvriers sont appelés à participer aux biens et avantages qui sont à la disposition de tous. Étudions donc dans quelle mesure ils satisfont alors leurs besoins, et suivant quel ordre ceux-ci peuvent être classés.

Les besoins, nous disent les psychologues, sont des dispositions psychiques de nature qualitative. Cependant ils peuvent être mesurés, en particulier dans leur forme collective. Il suffit de voir quelles sont les dépenses, quelle est leur importance, pour reconnaître comment les besoins sont satisfaits, et quels sont ceux d'entre eux qui, dans la classe ouvrière, passent au premier plan.

Il s'est constitué au milieu du XIXe siècle une branche d'enquêtes qui a pour objet d'étudier les revenus et les dépenses de différentes classes. C'est ce qu'on appelle les budgets de familles. Quant à l'étude de la consommation, la plus difficile, c'est surtout en Allemagne qu'elle a donné les résultats les plus remarquables, notamment dans une enquête faite en 1928-1929, sous la direction de l'Office de statistique du Reich, qui a obtenu de 2.000 familles qu'elles tiennent jour par jour pendant toute une année le compte exact de leurs recettes et surtout de leurs dépenses ${ }^{1}$. Elle portait sur 1.000 familles d'ouvriers, 500 d'employés et 500 de petits fonctionnaires, si bien que les comparaisons sont possibles de l'une à l'autre et surtout à égalité de revenu.

D'autres enquêtes ont été faites, en particulier aux États-Unis, par des méthodes différentes ${ }^{2}$. Au lieu de faire tenir leurs budgets par les chefs de famille, on leur posait des questions : méthode extensive, par opposition à la méthode intensive des Allemands, parce que, pour compenser la rapidité de l'enquête, on l'étendait à un nombre très grand de ménages : 10.000, 20.000 ménages, etc. Si bien que l'on peut admettre que les erreurs se compensaient, et que les grosses différences ressortaient suffisamment. De ces enquêtes, quel résultat pouvons-nous tirer?

Die Lebenshaltung von 2.000 Arbeiter-, Angestellten-, und Beamtenhaushaltungen. Erhebungen von Wirtschaftsrechnungen im deutschen Reich vont Jahre 1927-1928. Einzelschriften zur Statistik des deutschen Reichs, nos 22-1, 22-11, 2 vol. (Teil 1, Gesamtergebnisse, Teil Il, Einzelhaushaltungen). Tout le chapitre II de notre livre L'Évolution des besoins dans les classes ouvrières, op. cit., porte sur cette enquête.

2 Voir, dans notre livre, L'Évolution des besoins, etc., p. 74 et bibliographie. 
Il s'agit de classer les dépenses suivant les besoins. En général on les a distinguées en quatre grandes catégories : trois correspondent aux besoins les plus caractéristiques, de nourriture (y compris les boissons), de vêtement, de logement ; sous une rubrique simple : autres dépenses, on groupait tout le reste.

Il est à remarquer que, dans les premiers budgets que nous connaissons, au début de la grande industrie, la nourriture, le logement et les vêtements absorbent à peu près tout le revenu, et il ne reste rien pour les autres dépenses. Mais depuis, les salaires des ouvriers se sont élevés, leur niveau de vie est supérieur à ce qu'il était autrefois, et cette catégorie des autres dépenses a notablement augmenté.

$\mathbf{1}^{\mathbf{0}}$ La nourriture. - Les aliments, c'est le premier besoin : «primum vivere ». On s'est beaucoup occupé de la question de l'alimentation des ouvriers. C'est le besoin élémentaire. S'il n'est pas satisfait, les ouvriers ne peuvent ni subsister, ni assurer la perpétuation de leur classe. L'année dernière encore ${ }^{1}$, la S.D.N. et le B.I.T. avaient mis ce problème à l'ordre du jour de leurs débats. Ceci à différents points de vue. Celui de l'intérêt des grands pays agricoles, qui désirent vendre leurs produits et espèrent que, si on relevait la consommation des ouvriers, ils écouleraient plus facilement leur blé, leur bétail. Mais les points de vue des hygiénistes et des médecins a passé au premier plan. Des recherches très scientifiques ont été faites sur la meilleure façon de se nourrir, sur le minimum nécessaire pour que l'alimentation soit suffisante, pour qu'elle assure la reproduction des tissus, la réparation des forces, pour qu'elle permette à des ouvriers chargés d'un travail moyen ou fatigant de supporter la perte d'énergie qui en résulte ${ }^{2}$. Seulement les médecins ont trop insisté sur la quantité d'éléments chimiques qu'il faut fournir à l'organisme, sur les vitamines, les protéines, sur la quantité d'énergie, calculée en calories, qui doit être contenue dans une ration alimentaire. Ce qui revient à traiter l'homme comme une espèce de moteur auquel on fournit une certaine quantité de combustible ou de force.

Il faut bien observer que les ouvriers, comme tous les autres hommes, mangent sans doute pour se nourrir, pour réparer leurs forces, mais aussi parce qu'ils ont plaisir à manger. Il y a par conséquent de tout autres préoccupations qui interviennent, et dont on doit tenir compte. Il faut que l'alimentation soit attrayante et suffisamment variée. D'autre part les ouvriers doivent assurer aussi la nourriture des leurs, femmes et enfants.

Sur le plan social, la question de l'alimentation se poserait en d'autres termes. En effet, il intervient là des éléments de traditions, des habitudes, des préoccupations qui ont un caractère social, puisqu'il y a des aliments qu'on ne mange pas parce qu'ils sont considérés comme inférieurs, et d'autres qu'on recherche non seulement parce qu'ils apportent une satisfaction à l'organisme, mais parce qu'ils font honneur. On est rehaussé à ses propres yeux comme à ceux des autres parce qu'on a une table bien garnie.

Voir le rapport du B.I.T. : L'Alimentation des travailleurs et la Politique sociale, Bureau international du Travail, Genève, 1936.

2 Et. BURNET et W. R. Aykrood, L'Alimentation et l'hygiène publique (publié dans le Bulletin trimestriel de l'Organisation d'hygiène), Société des Nations, Genève, 1935. - Voir aussi le Rapport sur les bases physiologiques de l'alimentation, présenté à la réunion, de Londres, 25-29 novembre 1935, par la Commission technique du Comité d'hygiène, S.D.N., Genève, 1935. 
Néanmoins, et si nous nous plaçons au niveau de la classe ouvrière, il faut bien dire qu'il n'y a pas de besoins qui aient davantage un caractère physique, organique, et où le côté social proprement dit passe plus à l'arrière-plan. Or, à ce point de vue, il est à noter que, dans les milieux ouvriers, la dépense en aliments joue le principal rôle. A égalité de revenu, la proportion de la dépense pour la nourriture est plus élevée chez les ouvriers que chez les employés ou les petits fonctionnaires.

Est-ce une nécessité ? Nous voulons dire quand nous remarquons que les ouvriers dépensent trop pour leur alimentation, ne sommes-nous pas un peu pharisiens ? S'ils dépensent tant, c'est parce qu'il faut qu'ils vivent. Eh bien, en fait, et sans leur reprocher de consacrer tant d'argent à leur alimentation, il faut bien dire qu'il leur serait possible, s'ils avaient d'autres besoins à satisfaire, d'épargner sur la nourriture. Ce qui le prouve, c'est que, dans des conditions particulières, les familles ouvrières sont capables d'opérer une compression très forte sur cette dépense. Que l'on compare ce qu'elle est dans des familles qui n'ont pas d'enfant et dans celles qui en ont trois ou quatre, on constate que, par personne unité (c'est-à-dire par unité en tenant compte de l'âge), elle a pu être réduite dans une proportion qui va jusqu'à $42 \%{ }^{1}$. C'est donc que ce besoin lui-même présente une certaine élasticité. Retenons en tout cas que c'est celui qui passe au premier plan dans les ménages ouvriers, et auquel ils sont disposés à consacrer le plus possible de leur revenu.

$2^{\circ}$ Le vêtement. - A égalité de revenu, la proportion de la dépense pour le vêtement est, a très peu près, la même dans le groupe des employés et des ouvriers.

Mais comparons, d'abord, la part de cette dépense qui est faite pour les différents membres de la famille. Supposons qu'il y ait deux enfants par ménage, et qu'ils puissent être considérés comme une grande personne. On constate que la part la plus forte dans les ménages d'employés est celle du père ; la mère vient ensuite, puis les enfants, tandis que, dans un ménage d'ouvrier, on petit faire trois parts, non pas égales, mais beaucoup moins inégales. Si l'on considère que dans la dépense pour le vêtement, il y a la représentation, en dehors de ce qui est nécessité, et que c'est le père, la mère ensuite, qui absorbent ce qui y est consacré, il apparaîtra que cette part est beaucoup plus réduite dans les ménages ouvriers, qui se contentent ici du nécessaire.

Faisons une autre comparaison, en distinguant, dans l'habillement au sens large, les vêtements proprement dits, les plus apparents, puis le linge, enfin les chaussures. On constate alors que les ouvriers, comparés aux employés, dépensent moins qu'eux (en proportion) pour les vêtements, plus pour le linge, nettement plus en chaussures. C'est un trait bien défini de leur condition. Là encore, si l'on considère que les vêtements sont la partie la plus extérieure et en tout cas la plus visible de l'habillement, que c'est sur quoi l'attention se fixe d'abord et le plus aisément, on peut conclure que dans les ménages ouvriers on dépense moins que chez les employés pour la montre, pour l'apparence extérieure, plus pour ce qui est indispensable ${ }^{2}$.

La dépense pour le vêtement (au sens large) répond d'ailleurs à plusieurs besoins : se couvrir, afin de se défendre contre les intempéries ; attirer les regards par des couleurs voyantes, par un costume seyant, pittoresque : ceci est déjà un commence-

Voir dans notre livre cité, L'Évolution des besoins, etc., le tableau, p. 47, et le diagramme I, p. 48.

Op. cit., pp. 39 et suivantes. 
ment de préoccupation sociale, mais élémentaire, telle qu'on la trouve dans le règne animal lui-même de Paon qui fait la roue, le plumage des oiseaux, etc.), et surtout dans les tribus de sauvages. Ce besoin prend un caractère nettement social du jour où l'on se préoccupe d'obtenir des autres non pas simplement cette attention un peu superficielle, mais leur considération, de leur prouver, par la façon dont on s'habille, qu'on appartient à une classe élevée, qu'on est du monde, ou qu'on paraît en être.

Ces faits laissent supposer que la préoccupation sociale est moins développée dans les ménages d'ouvriers que chez les employés. Mais venons à une dépense qui nous paraît avoir un caractère plus social encore.

$3^{\circ}$ La dépense pour le logement. - Elle est nettement plus faible en proportion, toujours à égalité de revenu, pour les ouvriers que pour les employés. C'est un des traits les plus notables de la façon dont ils emploient leur salaire. On peut le vérifier pour toutes les catégories de revenus sans exception distinguées dans l'enquête allemande. De toutes les enquêtes qui ont été faites dans ces vingt dernières années dans des pays bien différents de l'Allemagne, comme aux États-Unis, où les ouvriers ont un niveau de vie très supérieur, il résulte qu'il en est de même. La différence n'est pas très forte, mais elle subsiste.

Considérons maintenant non seulement le loyer, mais le logement envisagé dans ses divers éléments, c'est-à-dire non point le prix, mais l'objet lui-même. On envisagera, par exemple, la surface occupée par le logement, ou bien le cubage d'air, ou bien encore le nombre de personnes par pièce, et la présence ou l'absence de tout ce qui fait le confort des logements modernes, même modestes : l'eau, le gaz, l'électricité, la salle de bain, et encore toutes ces annexes du logement qui répondent à des besoins d'hygiène. On constate sur tous ces points, à tous ces égards, une différence très nette en faveur des employés et des fonctionnaires.

On peut le dire d'une façon très certaine : ce qui caractérise le plus nettement le train de vie des ménages ouvriers, c'est qu'ils sont moins bien logés que les autres hommes, c'est qu'ils sont moins disposés qu'eux à élever leur dépense pour le logement ${ }^{1}$.

Nous l'avons vu, il leur serait possible de réduire la dépense pour l'alimentation et d'augmenter d'autant ce qu'ils consacrent au loyer. Mais surtout, s'ils éprouvaient vraiment d'une façon intense le besoin d'un logement meilleur, s'ils avaient un désir assez fort d'obtenir de quoi payer un loyer plus élevé, ils l'obtiendraient. C'est ce qu'on peut constater à propos d'une dépense comme celle pour le vin en France. SIMIAND disait que cela avait été pour la classe ouvrière un moyen de relèvement de son salaire, parce que, étant habitués à une consommation donnée du vin, ils résistaient à toute réduction qui les en priverait. Donc, si les logements ouvriers ne sont pas meilleurs, c'est que le besoin d'une habitation confortable est insuffisamment développé dans la classe ouvrière.

On peut en donner plusieurs raisons. D'abord il y a, par exemple pour les aliments, des marchés, des étalages où les hommes de toutes les classes peuvent choisir ce qu'ils veulent acheter. Bien que quelques-uns soient fréquentés surtout par les riches ou par les pauvres, on peut dire que la majorité des magasins s'adressent à

1 Op. cit., p. 28. 
toutes les classes. Tous peuvent acheter les mêmes sortes d'aliments, et tous sont amenés ainsi à s'imiter de classe à classe. Quant aux vêtements, on les porte dans la rue, et les gens des différentes classes se confrontent, s'observent, si bien qu'une certaine uniformité à cet égard tend à s'établir. Il y a unité de marchés pour les aliments et, dans certaines limites, pour le vêtement. Mais il n'en est pas de même pour les appartements. Il y a un marché des appartements riches ou qui correspondent à une catégorie sociale élevée, et un autre marché des logements pour la classe ouvrière. D'ailleurs les ouvriers vont rarement dans des appartements d'employés ou de bourgeois. Ils ont plus de difficulté à établir une comparaison entre ces appartements et leurs logements, et à prendre idée d'un degré de confort qui ne leur manque pas parce qu'ils n'y sont pas habitués.

D'autre part il n'y a pas une différence considérable, au point de vue apparence extérieure et luxe relatif, entre les ateliers où travaillent les ouvriers et les logements dont ils se contentent. Ils passent indifféremment des uns aux autres, et ils ne sont pas choqués de retrouver chez eux le genre de meubles assez frustes et une apparence générale de dénuement et de simplicité qui rappelle l'atelier et les locaux de travail. Au contraire, les employés et les fonctionnaires séjournent dans des bureaux qui sont mieux tenus en général, mieux meublés, plus confortables, et ils auraient peine à rentrer ensuite dans des logements qui représentent à cet égard une régression.

Mais le motif le plus important est celui-ci. A quoi correspond le besoin de logement ? Certes, dans le lieu où l'on habite, on reçoit ses amis, ses relations. Bien des événements de la vie sociale, mondaine aussi, s'y déroulent et y trouvent leur cadre tout naturel. Mais le logement, c'est surtout l'abri de la famille. L'expression anglaise : «le home indique bien cela, de même le nom français « le foyer », quand on dit que les hommes, les soldats libérés, sont renvoyés dans « leurs foyers ». C'est le cadre dans lequel se développe la vie domestique, et dans la mesure où l'on désire assurer à sa famille des conditions de vie confortables et favorables à son intimité comme à son bien-être, on tient à avoir un logement spacieux, agréable, et même, dans certaines limites, un logement luxueux. Alors, si les ouvriers éprouvent ce besoin à un degré nettement moindre que les membres des autres classes, n'est-ce pas que chez eux l'attachement à ce que représente la vie de famille est un peu moins développé ? Par là, l'ouvrier ne se distingue-t-il pas profondément à la foie, du paysan et du bourgeois ?

A vrai dire, il n'y a peut-être pas de milieux plus opposés que la famille et l'usine. Nous avons dit que, dans les locaux industriels, l'ouvrier perd en partie sa personnalité, qu'il y est considéré comme une chose. Au contraire, le groupe des siens lui présente une petite société dans laquelle les relations d'homme à homme sont vivantes et colorées, non mécaniques et privées de chaleur comme à l'atelier. L'individu y est jugé en lui-même, d'après sa nature et ses qualités. Il ne peut y être remplacé, mais y trouve sa place bien définie dans la pensée des autres, pour le présent comme pour le passé. Groupe qui existe en vue de soi, et non d'un but extérieur, la famille n'a d'autre fin qu'elle-même, et non, comme l'entreprise, une production quelconque. A cet égard les deux ensembles constitués par les familles et par les groupes industriels diffèrent du tout au tout. Quoi d'étonnant qu'un homme ou des hommes qui sont obligés chaque jour de demeurer longtemps dans l'un perdent le 
sentiment de ce que devrait être l'autre, pour eux, s'ils y passaient une plus grande partie de leur vie ${ }^{1}$.

Dans ces conditions, le milieu le plus naturel à l'ouvrier, celui où il s'attarde le plus volontiers, ce n'est pas la maison, c'est la rue. Les rues, dans nos grandes villes, représentent comme une zone intermédiaire entre l'atelier et la maison. C'est comme une région de l'univers social dans laquelle la vie est plus éparpillée et toute chargée encore d'influences mécaniques. Le long de ces voies se succèdent des maisons d'habitations, des locaux de commerce, des gares de chemin de fer, des murs couverts d'affiches, des bâtiments officiels, et aussi des dépôts, des usines. Il y a des portes d'ateliers qui s'ouvrent sur la rue. D'autre part la rigidité, l'étroitesse ou la largeur des rues, ruelles, boulevards, les formes géométriques des places et dès pâtés de maisons, l'ensemble des directions que représente un carrefour, la série de montées et de descentes, l'encombrement, les courants de circulation, imposent de plus en plus à l'individu qui s'y trouve entraîné l'idée qu'il n'est qu'un morceau de matière en mouvement. PASCAL disait : «Quand quelqu'un se met à la fenêtre pour regarder les passants, si je passe par là, puis-je dire qu'il s'est mis là pour me voir ? Non, car il ne pense pas à moi en particulier. » Il ne me voit pas. Il voit passer un être qu'il assimile à une chose.

La rue est un milieu beaucoup plus mécanisé et désocialisé que les groupes familiaux. Par rapport à eux, elle est vraiment « le dehors », mais, par rapport aux locaux de travail, elle constitue, autour des groupes d'ouvriers, comme un milieu de transition entre l'atelier et la famille. Au lieu, dès qu'ils sortent de l'usine, de parcourir en hâte les voies qui les ramènent chez eux, beaucoup s'y attardent et se laissent impressionner au passage par toutes les influences, absorber par toutes les images de la rue. Ils trouvent là un degré de vie sociale qui les satisfait déjà, s'il ne leur suffit entièrement. Faut-il dire que la cause en est dans l'organisation imparfaite de la vie de famille ? Mais la cause est peut-être l'effet. Car, dans les quartiers ouvriers, la rue pénètre dans la maison. On se penche trop volontiers des intérieurs sur l'escalier et sur la cour, et sur toute la rumeur et l'agitation des voies populeuses. En réalité, il n'y a pas à distinguer ici cause et effet. L'importance de la vie de la rue pour l'ouvrier et la faible consistance de la famille s'expliquent l'une et l'autre par l'action rayonnante, qui s'exerce à partir de l'usine, des conditions de travail faites à l'ouvrier sur ses conditions de vie.

$4^{\circ}$ Les autres dépenses ou dépenses diverses. - Elles représentent à peu près le quart, en moyenne, de la dépense totale pour les ouvriers, près du tiers pour les employés. Au reste, tandis que, pour le vêtement et le foyer, la proportion de la dépense reste à peu près la même dans les ménages ouvriers quel que soit le revenu, c'est-à-dire s'écarte peu de la moyenne pour tous les revenus, ici la proportion augmente de $29 \%$, de la catégorie la plus basse à la plus haute (tandis que la part de la nourriture diminue de $18 \%$ ). Elle tend à s'étendre dès que cela lui est possible. Ajoutons que, toujours d'après l'enquête allemande, si on entre dans le détail de ces autres dépenses, voici ce qu'on observe. $\mathrm{Si}$, à la dépense pour maladie, on ajoute ce que les ouvriers paient de ce chef aux assurances, elle est nettement plus élevée pour eux que pour les employés. Le tabac absorbe aussi une part plus forte de leur revenu. Les employés dépensent un peu plus pour le coiffeur, l'école, les voyages et les -

Sur ces « deux aspects de la vie ouvrière », voir notre livre cité, La Classe ouvrière et les niveaux de vie, pp. 129 et 130. 
sports, les distractions. Pour les autres assurances que la maladie, les moyens de transport, les journaux et livres, le blanchissage, il n'y a -entre les deux groupes que des différences minimes.

Telles sont les conclusions où nous amène l'étude des besoins tels qu'ils se sont développés dans la classe ouvrière. Nous constatons qu'ils se classent chez eux d'une autre manière que dans les autres milieux, et que ceux qui supposent une capacité plus grande, des exigences plus grandes en ce qui concerne la vie familiale, même sociale, telle qu'elle est organisée dans nos sociétés, et un goût profond de cette vie et de ses formes, ceux-là sont le moins développés chez eux.

Est-ce un état définitif ? Notre étude porte sur ce qui est et sur ce qui a été. Il se peut que s'accomplisse une évolution, et qu'on puisse s'en rendre compte en examinant les conditions dans des pays tels que les États-Unis d'Amérique, moins traditionnels, et qui se prêtent mieux aux expériences.

Aussi, la déformation qui, comme nous l'avons signalé, résulte pour l'ouvrier en général de ce que son travail l'oblige à rester, isolé, en contact avec la matière inerte, sera d'autant plus forte et plus irrémédiable que la durée de la journée de travail se prolongera. Si cette durée peut être réduite, si, cependant, une partie de la semaine les ouvriers peuvent être soustraits à ces conditions un peu anormales, ils auront plus de possibilités de reconstituer en eux la nature d'un être social. Primum vivere, sans doute. Mais il peut rester assez de temps et de ressources pour qu'on participe aux formes les plus élevées de la vie collective ${ }^{1}$.

Voyons ce que nous apprend à cet égard une enquête qui fut faite en Amérique, dans la ville de Detroit, sur 100 familles ouvrières, au terme de la période des hauts salaires. Enquête précieuse, puisqu'elle enregistre en quelque sorte l'avance extrême de la classe ouvrière, les salaires les plus forts et le niveau de vie le plus élevé qui aient été atteints par des travailleurs manuels depuis que l'industrie existe.

Fixons notre attention sur le chapitre des dépenses diverses : on peut dire qu'elles représentent près de $30 \%$ de la dépense totale (au lieu de $20 \%$ en 1902), et qu'elles avaient augmenté (depuis 1902), en valeur absolue, de $45 \%$.

D'autre part, sur les 100 familles étudiées, 35 avaient une radio, 13 avaient un piano, 45 un phonographe, 76 une machine à coudre, 21 un vacuum cleaner, 51 une machine à laver, 98 un fer électrique, 6 un appareil pour griller les toasts, 94 avaient des tapis dans leur « living-room » et 90 dans leur salle à manger. Enfin 47 familles possédaient une automobile. D'une manière générale, dans cette période, tandis qu'on réduisait beaucoup la dépense pour la nourriture $(32,3 \%$ de la dépense totale au lieu de 43,1\% 1902), et que les loyers ne montaient que lentement, des besoins nouveaux, qui n'existaient pas jusqu'ici, ou qui ne jouaient qu'un rôle très modeste, brusquement prenaient leur essor. En même temps les ouvriers se sont assurés de plus en plus, et ont recouru davantage aux soins du médecin.

Standard of Living of Emplogees of Ford Motor Co. in Detroit, Monthly Labor Review, juin 1930. Traduction française presque intégrale dans : Contribution à l'étude de la comparaison internationale du coût de la vie, B.I.T., Genève, 1932. - Voir aussi, dans notre livre cité, L'Évolution des besoins, etc., chap. III, pp. 97 et suivantes. 
Or, dans la mesure où l'ouvrier satisfait ses besoins nouveaux, auxquels répondent des ustensiles ménagers ou des objets de distraction d'un caractère mécanique, ou des avantages et services procurés par des organisations privées et publiques, ellesmêmes rationalisées et mécanisées, dans cette mesure aussi il participe à une civilisation qui le dépasse et qui d'ailleurs le domine de toutes parts. Au contraire, d'autres besoins plus familiers, plus anciens, n'ont pas ou n'ont plus la même importance. Autrefois on a pu éprouver le sentiment que, lorsqu'on achetait des aliments et qu'on s'installait dans une maison, on participait aussi à la civilisation qui avait institué, suivant certaines règles, l'alimentation et l'habitation. Cette civilisation ancienne existe encore sans doute. Mais elle a perdu son prestige, parce qu'on sait bien qu'elle a rempli sa tâche, et qu'on est habitué depuis longtemps aux satisfactions qu'on lui doit.

Ainsi, cette emprise qu'exercent les nouvelles inventions, les nouveaux produits, les formes modernes du confort, mais aussi les distractions collectives, les agences de voyages, les organisations de santé, d'hygiène, de prévoyance, d'assurance, de crédit, s'expliquerait non par le caractère mécanique de ces objets et de ces institutions, mais parce qu'on y reconnaît la marque de la société contemporaine et ses tendances maîtresses, et, plus généralement, qu'on aperçoit derrière eux une civilisation que l'on considère, à tort ou à raison, comme plus large, plus riche et plus progressive que les autres.

A de telles influences la classe ouvrière a obéi peut-être plus docilement encore, parce qu'elle était moins habituée et moins liée que les autres aux modes de vie anciens, aux types de civilisation qu'on peut croire dépassés. Elle n'a pu en éprouver les bienfaits, parce qu'elle ne disposait pas autrefois des moyens pécuniaires qui lui échoient aujourd'hui. Quoi d'étonnant si un rapport s'établit, dans sa pensée, entre l'accroissement de ses revenus et les formes nouvelles de la vie sociale, et qu'elle soit dès lors moins sensible aux insuffisances de cette société ?

Ajoutons, quant à la classe ouvrière américaine, qu'elle se caractérise, d'autre part, par une vie familiale assez simplifiée (vie au dehors, repas pris dans des restaurants populaires, clubs, etc., réduction poussée aussi loin que possible des occupations ménagères, nombre croissant des divorces), par des besoins religieux assez limités (religion de plus en plus pratique et terre à terre), par l'insuffisance des besoins de culture, par un faible développement, enfin, de la conscience de classe.

Quant aux ouvriers en général, concluons que les motifs dominants auxquels ils paraissent obéir sont la tendance au maintien et au relèvement de leurs conditions de vie par des règles collectives, la formation d'organisations professionnelles et d'associations propres à développer et satisfaire leur esprit social, enfin, dans la mesure où ils le peuvent, c'est-à-dire quand leurs salaires sont assez élevés pour laisser, après la satisfaction des besoins essentiels, un surplus disponible, la participation croissante aux formes de la civilisation moderne, telle qu'elle est en voie de se construire. 


\title{
$\mathbf{V}$ \\ LES MILIEUX URBAINS \\ ET LA CIVILISATION INDUSTRIELLE
}

\author{
TROISİ̀ME PARTIE
}

\section{Les classes moyennes}

\section{$\underline{\text { Retour à la table des matières }}$}

La notion de classes moyennes est assez flottante et mal définie. Entendrons-nous par là « une catégorie durable de personnes, considérées avec leurs familles, qui ont des revenus et souvent aussi un patrimoine de niveau moyen, intermédiaire entre celui de la classe sociale la plus élevée et celui des travailleurs et salariés » ? Ajouteronsnous qu' « elle se réfère plutôt à des catégories de population urbaine et notamment de petites villes », et comprend le haut artisanat, les petits et moyens commerçants et industriels, une partie des professions libérales, et les fonctionnaires moyens ${ }^{1}$ ? Ce sont là des caractéristiques plutôt négatives. Autrement dit, on les définit en les distinguant des ouvriers et des bourgeois, comme s'ils occupaient l'entre-deux.

Ou bien on s'en tient à une énumération de professions qu'on juxtapose, sans qu'on aperçoive une raison de les réunir ainsi en un groupe, en une classe qui posséderait quelque unité.

Cela est d'autant plus sensible que les catégories professionnelles ainsi rassemblées sous le nom de classes moyennes présentent des traits bien différents, et que leur conduite s'inspire de motifs qui, nous allons le voir, sont propres à chacune d'elles, et s'expliquent par leurs conditions particulières.

$1^{\circ}$ Les artisans et les petits commerçants. - Dans les recensements, on calcule séparément le nombre des personnes qui travaillent seules ou à leur compte. Sans doute ce ne sont pas tous des artisans au sens ancien du terme, car on n'en distingue point les travailleurs à domicile, qui sont le plus souvent de véritables ouvriers, bien qu'ils œuvrent chez eux et non dans les ateliers. On comprend aussi dans cette catégorie les ouvriers irréguliers qui travaillent tantôt chez un patron, tantôt chez un autre. Au reste les artisans qui travaillent seuls exécutent des opérations de même

$1 \quad$ Simiand, Cours d'économie politique, 21 année, 1928-1929, p. 470. 
nature que les ouvriers, et ne gagnent guère plus en général. Cependant, comme ils entrent en rapports directs avec les clients, et qu'ils s'occupent de la partie commerciale de leur métier, on les a rangés d'ordinaire dans la classe moyenne et rattachés aux petits commerçants.

Or la proportion des travailleurs isolés est assez forte, en France, dans certaines branches : d'un peu plus de la moitié (sur l'ensemble des ouvriers au sens large) dans le travail des étoffes et les industries du vêtement ; forte encore (autour de30\%) dans les cuirs et peaux, les pailles, plumes et crins ; encore assez forte (autour de $20 \%$ ) dans les industries du bois, dans la taille et le polissage des pierres. Mais elle est plus faible (à peine de $10 \%$ ) dans le terrassement et la construction, les industries textiles, les industries des fers et aciers, des métaux divers, des métaux fins, de la bijouterie ; plus basse encore dans l'alimentation, la librairie ; extrêmement faible et presque inexistante dans les industries chimiques, la métallurgie, les mines et minières. Elle ne dépasse pas en somme $15 \%$ de l'ensemble des travailleurs manuels ${ }^{1}$.

D'un recensement à l'autre, cette proportion se maintient à peu près. MARX, et d'autres économistes après lui, se sont trop hâtés, lorsqu'ils annonçaient la disparition des travailleurs indépendants. Ils subsistent (à la différence, sans doute, des petits commerçants dont le nombre ne cesse pas de décroître), soit par la force de certaines traditions, soit que, dans certaines industries (comme le vêtement sur commande ou pour divers travaux de réparation), il y ait des raisons pour que le client reste en rapport direct avec le producteur travaillant de ses mains.

Quelle est la raison qui explique la subsistance d'une telle catégorie sociale ? Sans doute l'attachement à une situation indépendante, motif comparable à celui que nous avons observé chez les paysans propriétaires. En effet, ils ne dépendent pas d'un directeur ou d'un entrepreneur, mais, travaillent à leur compte, et s'acquittent en même temps des fonctions d'exécution et de direction technique et commerciale, dissociées dans les grandes entreprises où les patrons dirigent et les ouvriers (et employés) exécutent. Sans doute ils travaillent matériellement, le travail matériel est du moins une part de leur activité, et ils ressemblent par là aux ouvriers d'établissement. Ils s'en distinguent cependant en ce qu'ils possèdent leur matériel de travail, louent leur atelier ou leur boutique, achètent leurs matières premières, s'occupent de l'écoulement et de la vente, entrent directement en rapport avec les clients; ils ont même à s'occuper du côté financier de l'entreprise et à gérer un petit capital: Il n'est pas facile, souvent, de fixer la limite qui les sépare des entrepreneurs proprement dits. On tiendra compte de l'importance de leur capital, de la grandeur de leur revenu, et surtout de la part d'activité manuelle qu'ils doivent déployer derrière le comptoir et dans l'atelier.

Certes, cette indépendance est souvent toute apparente, puisqu'ils sont soumis aux conditions du marché du travail, comme du marché des produits. Qu'ils y tiennent cependant, c'est ce qui résulte du fait observé par SIMIAND, qu'en période de prospérité une partie assez importante des salariés de la grande industrie quittent l'usine pour s'établir à leur compte et qu'inversement, en période de resserrement, la proportion des indépendants diminue après un certain temps ${ }^{2}$.

SIMIAND, Cours d'économie politique, 1930-1931, p. 500,

SIMIAND, Le Salaire, L'Évolution sociale et la Monnaie, op. cit. 
Considérons, en ce qui les concerne, la dernière crise et ses conséquences sociales telles qu'elles ont été étudiées tout récemment par le B.I.T. ${ }^{1}$. Il faut distinguer ici entre les petits commerçants et les artisans. On constate alors que les effectifs du commerce, en beaucoup de pays, ont augmenté pendant la dépression. Cela peut étonner d'autant plus que le volume des échanges a considérablement diminué. Faut-il en déduire que la part du commerce dans l'ensemble des revenus a augmenté ? Non. Mais les entreprises commerciales ont augmenté leur activité et leur personnel, simplement pour conserver leur situation, pour se défendre. D'autre part, des chômeurs ou de petits industriels empêchés de continuer de travailler par la crise ont essayé de faire du commerce. En France, dit le B.I.T., plus encore que dans les autres pays, on a vu naître pendant la dépression d'innombrables entreprises commerciales éphémères qui se disputaient le marché en s'entre-détruisant dans une concurrence acharnée. Augmentation des effectifs commerciaux en somme malsaine, et qui ne signifie nullement qu'en temps de crise on peut trouver un refuge dans le commerce.

Quant aux artisans, aux petits entrepreneurs travaillant eux-mêmes, ils ont résisté mieux que les ouvriers d'établissements ${ }^{2}$. D'une statistique allemande, en 1933 (par comparaison avec 1925), où l'on distingue les petites entreprises (de 1 à 5 personnes) et les moyennes ou grandes, il résulte que, sauf dans les mines et l'industrie textile, dans le vêtement encore, les petites entreprises n'ont guère réduit leurs effectifs. Il y a augmentation sensible dans les petites entreprises pour les branches suivantes : pierre et terre, métallurgie (augmentation de $50 \%$ ), articles en métaux, machines, électrotechnique, papeterie et imprimerie, alimentation (augmentation de $12 \%$ ), bâtiment (de $18 \%$ ), eau, gaz, électricité (de $38 \%$ ). C'est qu'ici l'activité économique ne fait qu'un avec la vie même de ces personnes, et qu'il ne leur est pas très facile de changer de mode d'existence. En tout cas, malgré la crise, des milliers de boulangers, de bouchers, de couturiers, de chemisiers, de bonnetiers, d'installateurs, de menuisiers, de serruriers, restent à leur place.

Certes, il faut tenir compte aussi de l'attachement au métier, qui est un trait notable de cette catégorie sociale. Dans beaucoup de cas, si l'artisan a réussi à se maintenir, s'il a pu résister à la concurrence de la grande industrie, c'est en raison de ses qualités professionnelles, parce qu'il est bon travailleur et que, pour certains produits, ce à quoi on tient avant tout, c'est à ce que le travail soit bien fait. Or, le bon ouvrier, c'est celui qui aime son métier parce qu'il y excelle. Beaucoup d'artisans s'en rendent bien compte et croiraient déchoir s'ils entraient dans une équipe où l'on travaille en série, où le travail ne porte plus la marque personnelle du travailleur.

Il n'en est pas moins vrai qu'en dehors des transformations techniques, certaines professions, certains métiers s'éliminent d'eux-mêmes, parce qu'ils ont perdu leur raison d'être, sans que pour cela, d'ailleurs, le nombre des artisans diminue. lis s'occupent dans un autre métier qui s'est substitué au précédent, quelquefois sur place. Ainsi, avec la révolution des moyens de transport, le maréchal ferrant, à l'entrée du village, s'est transformé en mécanicien-garagiste ; niais, de la sorte, le nombre de ces petites entreprises n'a pas diminué. Il y a d'autre part des métiers qui disparaissent sans qu'ils soient remplacés des porteurs d'eau, les écrivains publics : récemment, à Stamboul, les portefaix), et d'autres qui se créent et s'étendent en l'espace de quelques -innées (chauffeurs d'autos, dactylographes, personnel des cinémas, etc.). Mais, dans

1 WOYTINSKY, Les Conséquences sociales de la crise, Bureau international du Travail, Genève, 1936.

2 Op. cit., p. 246. 
son ensemble, si la catégorie des artisans répare ses pertes, réussit à trouver sa place dans les intervalles ou les lacunes de la grande industrie, c'est bien parce que beaucoup de travailleurs, en dépit des risques et même d'une insuffisance de revenu, tiennent avant tout à une situation indépendante.

Individualisme subsistant, qui a comme contrepartie une insuffisance marquée d'esprit social, d'aptitude à l'organisation collective. Il y a bien des syndicats d'artisans, de petits marchands, de marchands forains, niais peu nombreux, sans grande vitalité ${ }^{1}$. C'est que manque ici la relation, l'opposition caractéristique du patron à l'ouvrier, puisque l'artisan est à la fois l'un et l'autre. Les artisans ont essayé cependant de se grouper, sur le plan non pas syndical, mais coopératif ${ }^{2}$. Ils ont formé des associations coopératives, par exemple pour l'achat des matières premières, pour la vente, pour le crédit, pour l'outillage, c'est-à-dire pour toutes les opérations qui sont complémentaires du métier. Encore ces tentatives n'ont-elles pas été très loin, et n'ontelles pas donné de résultats très remarquables. Pour que l'esprit d'association puisse pousser vraiment ses racines dans ces milieux, il faudrait que l'action coopérative portât non pas sur l'accessoire et le complément, sur le crédit par exemple, mais sur lé travail de production lui-même, sur ce qu'il y a de plus intérieur et central dans la profession, sur les conditions du travail, sa durée, son intensité, et encore sur la fixation des prix. Mais on aperçoit tout de suite que du jour où les artisans s'orienteraient dans ce sens, ils en viendraient à former de grandes entreprises par fusion ou, comme disent les Anglais, par amalgamation de petites exploitations, - et ils retourneraient à la grande industrie, alors que leur raison d'être c'est de se trouver et de rester en dehors d'elle.

$2^{\circ}$ Les employés. - Considérons maintenant le vaste groupe des employés, dont le plus grand nombre de beaucoup font partie des classes moyennes. Dans l'ensemble, les recensements les confondent avec les ouvriers. On a cependant essayé d'indiquer séparément, quelquefois, pour toutes les branches réunies, agriculture, industrie, commerce, la proportion des employés et ouvriers occupés dans un établissement d'un certain nombre de personnes à toute la population active, soit $40 \%$, et la proportion des ouvriers seulement, soit 33 à $35 \%$, cela ferait 15 à 17 employés pour 100 ouvriers, mais pour la Production agricole, industrielle et le commerce réunis, et seulement pour les grandes entreprises ${ }^{3}$.

Entre eux et les artisans ou petits commerçants, existe une différence essentielle : ils ne travaillent pas à leur, compte ; mais bien des distinctions seraient à faire dans cette catégorie elle-même. Au bas de l'échelle on trouvera bien des employés qui plongent à demi dans la classe ouvrière, parce que leur travail comporte une part importante d'opération matérielle : le garçon bouclier, ceux qui, dans les grands magasins, font toute la journée des paquets, et même les caissiers qui manient et comptent des pièces de monnaie, ceux encore qui portent les commandes en ville. D'une manière générale la plupart des employés se rapprochent des ouvriers et s'opposent aux artisans et aux petits commerçants, en ce qu'ils n'ont pas à faire preuve

1 Maxime Leroy, La Coutume ouvrière, Syndicats, Bourses du travail, Fédérations professionnelles, Coopératives, Doctrines et Institutions, Paris, 1913, 2 volumes. (Syndicats d'artisans, petits marchands, chiffonniers, étameurs, ramoneurs, commissionnaires, etc., I, p. 99). -Voir aussi Hector LAMBRECHTS, Les Syndicats bourgeois en Belgique (Revue d'économie politique, 1908, p. 575) (Syndicats de petits commerçants, de classes moyennes).

2 SIMIAND, Cours d'économie politique, 1930-1931, p. 685 (Coopération artisanale).

3 SIMIAND, Cours d'économie politique, 21 année, 1928-1929, p. 448. 
d'initiative et n'ont pas une grosse part de responsabilité, en tout cas, quant à la marche générale de l'entreprise.

Mais, d'autre part, se situent au haut de l'échelle des employés supérieurs, auxquels on laisse au contraire une certaine initiative, qui suppléent parfois le patron dans la direction et le contrôle technique, et même dans certaines opérations financières et commerciales. Ils se rapprochent à cet égard des entrepreneurs, se confondent même avec eux, et se distinguent des artisans par l'importance des intérêts dont ils ont la charge et par le niveau plus élevé de leurs revenus : par exemple un ingénieur, un chef de comptoir, et même un certain nombre de vendeurs, le personnel supérieur des banques, etc.

En tout cas, un des motifs majeurs de leur conduite, et par là ils se distinguent nettement des ouvriers, paraît être l'attachement à l'entreprise dans laquelle ils sont occupés. On en voit bien les raisons. Les ouvriers, nous l'avons vu, sont payés suivant la quantité de travail qu'ils donnent, c'est-à-dire suivant quelque chose qui est en effet une quantité, une chose homogène. On ne tient pas compte, dans la mesure de leur travail, de leurs qualités personnelles, de leur personnalité même, mais uniquement d'une dépense de force considérée comme mécanique et inerte. Il n'en est plus de même des employés. C'est que ceux-ci sont beaucoup plus étroitement intégrés dans l'entreprise et fondus avec elle.

Les traitements des employés sont fixés d'après des règles générales comme les salaires. Mais la règle la plus importante ici, c'est qu'il est tenu compte d'ordinaire de l'âge de ces agents, du temps qu'ils ont passé dans l'exercice de leur activité, plus spécialement dans la maison. Il en est d'ailleurs de même des fonctionnaires. C'est parce que le rôle que jouent les employés, comme les fonctionnaires, n'est pas le même que celui que remplissent les ouvriers. Les employés sont intéressés moralement à la marche de l'entreprise et on a besoin qu'ils s'y intéressent, on a besoin par conséquent de les y attacher. Puisqu'ils transmettent les ordres des directeurs, puisqu'ils entrent en relation avec les clients, puisque c'est de l'exactitude de leurs comptes, de leur régularité, de leur assiduité et du zèle dont ils font preuve que dépend la bonne marche de l'entreprise, il faut qu'ils considèrent celle-ci un peu comme leur chose. La meilleure façon de les y attacher, c'est justement d'obtenir qu'ils y restent d'abord longtemps, - tout le temps de leur vie active, si possible, qu'ils considèrent qu'ils n'en partiront qu'à la fin, de façon à être pénétrés de son esprit et de ses traditions. C'est aussi par des gratifications, des avancements au choix, par des récompenses honorifiques, de stimuler leur zèle, parce qu'il est beaucoup plus difficile de surveiller leur activité qu'il n'est possible de constater la présence de la rouille sur un rouage ou d'une malfaçon sur un produit que le client refuse.

Ce qu'on leur demande, en somme, c'est de faire preuve de qualités qui dépendent du caractère, de la bonne volonté, de ce qu'on peut appeler la nature morale, toutes exigences qu'on n'a pas avec l'ouvrier. Il est nécessaire d'entretenir avec eux des relations d'ordre personnel, de les traiter comme les membres d'un groupe social bien défini qui est l'entreprise.

C'est pourquoi aussi les employés s'efforcent de développer les qualités qu'on apprécie en eux, qu'ils ont ou qu'ils acquièrent le souci de la régularité et de l'exactitude dans un travail modeste. Ils comprennent et sentent en effet que de là dépend leur valeur professionnelle, le prix que leurs chefs attribueront à leurs services, l'estime des autres employés occupés dans la même maison. Ils s'attachent 
aussi aux avantages mêmes par lesquels on essaie de les stimuler : avancement à l'ancienneté, si possible au choix, et sécurité dans leur emploi.

Cependant, tenons compte de ce qu'il s'est formé d'assez bonne heure, en France, des syndicats d'employés, et qu'ils se sont rattachés aux organisations ouvrières par leur affiliation à la C.G.T. Il semble en résulter que la distinction signalée entre ouvriers et employés n'est pas si profonde qu'il ne puisse y avoir rapprochement et même fusion en certaines parties des deux groupes. En tout cas, c'est le signe d'un esprit de solidarité qui se développe en effet, du moins en de certaines périodes, dans la catégorie des employés, et même qui tend à s'étendre au delà.

Dans toute la classe moyenne, en effet, c'est parmi les employés que les syndicats ont joué le plus grand rôle : les syndicats d'employés sont, d'ailleurs, ceux qui se rapprochent le plus des syndicats d'ouvriers ${ }^{1}$. Par leur situation économique, les employés ont souvent eu le sentiment qu'ils ne se distinguaient qu'en apparence des travailleurs manuels. Comme eux, ne sont-ils pas dans une situation dépendante par rapport à des patrons privés ? Il est naturel qu'ils aient jugé nécessaire à un moment donné d'utiliser, pour des raisons de tactique, des méthodes d'organisation qui avaient été inventées par les ouvriers et qui s'étaient révélées efficaces dans leurs débats avec les entrepreneurs. De plus, en période surtout de resserrement, de dépression économique, les couches inférieures de la classe des employés se sentent menacées. Les employés les moins bien situés ont des revenus peu supérieurs aux salaires des ouvriers. Exposés à des réductions nouvelles, qui les empêcheraient de satisfaire leurs besoins vitaux, ils se considèrent comme étant, eux aussi, des exploités, et se sentent appelés à s'unir avec les autres exploités.

C'est pourquoi ils n'hésitent pas non plus à se mettre en grève, comme de simples travailleurs.

Pourtant on peut dire qu'à ces moments, toute une partie de leur conscience sociale proteste, que ces groupes n'appliquent pas de telles méthodes sans une inquiétude sourde et un sentiment de malaise, et qu'ils hésitent à s'unir pleinement avec les organisations d'ouvriers, bien qu'ils soient associés dans les mêmes cadres. C'est qu'ils tiennent à ne pas laisser oublier qu'ils se distinguent d'eux, qu'ils occupent un rang social plus élevé. On sent très bien cette indécision et cette incertitude lorsqu'ils doivent combiner leur action avec celle des syndicats ouvriers. Les différences entre eux subsistent. Ils ne se mêlent pas entièrement. Ils concluent entre eux des traités d'alliance. Mais ce n'est pas une même organisation qui intervient. Même différence qu'entre des militaires de carrière ou une armée active, d'une part, et d'autre part, une milice levée dans des lieux qui n'ont jamais fait la guerre et n'y sont aucunement préparés : ils peuvent manœuvrer ensemble, mais ils se distinguent, il n'y a pas entre eux réellement unité d'esprit. Dans les périodes normales, ce sentiment des différences passe au premier plan, alors qu'il n'est pas obscurci par la nécessité de la lutte. Alors, c'est plutôt dans le domaine des mutualités et des coopératives, qui ne sont pas des organisations de classes, que leur esprit d'association trouve à s'exercer.

Considérons l'esprit de prévision aussi, de prévoyance, l'attention portée sur l'avenir. Se rapprochant à certains égards de la bourgeoisie, bien des employés espèrent, par des efforts d'épargne, d'économie, par des placements, des assurances sur la vie, élever peu à peu leur situation pécuniaire, s'assurer, quand ils seront plus

1 Maxime Leroy, La Coutume ouvrière, etc., op. cit., p. 94 des syndicats d'employés). 
âgés, une sécurité relative et quelques loisirs peu dispendieux. Ils songent aussi à leurs enfants, font de sérieux sacrifices pour qu'ils puissent poursuivre leurs études jusqu'au bout dans un établissement d'instruction de second degré (enseignement secondaire), lycée ou collège, pour qu'ils se présentent aux grandes écoles. Leur ambition est en somme telle que dans ces milieux bourgeois d'ancien régime, d'où l'on rêvait de s'élever à la noblesse, soi-même ou par ses enfants : les employés, petits et moyens, afin de supporter leur situation dépendante, ont besoin de se représenter qu'il y a pour eux, pour leur famille plus tard, en tout cas, possibilité de pénétrer dans la classe élevée, dont ils sont déjà bien plus proches que les ouvriers, dont ne les séparent plus qu'une ou deux étapes. Au moins tiennent-ils à ce qu'en tout cas, si leurs enfants ne peuvent monter, ils ne redescendent pas. Ils comptent alors sur les protections, sur la reconnaissance que leur valent les services rendus fidèlement dans une ou dans un petit nombre de maisons, où leurs fils, leurs filles trouveront accès. Recours aux relations personnelles, qui contraste avec le recours à l'action collective pour la profession, - sans qu'il y ait d'ailleurs contradiction, car les employés s'inspirent tantôt de la classe supérieure et tantôt de la classe inférieure, étant compris entre l'une et l'autre.

$3^{\circ}$ Les petits fonctionnaires. - C'est une troisième catégorie, dans les classes moyennes, un ensemble d'ailleurs singulièrement accru avec l'extension et la complication croissante des services publics. Ils sont cependant moins nombreux que les employés des entreprises privées. Bien qu'on dise que la France est un pays de fonctionnaires, leur proportion n'y dépasse guère 5 à $6 \%$ de la population active ${ }^{1}$.

Il y a une différence très apparente entre eux et les autres parties de la classe moyenne. On oppose quelquefois l'esprit bureaucratique, routinier et passif des fonctionnaires à l'activité indépendante et personnelle des artisans qui travaillent à leur compte : même sorte de différence observée déjà entre artisans et employés. Mais les fonctionnaires ne se confondent pas cependant avec ceux-ci. Personnel des chemins de fer (bien qu'ici, ce ne soit pas une entreprise de l'État, ils sont cependant sous son contrôle et se rapprochent plus d'une administration publique que d'une société privée), agents des postes, des douanes, agents chargés d'établir les impôts directs et d'en répartir le montant, employés des préfectures, des municipalités, instituteurs, tous dépendent non point de Personnes ou de sociétés privées, mais de l'État, de la collectivité.

Astreints peut-être plus que les employés à une discipline et à des règlements plus stricts (par quoi certains ensembles de petits fonctionnaires se rapprochent des groupes ouvriers soumis à la discipline de l'usine), moins libres qu'eux à cet égard, en revanche ils représentent l'État, beaucoup d'entre eux détiennent une part de la puissance publique ; ils ont, pour cette raison, une autorité et un prestige qui les

SIMIAND, Cours d'économie politique, 2e année, 1928-1929, p. 470 : « Les petits patrons et chefs d'établissements sans salariés (classe moyenne) donnent une proportion de 20 à $25 \%$ de la population active. Si on y ajoute les fonctionnaires (et les services publics), cela augmente la proportion de plus de $5 \%$. »- [Chiffres actuels : la population active de la France métropolitaine est évaluée par le recensement de 1946 (voir ci-dessus p. 63, no 3) a 20.520000 en chiffres ronds. Le nombre des fonctionnaires civils (titulaires, auxiliaires ou contractuels) est de 817000 , ce qui donne une proportion d'un peu moins de $4 \%$. Ajoutons-y 370000 employés communaux : la proportion ne s'élève encore qu'à 5,78 \%. Voulons-nous même tenir compte des 96000 fonctionnaires employés dans les territoires d'outre-mer? la proportion est alors de 6,25\%. Nous ne comptons, bien entendu, ici ni les ouvriers d'État au nombre de 148.000 ni les 490000 militaires à solde mensuelle.] A. C. 
apparentent à la classe la plus haute. Ils représentent davantage, aux yeux du publie, ils le savent, et doivent en tenir compte dans leurs paroles, leur attitude, leur tenue. En Allemagne, il est établi, par des enquêtes précises, que, dans les budgets de petits fonctionnaires, la part de la dépense consacrée aux vêtements est nettement plus élevée que dans les budgets d'employés de même revenu ${ }^{1}$. La dignité apparente plus grande est ici la rançon d'une dépendance peut-être plus marquée, mais dépendance par rapport à l'État et au publie qui, remarquons-le, est commune aux fonctionnaires de tout rang.

Dépendre de l'État, c'est-à-dire de tous, ce n'est pas une servitude, c'est même le contraire. Tous les hommes qui n'exercent pas une fonction publique dans la société sont, d'une façon ou de l'autre, au service de quelque intérêt privé. Quand, par leur activité, ils ne poursuivent que leur intérêt propre, on n'a pas de raison de les estimer plus. Seuls les fonctionnaires sont au service de l'intérêt de tout le monde (qui n'est l'intérêt de personne en particulier). Il est donc naturel qu'ils s'efforcent d'abord (c'est leur préoccupation principale) de sauvegarder le prestige et autorité de leur fonction. Dans certains pays, ils cherchent et trouvent dans ce sentiment un stimulant à des efforts, à un zèle et même à un désintéressement qui caractérise leur élite. Mais, moins libres en un sens, moins désireux de liberté que les employés, dépendant davantage de leur fonction, ils ont un sens collectif plus marqué, obéissent à un esprit commun, ont une morale professionnelle plus impérative.

Il existe cependant des syndicats de fonctionnaires, mais qui ne ressemblent pas tout à fait aux autres. Question assez controversée pendant longtemps : les fonctionnaires auront-ils le droit de se syndiquer ? Jusqu'à une époque assez récente, la doctrine gouvernementale, celle des partis qui ont eu la majorité au Parlement, était que, sous aucun prétexte, ce droit ne devait leur être attribué. Principe auquel dans beaucoup d'administrations de l'État on est resté longtemps attaché. L'opinion a évolué à cet égard, sans doute parce qu'il y a, à côté des fonctionnaires dits d'autorité, des fonctionnaires de gestion, qui, par les conditions. de leur travail, par le niveau de leurs revenus, ne se distinguent guère des employés et ouvriers des entreprises privées, et qu'avec l'extension des services publics de forme industrielle, leur nombre, leur proportion par rapport aux autres, a beaucoup augmenté. Tolérés d'abord en fait, mais non reconnus en droit, les syndicats de fonctionnaires, même ceux des agents des douanes, des agents de police, ne se heurtent plus aujourd'hui en France à aucune interdiction officielle ${ }^{2}$. Mais (et c'est là le point essentiel), on ne leur reconnaît pas le droit de se mettre en grève. Toute grève de fonctionnaires est illégale ${ }^{3}$. Pourquoi ?

Parce que la situation des fonctionnaires reste, tout de même, assez particulière. Le traitement des fonctionnaires est fixé par la loi, par des mesures législatives, et non par un libre débat entre les employeurs et les employés. On considère qu'ils ont un moyen, dont ne disposent pas les ouvriers et les employés, d'obtenir un relèvement de leur traitement, un changement favorable dans leurs conditions de travail : ils peuvent

1 Voir dans notre livre cité, L'Évolution des besoins, etc., le tableau 1, p. 29. La proportion de la dépense pour vêtements, linge, est de 12,9\% pour l'ensemble d'employés, 13,3 pour tous les ouvriers et 14,3 pour tous les fonctionnaires, mais, à égalité de revenus, elle est à peu près, pour les employés de 13,5\%, pour les fonctionnaires de $15 \%$ (différence bien plus marquée encore pour les plus faibles revenus).

2 La Tribune des fonctionnaires et des retraités, organe de la Fédération générale des fonctionnaires, est à sa trentième année : c'est en effet en 1907 qu'ont été formés les premiers syndicats de fonctionnaires [note de 19381.

3 [On sait que, sur ce point, des modifications sont intervenues dans la législation.] A.C. 
s'adresser aux pouvoirs publics. C'est le régime du statut, et non pas du contrat individuel ou collectif.

Il est vrai que cette pression que les fonctionnaires ont le droit d'exercer, dans certaines conditions, sur les pouvoirs publics, soit par l'envoi de représentants et l'exposé de leurs revendications, soit en faisant appel à l'opinion pour l'avoir avec eux, ce genre d'action suppose que les fonctionnaires peuvent se réunir, discuter de leur situation, de leurs intérêts, nommer des délégués, rédiger des programmes. Ainsi s'explique que nous trouvions dans ce groupe des organisations, mais d'un type particulier et qui se distinguent profondément des syndicats d'ouvriers et d'employés, bien qu'elles portent le même nom, en ce qu'elles n'ont pas été créées et ne fonctionnent pas en vue de suspensions du travail concertées.

Ainsi, entre les trois catégories de personnes les plus nombreuses qui entrent dans les classes moyennes, il y a des différences marquées, et chacune obéit à un ordre de motifs particuliers qui résultent de sa fonction propre dans la vie sociale. Pourtant, puisque tous ces groupes font partie d'un même ensemble social, intermédiaire entre la bourgeoisie et le monde ouvrier, ils doivent avoir des traits communs. Comment les définir?

Toutes les professions exercées dans ces milieux, si diverses soient-elles, présentent un caractère technique, dans la mesure où l'on distingue l'activité technique à la fois du travail machinal de l'ouvrier et de l'exercice de fonctions plus difficiles, qui exigent plus d'initiative et des vues d'ensemble plus étendues. L'activité technique, en effet, consiste simplement à connaître et à appliquer les règles et préceptes qui, à chaque époque, prescrivent à un agent, en termes généraux, les actes, les paroles et les gestes de sa fonction.

Une technique offre un aspect surtout négatif. Elle dit ce à défaut de quoi la fonction ne serait pas accomplie. Si un professeur ne suit pas le programme, si un juge ne rend pas son arrêt dans les formes, si un banquier escompte à un taux illégal, leur activité, dans tous ces cas, n'atteint pas son but. Ce n'est là, bien entendu, qu'un aspect et qu'une partie, la moins difficile, de telles fonctions.

Surtout une règle, comme un instrument; s'applique à une réalité qu'on suppose à la fois immobile et uniforme. C'est pourquoi on dit quelquefois qu'il n'y a pas de règle pour juger des caractères, des sentiments, des goûts, si divers et changeants. Mais là où on peut l'appliquer, la règle perdrait toute autorité s'il fallait sans cesse la modifier, l'adapter à des circonstances momentanées et à des objets trop différents. Certes, les règles administratives, juridiques, pédagogiques qui s'imposent aux individus du dehors, leur apparaissent comme l'œuvre de la société. Ce ne sont pas des lois physiques, Par leur rigidité et leur immobilité, elles n'en imitent pas moins les lois et les forces de la matière. La volonté sociale qu'on entrevoit derrière elles s'est fixée et simplifiée. Elle a renoncé à se plier à toutes les variations qui se produisent, dans le temps et dans l'espace, à l'intérieur du groupe d'où elle émane. De toutes les actions sociales, celles qui prennent la forme d'une technique ressemblent le plus au mécanisme des choses non sociales ${ }^{1}$.

Sur cette distinction entre la technique et la fonction, voir notre livre cité, Les Cadres sociaux de la mémoire, pp. 334 et 359 et suivantes. 
Bien entendu, de telles techniques ne sont possibles que parce que les hommes, les groupes humains, les qualités humaines sur lesquelles on veut agir peuvent être considérées à certains égards comme des réalités uniformes, invariables, qu'on peut mesurer, dénombrer, - que parce que les hommes peuvent être traités comme des unités semblables, qui peuvent être réparties entre un certain nombre de catégories. C'est bien ainsi que les envisage l'employé et, le plus souvent, le fonctionnaire.

Pourtant, si les êtres auxquels s'appliquent les diverses fonctions de la société représentent, par un certain côté, de la matière, ils sont, essentiellement, une matière humaine, de l'humanité en quelque sorte matérialisée et momentanément immobilisée. Si, d'autre part, l'action que la société exerce sur eux, par son uniformité et sa fixité, ressemble à une action physique, c'est aussi, en même temps, une action qui met en rapport des hommes avec des hommes.

C'est pourquoi ceux qui sont préposés, comme employés et petits fonctionnaires, à ce genre d'opérations techniques, ceux mêmes qui, en sous-ordre, se bornent à les exécuter, sans grande réflexion, sans réelle initiative, se distinguent cependant des ouvriers, qui, eux, n'exercent leur technique que sur une matière inerte. C'est pourquoi, dans une société qui s'intéresse surtout aux relations humaines, employés et fonctionnaires occupent un rang plus élevé que les ouvriers.

En revanche, ils restent au-dessous du niveau de la classe la plus élevée, parce que toute technique n'est qu'une partie secondaire et comme l'aspect inférieur de la fonction envisagée en sa plénitude. La société, en effet, ne peut pas s'emprisonner dans les formes qu'elle a ainsi arrêtées. La technique ne se suffit pas. Livrée à ellemême, elle devient vite un mécanisme et une routine. Même dans une période limitée, il faut être en mesure d'adapter les règles, toutes les fois que cela est nécessaire, aux conditions sociales complexes et mouvantes. C'est la partie la plus difficile, mais aussi la plus importante de la fonction. Ici, un juge ne peut être remplacé par un greffier, pas plus qu'un entrepreneur par un contremaître, ni un commerçant par un commis.

Il n'y a pas de différence capitale, à cet égard, entre les employés et les petits fonctionnaires qui sont les uns et les autres préposés à la partie technique des fonctions accomplies et dirigées soit par des personnes et sociétés privées, dans l'industrie et le commerce, soit par les fonctionnaires supérieurs de l'État, dans la justice, les services publics et les grandes administrations. Quant aux artisans et petits commerçants, bien qu'ils assument toute la direction et le contrôle de leurs entreprises, il s'agit de petites entreprises, et l'on peut montrer que là aussi ils sont soumis à des coutumes ou à des règles, et qu'il leur suffit, pour qu'ils puissent s'acquitter de leur tâche, d'un dressage rapide et d'un peu d'expérience. S'ils travaillent et produisent sur commande, ils sont aux ordres des clients dont les exigences restent, en somme, assez uniformes. En tout cas, ils obéissent aux directives des grandes entreprises, qui font la loi sur le marché, et, quant à la part d'opérations commerciales dui leur incombe, elle est assez réduite et assez simple et ne réclame qu'une fonction technique élémentaire.

D'où il résulte, puisque tous ces membres des classes moyennes sont plus ou moins des techniciens, un attachement aux règles qu'ils ont apprises et qu'ils doivent introduire, appliquer, maintenir telles quelles dans une période assez longue et dans un groupe plus ou moins étendu. 
Ils ont l'amour-propre professionnel de celui qui sait, qui possède une compétence dans un domaine d'activité sociale et humaine. Ils sont méticuleux, pleins de scrupules, fidèles à la lettre des règlements, aux formules, aux procédures. Tel a bien été l'état d'esprit conformiste, formaliste, déjà sous l'ancien régime, de tout le personnel subalterne des administrations royales, provinciales, municipales, des offices, des cours, des tribunaux, greffiers, scribes, etc. Ils ont joué un rôle important dans la Révolution, dans la Commune de Paris, dans les comités révolutionnaires à travers tout le territoire. Ce sont eux qui, dans toutes les parties de la France, ont mis au service du nouveau régime l'expérience qu'ils avaient acquise dans les emplois inférieurs de l'administration, pour toutes les mesures d'exécution. Par eux s'est établie une certaine continuité d'esprit et de tradition dans les ministères, les tribunaux, les municipalités, quant aux méthodes, au détail de la procédure, à l'activité des bureaux, et de même, dans le domaine de la production et de la vente, par les artisans et les petits commerçants.

Mais d'autre part, cette classe qui a pour fonction d'assurer ainsi la stabilité, la continuité dans le jeu des rouages sociaux, a beaucoup de peine, en certaines périodes, à définir exactement et à maintenir sa place dans la société. En raison de sa situation intermédiaire, elle est soumise en quelque sorte à l'attraction de deux pôles opposés. Tantôt, aux moments critiques dans l'évolution économique et sociale, elle est portée à considérer que ses conditions d'existence précaires et menacées la rapprochent du groupe des ouvriers, et tantôt (quelquefois en même temps) à faire effort au contraire en vue de se distinguer, et à insister sur les liens par lesquels elle se rattache à la bourgeoisie.

Dans la période récente, notamment, il semble que les classes moyennes aient été les plus atteintes par les mouvements économiques que la guerre et ses suites ont entraînés, notamment dans les revenus mobiliers, dans les revenus fixes. On a même cru que, dans des pays où l'inflation a été particulièrement forte, en Allemagne et dans l'Europe centrale, la classe moyenne avait été si éprouvée qu'elle risquait de disparaître. En France aussi, bien qu'à un degré moindre, on admet assez volontiers que c'est la classe moyenne qui a subi, du fait de diverses circonstances, le changement tout au moins relatif le plus grand, soit en situation, soit en importance. Cependant, même en Allemagne, on constate depuis quelques années une reconstitution assez rapide de cette classe moyenne. Il en est de même en France et dans d'autres pays.

Catégorie sociale, en somme, très ébranlée par les fluctuations économiques, notamment dans les périodes de resserrement et de régression, mais qui manifeste une notable résistance et même une faculté remarquable de reconstitution. Comme le dit SIMIAND, Si on la suit à travers l'histoire, il apparaît qu'elle diminue en un certain sens, dans certains cadres, et cependant qu'elle se maintient -et même se développe à nouveau en un autre sens et dans d'autres cadres. Mais ces nouveaux cadres « elle ne les crée point elle-même par son effort propre. Elle attend qu'ils se forment pour, tant bien que mal, s'y adapter ». Elle est manifestement bien plus commandée par eux qu'elle ne les commande ${ }^{1}$. D'où une alternance d'attitudes : tantôt résignée à des conditions et mouvements qu'elle ne comprend pas, dont elle n'aperçoit ni les raisons, ni les conséquences, et tantôt dressée dans un mouvement de révolte violente et aveugle contre une évolution qu'elle pense pouvoir arrêter ou détourner de son cours.

1 Cours d'économie politique, 2e année, 1928-1929, pp. 472-473. 
Malgré tout, son rôle n'est pas négligeable. Mais elle obéit le plus souvent à des impulsions momentanées, contradictoires. C'est que, ne constituant pas une classe vraiment une, et faute d'un horizon social assez large, absorbée aussi par le souci de la lutte quotidienne pour l'existence, elle ne prend jamais une conscience bien nette des motifs de sa conduite, qui ne sont chez elle que le reflet des aspirations qui se font jour dans la bourgeoisie ou dans la classe ouvrière. On peut bien lui appliquer encore le mot de TOCQUEVILLE à propos de l'esprit de la classe moyenne qui, " mêlé à celui du peuple. ou de l'aristocratie (disons, maintenant, de la bourgeoisie), peut faire merveille, qui, seul, ne produira jamais qu'un gouvernement sans vertu et sans grandeur ». 


\section{VI}

\section{CONCLUSION}

\section{REPRÉSENTATION DE CLASSE, PATRIOTISME., RELIGION, SCIENCE, ART, POLITIQUE, MORALE SOCIALE}

\section{$\underline{\text { Retour à la table des matières }}$}

«- La fonction d'un cheval, demandait Socrate à Thrasymaque, n'est-ce pas ce que l'on peut faire seulement à l'aide d'un cheval, ou principalement avec son aide ? - Je ne comprends pas. - N'est-ce pas avec les yeux que tu vois ? - Oui. - Par les oreilles que tu entends ? - Certes. - Voir et entendre sont donc les fonctions des yeux et des oreilles ? - C'est vrai. - Peux-tu émonder un cep de vigne avec un couteau, un tranchet ou d'autres instruments ? - Oui. - Mais aucun ne vaut mieux que la serpe, qui est faite exprès pour cela ? - Oui. - Comprendras-tu maintenant mieux, si je te demande si la fonction d'un être est ce qu'il est seul à faire, ou ce qu'il fait mieux que les autres ${ }^{1}$ ? »

Dans ce texte s'exprime ce qu'on pourrait appeler le naturalisme des anciens, des grands philosophes de l'antiquité. Pour eux chaque être a une fonction qui dérive non pas des circonstances, mais de sa nature même. Cette fonction, pour chaque homme ou, si l'on veut, pour chaque espèce d'homme, peut être aussi définie que la fonction d'une serpe fabriquée spécialement pour émonder la vigne.

Partant de cette idée, si nous avions voulu distinguer les hommes d'après leur nature et les motifs de leurs actions, les motifs naturels, à quelles difficultés ne nous serions-nous pas heurtés ? Les sages, les courageux, les avides, les avares, les cupides, les indifférents, les passifs, les hommes d'initiative, les esprits moutonniers, ceux qui obéissent avant tout au sentiment de l'honneur, les dévots, les ambitieux : il nous aurait fallu passer en revue tous les vices et les vertus dont les moralistes nous ont tracé le tableau. A quel résultat, d'ailleurs, serions-nous parvenus ? A constater d'abord qu'on trouve des hommes de toute nature dans les groupes les plus divers de la société, ensuite et surtout, qu'on ne peut pas dire si, oui ou non, les hommes règlent leur conduite d'après leurs tendances naturelles, puisque leur nature est entièrement remaniée et transformée par la vie sociale. La question aurait été mai posée.

Nous nous sommes préoccupés, au contraire, des groupes en eux-mêmes, des hommes tels qu'ils se présentent, encadrés dans les formations sociales, portant notre attention sur les motifs de la conduite tels qu'ils résultent de la vie en société.

1 République, livre II, 352 e, cité par E. BRÉHiER, 1re partie, Le Sage antique, dans : Du Sage, antique au citoyen moderne (Bouglé, Bréhier, DELACROIX et Parodi), Paris, 1921. 
C'est dans le cadre des classes économiques et sociales que nous avons poursuivi cette enquête. Ainsi, il nous est apparu progressivement, et de mieux en mieux à mesure que nous avancions, que, sans doute, on ne naît pas paysan, gros propriétaire, fermier, manœuvrier de la campagne, en ce sens qu'on porterait dès la naissance, dans son organisme, annoncés et préformés, tous les traits qui caractérisent les hommes qui exercent ces métiers. On ne naît pas non plus bourgeois, entrepreneur, avocat, magistrat, ni ouvrier de la grande industrie. La nature de l'employé, du petit fonctionnaire, du petit commerçant n'est pas un fruit poussé spontanément sur la plante humaine. Mais en revanche, ces catégories sociales existent. Elles sont, le plus souvent, tranchées : bien tranchées, lorsqu'on passe des classes paysannes aux classes urbaines, des ouvriers à ceux qui ne le sont pas ; mal délimitées, au contraire, si nous comparons les employés haut situés aux entrepreneurs, les employés plus pauvres aux ouvriers. Chacune d'elles en tout cas détermine la conduite des membres qu'elle comprend, elle leur impose des motifs d'action bien définis ; elle leur imprime sa marque, une marque propre et bien distincte pour chaque groupe, avec une telle force que les hommes faisant partie des classes sociales séparées, bien qu'ils vivent dans un même milieu et à la même époque, nous donnent quelquefois l'impression qu'ils appartiennent à des espèces différentes. Ainsi les motifs des hommes et leurs tendances nous paraissent être, dans la plus grande quantité des cas, entièrement relatifs aux conditions qu'ils occupent dans la société.

Ce n'est là, à vrai dire, qu'un aspect de la question. Naturalisme philosophique des anciens, relativisme scientifique et sociologique des modernes : nous étions amenés à faire une part à ces deux conceptions, qui expriment des faces bien différentes, mais complémentaires, de la réalité. Dans tel de ces groupes sociaux que nous appelons classes, en effet, il n'est pas douteux que certains milieux plus étroits, et même des personnes définies plutôt que les autres, ne représentent plus pleinement et de façon plus naturelle que la masse, ce qu'on peut appeler les instincts et les aspirations dominants du groupe. C'est ce que nous disions, au début, à propos de la famille, du groupe confessionnel, du parti politique. Pourquoi n'en serait-il pas de même de la classe sociale?

Il arrive, en effet, qu'il y ait correspondance, de fait et peut-être accidentelle, mais harmonie en tout cas et presque pré-harmonie, entre les tendances personnelles et innées et celles qui correspondent à la situation. Heureuses natures, puisqu'elles trouvent dans leur condition même un stimulant à se développer dans leur propre sens, puisque, étant elles-mêmes, se confirmant dans leurs dispositions les plus innées, elles réalisent sans peine, avec aisance et satisfaction, le type même qui est désiré et attendu autour d'elles. C'est ainsi que dans la galerie des rois il se trouve, en petit nombre il est vrai, quelques figures vraiment royales et qui ont fixé le type de la royauté. Dans l'ensemble des familles nobles, on a la surprise d'en rencontrer qui furent nobles en effet au plein sens du terme, c'est-à-dire par l'intérieur, par la générosité, la grandeur d'âme, le désintéressement, aussi bien que par l'éclat, qui rachetèrent le démérite de beaucoup d'indignes et par qui le prestige de la noblesse fut souvent rénové.

Mais on peut dire aussi de certains travailleurs manuels qu'ils sont de bons ouvriers, de vrais ouvriers, ce qui signifie non seulement qu'ils aiment leur métier, car un amour de ce genre peut être fondé sur l'habitude, même sur la nécessité, mais qu'ils l'aiment comme s'ils l'avaient choisi entre beaucoup, parce qu'il était fait pour eux, comme eux pour lui. A les voir, à les fréquenter, et rien qu'à savoir qu'ils existent, 
leurs compagnons et camarades, moins bien adaptés, moins satisfaits, qui sentent que la tâche industrielle n'est peut-être pour eux qu'un pis-aller, reprennent cependant courage, cessent d'avoir honte, sont même fiers de leur profession, comme si on leur en avait découvert tout le sens caché, les vertus ignorées.

Y a-t-il beaucoup de paysans qui aiment la nature et la campagne pour ellesmêmes ? Il y en a, en tout cas, qui se confondent avec leur terre, dont la vie se conforme si naturellement aux coutumes et traditions paysannes, qu'ils semblent ne pouvoir prendre racine dans un autre sol : vieilles souches sur quoi se briseront tous les essais de nouveauté, tout ce qui est étranger à la civilisation paysanne. Ce n'est pas un effet de l'hérédité, mais parce qu'il naît quelquefois ici comme ailleurs des hommes prédisposés à la vie dure et ralentie, à l'isolement de la campagne. De même il y a des natures méticuleuses, méthodiques et modestes, qui donneront parfois de parfaits employés, ceux qu'on citera comme modèles et qui, au cours d'une longue existence de dévouement professionnel, en formeront beaucoup d'autres rien que par l'exemple. Ainsi l'esprit de chaque classe, de chaque groupe professionnel, anime plus vive ment quelques personnes, celles qui, par nature, sont le plus capables de le comprendre et de s'en inspirer.

Au reste, comme nous l'avons dit, si ces individus jouent un tel rôle, s'ils sont en quelque sorte la conscience du groupe, il faut considérer, en même temps que ce qu'ils lui donnent, ce qu'ils en reçoivent, comme un orateur qui a besoin de la présence et comme du contact de ses auditeurs, pour sentir et comprendre mieux qu'eux-mêmes ce qu'ils pensent et désirent obscurément. Les hommes en qui l'esprit d'une classe s'incarne ainsi doivent y avoir vécu et s'être trouvés placés dans un tel milieu à un juste point de perspective, pour développer et préciser en eux-mêmes des tendances qui, sans cela, n'auraient pu prendre corps et devenir efficaces.

Ainsi, et par une opération collective, par une sorte de pression qu'elle exerce sur sa propre substance, la classe découvre en elle et fait surgir au dehors ses meilleurs interprètes, ses agents les plus autorisés, ceux qui sont naturellement le mieux accordés à ses aspirations. En même temps elle les stimule et les oblige à se dépasser.

Mais il y a d'autres groupes que les classes. D'abord, et surtout, les nations. Notre examen des motifs qui interviennent dans la conduite des hommes serait incomplet, si nous n'insistions pas sur l'esprit national, de quelque nom qu'on le désigne : patriotisme, amour du pays, attachement au sol natal. Il suffit de se placer attachement sur le plan historique pour apercevoir que les groupements nationaux ont été longtemps le cadre principal dans lequel s'est exercée l'activité sociale.

Certes les classes débordent ce cadre. Elles sont plus vastes que les nations. De notre temps on peut dire que chacune d'elles s'étend d'un bout à l'autre des régions de civilisation occidentale, en y comprenant l'Amérique. Quand les émigrés de l'ancien régime ont quitté la France pour aller en des pays étrangers, en Allemagne, en Autriche, même en Russie, ils pouvaient traverser de nombreux pays sans avoir le sentiment de sortir de leur classe. Maintenant encore, quand des ouvriers émigrent pour aller en Amérique, ils retrouvent dans ce pays des ateliers, des quartiers ouvriers, une classe ouvrière de laquelle ils peuvent s'imaginer qu'ils ne sont pas sortis. N'est-ce 
pas Marx qui disait, dès 1848 : «Prolétaires de tous les pays, unissez-vous ${ }^{1}$ ? » PLATON, dans sa République, nous proposait une division de la société en trois classes : les philosophes et savants, les guerriers, et les artisans, et sans doute il songeait à la Grèce ; néanmoins, quand des philosophes interprètent cette théorie, leur tendance est de croire qu'il a songé à l'espèce humaine. Ainsi nous serions tenté de dire que les classes sont des groupes très étendus qui comprennent comme parties ces ensembles plus restreints que sont les nations.

Pourtant, les nations, pas plus que les cités antiques, ne sont des subdivisions de classes. Elles ne le sont pas historiquement. Nous savons qu'elles n'ont pas été constituées en partant de classes préexistantes, comme si, par exemple, on avait pris une partie de la casse élevée, une autre, de la classe inférieure, pour les réunir et en faire une cité. Au contraire, les cités se sont développées d'une façon indépendante, et c'est à l'intérieur de ces cités qu'on a vu apparaitre les distinctions de classes. Il en résulte qu'on ne peut pas, sans bien des Précautions et des réserves, établir une comparaison entre les classes des diverses nations.

Il y a, en particulier, des différences qui tiennent à ce que ces divers groupements de classe que nous appelons des nations se présentent comme des étapes différentes de l'évolution qui a fait passer, au cours du XIXe siècle, les sociétés de l'état agraire à l'état industriel. Si on compare, à la fin du XVIIIe, au début du XIXe siècle, ]'Allemagne, la France et l'Angleterre, que trouve-t-on ? En Angleterre, il. y a eu de bonne heure une classe ouvrière et industrielle développée ; en France, on s'oriente aussi vers la grande industrie, niais avec un certain retard ; entre la classe industrielle en France et en Angleterre, il y a des différences qui tiennent aux pays dans lesquels ces classes se sont développées. En Allemagne, on trouve encore au début du XIXe siècle le régime corporatif, et, dans la classe des agriculteurs, des traces très nettes de féodalité : cela contribue à modifier le caractère de ces classes. Il n'y a pas continuité de substance entre elles de pays en pays. Dans le reste du continent, il nous arrive de dire de tel pays de l'est de l'Europe : c'est un pays qui en est resté à l'état social du moyen âge : une économie presque uniquement agraire, des petites villes avec des artisans. Cela nous suffit pour constater que s'il y a une tendance à l'uniformisation de pays en pays, qui aurait pour effet de rapprocher les conditions des différentes classes, elle n'en est qu'à ses, débuts, et que ce processus se poursuit avec une lenteur incontestable.

On peut soutenir, cependant, qu'il y a, malgré les divisions qui séparent les pays, des fusions. Mais elles s'opèrent plutôt entre les hautes classes. La noblesse, par exemple, sous l'ancien régime était une classe cosmopolite : on s'y mariait souvent d'un pays à l'autre. Ce qui rapprochait ces milieux, c'est qu'ils étaient plus cultivés que les autres, et que la culture tendait à y atteindre un même niveau. Ajoutez que, sous l'ancien régime, toutes ces familles nobles de l'étranger parlaient, presque de naissance, la langue française.

Descendons-nous dans l'échelle sociale ? Les bourgeois, les commerçants, les hommes d'affaires ont encore une certaine ouverture sur les pays étrangers. Mais si nous arrivons aux paysans, aux ouvriers, au vrai peuple, ce qui nous frappera, c'est une incompréhension très grande quant aux mœurs, coutumes, façons de penser des autres pays. Pourquoi ne les comprennent-ils pas ? Étant données leurs conditions de

1 K. Marx et F. Engels, Le Manifeste communiste, traduction Charles Andler, 2 Vol ., Paris, 1901, I, p. 74 . 
vie et de travail qui font qu'ils participent plus que les autres hommes aux coutumes vraiment locales, aux traditions de leur province et de leur ville, la difficulté, aussi, qu'ils éprouvent à apprendre les langues, à recevoir certaines conceptions, ils sont plus fermés à cet égard. Aussi l'exclusivisme national caractériserait plutôt les classes inférieures que les classes élevées, qui ont toujours affecté et fait profession d'un certain cosmopolitisme.

Ajoutons que, jusqu'à présent, la force de cohésion qui tient rassemblés dans une même nation des hommes de situation sociale différente est plus grande que la force d'attraction qui pourrait fondre en un tout les membres d'une même classe dans les divers pays. Ce n'est pas que l'identité de leur situation ne soit une raison de rapprochement entre des groupes même très éloignés dans l'espace. Mais, en particulier depuis la guerre, les nations se distinguent l'une de l'autre plus nettement que jamais. Le Bureau international du Travail réunit des représentants non seulement des ouvriers, mais des patrons et des gouvernements : c'est une oeuvre de collaboration entre des pays. Les ententes, fédérations et congrès internationaux n'ont pas réussi jusqu'à présent à organiser une coopération permanente effective entre les classes ouvrières ou les classes non ouvrières des diverses nations. Il semble que les ententes économiques présupposent un rapprochement préalable entre les pays et non l'inverse. Les barrières douanières sont dressées le long des frontières politiques. La division du travail ne pourrait s'organiser sur le plan international que si la Société des Nations était elle-même une réalité ${ }^{1}$.

Il y a, en tout cas, cette différence entre les représentations de classe et l'esprit national, que toute classe se situe dans une hiérarchie, à un certain niveau de l'échelle sociale, alors que toutes les nations se placent sur un même rang, qui est, d'ailleurs le premier. Chacune, en effet, se confère un brevet de supériorité. Elles se considèrent tantôt comme le peuple élu, tantôt comme le foyer de la civilisation, ou bien elles s'estiment supérieures aux autres en vertu de leur nature ethnique. C'est là une prétention inoffensive en elle-même, sinon par ses conséquences, puisqu'elle est commune à tous les pays. C'est ainsi que, dans les théâtres nègres de New-York, on représente un paradis où il n'y a que des noirs, et un enfer où il n'y a que des blancs. Cela fait plaisir aux hommes de couleur et ne gêne pas les autres, puisque ceux-ci ne vont pas dans ces théâtres.

D'une manière générale, toute nation se considère comme supérieure à ses semblables, parce qu'elle porte son attention sur un caractère qui ne se rencontre pas au même degré chez celles-ci, pour fixer l'ordre des rangs entre elles toutes. Par exemple, telle nation qui a le sens de l'ordre, de la discipline, estimera qu'elle dépasse toutes les autres, qu'elle est au-dessus de toutes les autres, dans le monde, pour cette raison : la vertu suprême étant l'obéissance, le peuple qui n'a même pas besoin d'être dressé pour obéir, qui a l'obéissance dans le sang, n'est-il pas le sel de la terre ? Mais tel pays dans lequel on trouve plus de courage individuel, une fierté plus ombrageuse, un sens plus noble de la liberté, s'appuyant sur ces vertus comme sur des titres que personne ne peut égaler, revendiquera la première place. De même encore, les Grecs modernes se réclament des anciens Grecs. Les Américains des États-Unis sont fiers de faire partie d'une nation qui est tout entière tournée vers l'avenir. Mais ce sentiment

«Pour qu'un peuple se laisse pénétrer (économiquement) par un autre, il faut qu'il ait cessé de s'enfermer dans un patriotisme exclusif, et en ait appris un autre, plus compréhensif. »Émile Durkheim, De la division du travail social, Paris, 1902, 2e édition, pp. 259 et suivantes. - Voir notre étude : La doctrine d'Émile Durkheim (Revue philosophique, mai-juin 1918, p. 371). 
de supériorité, du moment qu'il est commun à toutes les nations, ne peut pas créer une hiérarchie. Une classe inférieure, au contraire, est telle non seulement pour les hommes des classes plus élevées, mais de l'aveu de ses propres membres.

Il en résulte qu'à la question : Qu'est-ce qu'une nation ? on ne peut faire une réponse simple. Auguste COMTE disait que l'idée de nation était essentiellement métaphysique, c'est-à-dire négative. Au moment de la Révolution française la nation s'opposait, en effet, à la multiplicité de provinces : c'était comme le symbole de la France une et indivisible, substituée aux particularités féodales de l'ancien régime. Mais le courant vers l'unité tire aussi un certain contenu positif de la force que lui apportent des tendances traditionnelles, des aspirations ou des intérêts de classe, enfin telle ou telle conception politique de l'État.

De ce point de vue, on s'aperçoit que le sentiment national non seulement s'analyse en éléments divers suivant les pays, mais encore, dans le même pays, se présente sous des formes différentes, et même opposées. En France, on parle souvent de la «vraie France »: on entend par là tantôt la France de saint Louis, de Jeanne d'Arc, de la Royauté, la fille aînée de l'Église, et tantôt la France de la Révolution, des Droits de l'homme, qui, comme disait Anatole FRANCE, n'a pas cessé d'être le professeur de droit de l'Europe.

Ailleurs, c'est une classe définie qui prétend représenter toute la nation, et le sentiment national exprime surtout un esprit de classe : aristocratique ou capitaliste en Grande-Bretagne, où l'idéal du gentleman s'impose aux travailleurs manuels euxmêmes ; ouvrier, prolétaire da dictature du prolétariat) dans l'Union Soviétique des classes moyennes, plutôt, dans notre pays.

Ailleurs encore, c'est la conception de l'État totalitaire qui passe au premier rang dans l'Allemagne naziste, sur la base de l'unité ethnique ; dans l'Italie fasciste, sur la base d'une formule politique nouvelle. Un des théoriciens les plus connus du fascisme définissait ce régime : l'unité idéale des producteurs et de la puissance politique. Pour lui, le bolchevisme n'a réalisé l'unité que dans la production ; le national-socialisme laisse subsister, comme deux domaines distincts, l'économie et la politique (tentative désespérée et dernière planche de salut du capitalisme); ce n'est qu'en Italie, qu'on aurait su fondre l'État, le capital et le travail ${ }^{1}$. Idées-forces, sur le plan collectif, qui recouvrent sans doute un sentiment vieux comme le monde, puisqu'elles portent à l'absolu l'hostilité naturelle vis-à-vis de tout ce qui est étranger.

Dans le monde nouveau d'aujourd'hui, sous ces formes diverses, avec une intensité qui varie extrêmement suivant les circonstances et les époques, le patriotisme répond bien à ce que Durkheim appelait la solidarité mécanique, fondée sur la ressemblance entre des hommes rapprochés dans l'espace. Il est rendu plus fort par l'unité linguistique, par la communauté des traditions, par l'activité des intérêts économiques et politiques. On ne peut dire qu'il soit en rapport avec l'étendue des groupes nationaux, avec leur importance numérique, ni même avec la vitalité démographique des populations, telle qu'elle s'exprime par l'excédent des naissances sur les décès.

Ugo Spirito, dans la conclusion de Nuove esperienze economiche (ouvra collectif, d'auteurs étrangers), traduction italienne, Florence, 1935. 
Certes, un tel sentiment a ses limites. L'ampleur des mouvements migratoires qui se sont développés d'Europe en Amérique, en Europe même, avant et depuis la guerre, de pays en pays, est la preuve que les difficultés économiques sont parfois plus fortes que l'attachement au sol natal. C'est que, dans nos civilisations, il y a une masse humaine relativement déracinée, et qui est prête à se porter là où elle trouvera sa subsistance. Pour arracher cependant les hommes aux pays où ils ont pris leurs habitudes, il faut qu'ils soient entraînés par un courant. Les migrations sont des déplacements collectifs, comparables aux anciennes migrations de peuples : l'émigrant est attiré, puis encadré dans la foule de ceux qui émigrent comme lui. Au reste, pendant quelque temps, dans le pays nouveau où il arrive, il cherche instinctivement la société de ses nationaux. Ce n'est qu'à la longue, après une et quelquefois deux générations, qu'il s'assimile. En tout cas, le peuplement des États-Unis, si rapide qu'il paraisse, n'a pas été tel qu'après un siècle et demi la population soit aussi dense, même de loin, en Amérique que dans le vieux continent. En Europe même, il y a de grandes inégalités à cet égard de pays à pays. Tant il est vrai que la nation tend à retenir ses membres, et y réussit dans une large mesure.

En dehors des motifs propres à certaines classes et à certaines nations, il en est d'autres, plus généraux par leur objet, et aussi parce que toute la population y obéit en quelque mesure, mais plus particuliers, en un sens, aussi, parce qu'ils sont développés et cultivés avec intensité et de façon continue dans des cercles plus restreints.

Si un sociologue avait dû écrire l'étude que nous rédigeons en ce moment, au XIIIe siècle, et mềme au XVIe et au XVIIe siècle, sans doute aurait-il mis au premier plan la religion, les motifs religieux. Nous aurions ainsi un diptyque tel que celui qu'a présenté CARLYLE dans Past and Present. Mais tenons-nous-en au monde social dans lequel nous vivons aujourd'hui. On peut dresser, on dresse des cartogrammes qui indiquent les zones correspondant en Europe aux diverses confessions religieuses, et peut-être diffèrent-ils assez peu de ceux qu'on aurait pu établir au lendemain de la Réforme. NOUS sentons qu'une telle comparaison serait tout extérieure et qu'il ne suffit pas que des hommes portent l'étiquette : catholique ou protestant, pour qu'on puisse rien en conclure touchant leur pratique et surtout leur foi.

Reportons-nous à une enquête récente, dont nous avons déjà dit quelques mots ${ }^{1}$. L'auteur n'a porté son attention que sur les foules, la pratique des foules. Il s'en tient au problème de la participation du peuple à la vie cultuelle, très exactement : aux sacrements, aux offices, aux oeuvres de dévotion. "Pourquoi, se demande-t-il, accordons-nous si peu d'attention aux religions vivantes ? L'obéissance à leurs commandements occupe, façonne des millions d'êtres dans notre voisinage, des milliers de groupes : car la pratique, bien plus qu'un fait individuel, est un fait social. » « Pratiquer, ajoute-t-il, ce n'est pas seulement se lier aux puissances d'En-Haut. C'est encore adhérer à une morale domestique et personnelle, dont le catéchisme, le confessionnal, le sermon inculquent les devoirs. Il est donc vraisemblable que la pratique aura son incidence sur la famille. Elle tend à exclure les unions libres et les divorces, le néo-malthusianisme et l'avortement ; à multiplier les mariages et les naissances, dans une mesure plus modeste les célibats volontaires, et aussi (au lieu de ruptures) les séparations de corps. Plusieurs de ces points ont déjà retenu l'attention

1 LE Bras, Les transformations religieuses des campagnes françaises depuis la fin du XVIIe siècle (Annales sociologiques, série E, fasc. 2, 1937). 
des enquêteurs. Il est moins aisé de saisir, bien qu'on l'ait tenté, l'action de la pratique sur la morale sociale, le frein à la criminalité, l'aiguillon dans l'accomplissement des devoirs civiques. »

Mais la pratique influe aussi sur la cohésion du groupe et la hiérarchie des groupes. PROUDHON avait déjà montré « comment l'organisation de la messe dominicale, et d'une façon générale l'organisation des cérémonies catholiques, avec ses distances, ses préséances (places pour les offices, classes dans les services), fortifie le sentiment hiérarchique, comment aussi l'incorporation provisoire à une assemblée nombreuse impose au paysan des soucis de tenue, de propreté, qu'il n'a point tout le long des jours ouvrables. La pratique impose au peuple non seulement des démarches, des attitudes, mais jusqu'à un certain point son costume, son habitat. Elle discipline les masses, par une action permanente et à peine sentie ».

Renonçons à retracer l'histoire des vicissitudes de la pratique, du XVIIIe siècle jusqu'à présent. Mais, pour la période 1930-1935, examinons une carte des 40.000 communes de France où est indiqué le nombre de ceux qui communient à Pâques. Ce qui frappe l'œil « c'est le partage du pays en vastes régions de fidélité ou d'infidélité. Au XVIIIe siècle, la pratique offrait partout des caractères à peu près pareils et d'identiques glissements. Aujourd'hui, la France religieuse est une confédération de pays disparates. Il y a trois grandes zones de pratique : Nord-Ouest, Est, Massif Central, et quelques quartiers moindres : Pays basques, Terres froides du Dauphiné, Queyras, où les pascalisants sont la majorité, parfois la quasi-unanimité. Entre ces régions s'étendent des déserts sans pratique, où la proportion des assidus atteint rarement le dixième de la population adulte. Chaque groupe régional compte plusieurs départements, plusieurs millions d'habitants, et les limites sont aussi nettes que celles des États ».

Les causes d'un tel état sont nombreuses, diversement combinées, inégalement actives. «Les zones fidèles de l'Ouest sont généralement habitées par des populations dociles, quelques-unes idéalistes, et que les missions du XVIIe siècle, puis les épreuves de la Révolution et de la résistance au mouvement laïque ont profondément remuées. Du dehors l'esprit nouveau n'a pas soufflé en tempête, les relations avec la France du Centre et même avec les villes voisines ayant toujours été intermittentes et sans grande portée. Au dedans, toute une armature maintient les usages - le clergé est nombreux, la structure féodale a subsisté, malgré les démantèlements : chaque paroisse a son curé, souvent le château protège le presbytère. Les écoles libres, soutenues par les grands propriétaires, et par tout un peuple ferme dans sa croyance, facile à taxer, inculquent à la majorité des filles et à un grand nombre de garçons les principes traditionnels. Une presse surveillée, en partie rédigée par le recteur, assure la propagande des doctrines orthodoxes. »

Il en est autrement des zones déchristianisées, qui ont presque toujours « une tradition religieuse ou molle, ou troublée... Tous ces pays du Centre ont subi, par les voyageurs ou leurs propres émigrants, par l'action de l'État et de la presse, l'influence de Paris, de Limoges, de Toulouse, un ébranlement de leurs habitudes, de leurs pensées. Peu de clergé, de noblesse, de bourgeoisie dévote ; chaque curé gouverne plusieurs paroisses, et il n'est guère de paroisse qu'un notable maintienne sous l'influence de l'Église. L'école publique élève presque tous les enfants, rares sont les Oeuvres où s'exerce l'action du catholicisme, tandis que les sociétés laïques se multiplient... Jadis, les fêtes ecclésiastiques étaient l'occasion ordinaire de rencontre et de récréation. Le développement des réjouissances, des transports, des modes 
parisiennes s'accomplit au détriment de ce que le langage ecclésiastique appelle la modestie chrétienne, c'est-à-dire la soumission à la coutume ${ }^{1}$ ».

Que les motifs religieux gardent leur force dans des groupes compacts de fidèles, ce n'est pas pour nous étonner. Le grand danger, pour la piété coutumière, c'est le contact avec des indifférents ou des incroyants. Autrefois la religion pénétrait la vie et la pensée tout entière : sa suprématie était à ce prix. Aujourd'hui est née une civilisation moderne orientée vers les intérêts temporels. Des institutions laïques prennent l'enfant, l'homme et les plongent dans une atmosphère toute différente de celle qu'on respire dans les milieux religieux. Chaque individu est compris à la fois dans des groupes dont le plus grand nombre ont leur fin propre, indépendante de toute pensée à un autre monde et, à passer sans cesse de la société confessionnelle, s'il s'y rattache encore, à d'autres qui ignorent totalement celle-ci, il en vient à considérer l'Église comme une institution pareille aux autres, et à laquelle il ne donne qu'une partie de plus en plus réduite de sa personne. La nation, surtout, dès qu'elle n'est plus soumise à la religion, dès qu'elle se considère comme la fin suprême, lui devient nécessairement hostile.. Elle prétend dresser l'homme pour en faire sa chose, l'absorber, l'accaparer entièrement. Elle aussi n'admet point de partage. C'est l'État totalitaire qui est le plus grand adversaire de l'Église. Mais, partout, à mesure que l'emprise de l'État sur ses membres s'affermit, c'est au détriment de la religion.

Le seul moyen pour celle-ci de se défendre, de conserver sa puissance de rayonnement, c'est de fortifier son élite. Dans le groupe des fidèles, en effet, il y a « une minorité fervente, dont les marques sont : dans le cadre publie, la communion fervente, l'assistance quotidienne ou habituelle à la messe, aux vêpres, saluts et autres cérémonies, la participation aux processions et aux pèlerinages ; dans le cadre familial, les prières en commun, le jeûne et l'abstinence. C'est au sein de cette élite que se recrutent le clergé, les congrégations religieuses, les confréries et les associations pieuses ». Mais l'existence et la subsistance de tels milieux où le sentiment religieux s'intensifie, sont en rapport, comme nous venons de le voir, avec tout un ensemble de circonstances sociales, coutumes, régime de la propriété, caractère urbain ou rural de la civilisation, nature de la population, aussi, formée par des influences traditionnelles, en même temps que l'hérédité y renforce les traits éthiques. Les milieux religieux sont conditionnés par l'ambiance collective. Mais les natures religieuses ne s'épanouissent pleinement et ne se réalisent que dans ces milieux tournés vers la piété, préoccupés de dévotion. Le groupe confessionnel, en ces régions les plus intactes, recherche et encourage les vocations : c'est aussi que les « convertis », ceux qui, du milieu des incroyants, se sont sentis appelés, trouvent l'entourage d'hommes, d'images, de symboles où ils s'encadrent le mieux, d'où ils peuvent exercer au dehors le plus d'action.

Entre les deux sources de la religion, la religion close, dans ses formes arrêtées et coutumières, et la religion ouverte, l'esprit opposé à la lettre, l'élan charitable et mystique, M. Bergson ouvrait un abîme. Mais les mystiques ont besoin de l'Église, dont ils sont en réalité le prolongement et l'avant-garde, si remplis de son esprit qu'en

Dans un livre curieux, intitulé Middletown, par Robert S. Lynd et Helen Merrel LYND, NewYork, 1929, on trouvera les résultats d'une enquête de ce genre sur la fréquentation des services religieux aux États-Unis, il y a vingt-cinq ans et aujourd'hui. Enquête, à vrai. dire, faite seulement dans quelques villes moyennes : simple coup de sonde. Et il a fallu, pour avoir des chiffres sur le passé, faire appel aux souvenirs incertains de pasteurs âgés. [Pour les données récentes en France, voir : Ch. BETTELHEIM et Suz. FRÈRE, Auxerre en 1950, A. Colin, 1950, 4e partie, chap. II, et Yvan DANIEL, Aspects de la pratique religieuse à Paris, éd. Ouvrières, 1952 ] A.C. 
eux il déborde, de la tradition. Ce n'est qu'après s'être, plus que les autres clercs, assimilé celle-ci, qu'ils se sont élevés ou se sont placés en dehors. La plupart des mystiques ont été des moines, des religieux, et, en tout cas, ont été formés au contact de prêtres ou de frères. D'autre part, l'Église peut bien, a bien pu en maintes circonstances se défier d'abord de ces illuminés, qui prétendaient voir jusqu'où la pensée religieuse traditionnelle n'atteignait point. Une collectivité étendue et ancienne, qui a éprouvé la valeur et la solidité de ses croyances, redoute les innovations des individus ou des groupes plus petits qu'elle renferme. Mais elle ne manquera pas de reconnaître que ces fidèles, chez lesquels le sentiment religieux s'exalte et s'approfondit, jouent un rôle nécessaire, que sans eux non seulement les dogmes et les rites s'useraient peu à peu, et perdraient de plus en plus leur relief, mais encore toute la piété se réduirait à un conformisme extérieur et figé ${ }^{1}$. Ainsi, loin d'être séparés et comme opposés, ces deux éléments de la religion : le cadre, et les ressorts ou les moteurs, les cours d'eau et canaux qui coulent entre des rives droites et résistantes, et la source vive d'où vient sans cesse un nouveau courant, sont inséparables l'un de l'autre. Un groupe restreint de fidèles entretient la foi dans le monde, mais il serait incapable de gérer tout seul le milieu religieux, fait d'institutions et de coutumes, hors duquel il ne pourrait prendre forme. C'est dans le clergé et autour de lui que les mots d'ordre, les méthodes de vie, les directions et les programmes s'élaborent pour la masse des croyants : c'est de là qu'elle se propage jusqu'aux tièdes et à ceux mêmes qui sont plus qu'à demi dégagés.

Nous ferions des observations du même genre, à propos d'autres motifs de pensée et d'action, qui n'ont d'influence ou n'ont de prétention à l'étendre sur la masse, que parce qu'ils tiennent d'une prise étroite un petit groupe d'hommes dispersés peut-être, mais que rapproche une commune orientation. Par exemple, la science, théorique et pratique, en toutes ses branches et ses applications. Pourquoi, au cours de l'histoire, y a-t-il eu quelques périodes et aussi quelques pays exceptionnels, dans lesquels des savants, de grands savants se sont rencontrés, non pas isolément, mais rapprochés dans l'espace et dans le temps ? Il n'y a rien là de miraculeux, si presque toujours, autour de ces personnes qui se détachent, et derrière elles, il a existé, il existe des groupements scientifiques. On a pu soutenir, en effet, que presque tous les grands philosophes ou physiciens de l'antiquité grecque furent des chefs d'école, et parlèrent au nom d'un groupe d'autres philosophes qu'on peut appeler leurs disciples, mais qui comprend aussi leurs précurseurs et qui constituèrent avec eux une pensée commune.

Certes la science vit surtout par les savants, dans l'esprit des savants. Au XVIIe siècle, avant qu'il y eût des journaux scientifiques, elle ne sortait guère d'un cercle restreint dont les membres étaient dispersés aux quatre coins de l'Europe, et qui, par correspondance privée ou au cours de visites personnelles, se communiquaient leurs découvertes, se tenaient au courant de leurs progrès dans chaque branche. A mesure qu'augmente le nombre des personnes qui s'absorbent dans ces travaux et que les contacts entre eux se multiplient, surtout à partir du moment où les inventions pratiques dont ils sont les auteurs proches ou indirects attirent l'action publique, la science pénètre dans beaucoup de milieux non scientifiques et, d'ailleurs, par des motifs divers - curiosité naturelle, chez ceux qui veulent comprendre ce qui leur paraît merveilleux ; vanité et snobisme, chez les «femmes savantes » et chez les hommes qui ont la prétention d'être confondus avec les vrais savants ; convictions philosophiques, philosophie des lumières, chez les philosophes du XVIIIe siècle et

Maurice Halbwachs, Les Cadres sociaux de la mémoire, op. cit., p. 286 des dogmatiques et les mystiques). 
plus tard chez les positivistes français, conviction que le progrès de l'humanité n'est possible que par une transformation des idées, par la participation de tous les esprits au mouvement et à la culture scientifiques.

Mais les savants, d'où semblent procéder tous ces mouvements de la pensée publique, de l'opinion sur la science, ne se sont pas en général formés tout seuls. Ils sont sortis de collèges, ils ont travaillé dans des laboratoires, dans des bibliothèques, 'vécu dans des milieux scientifiques, profité de tout un ensemble d'institutions qui ont pour objet de former et de maintenir, distincte de toutes les autres et se suffisant, avec son langage, ses conventions, ses traditions aussi, ce qu'on pour pourrait appeler la société des savants. Cette société même, qui comprend d'ailleurs bien des formes et des espèces, est en rapport avec la société plus large ou l'ensemble des groupes : la science, dans son extension et son développement, dépend de conditions sociales générales. Les savants ne s'en rendent pas compte toujours. Enfermés dans leur domaine spécial, ils croient pouvoir s'isoler du reste du monde, et même de ceux qui poursuivent leurs recherches en d'autres branches. Le motif scientifique se présente ainsi sous deux formes : telle science comme objet exclusif, mais aussi chaque science comme partie solidaire d'un tout, et même la science comme un moyen en vue du progrès humain. Il arrive que la masse des non-savants prenne une conscience plus nette que les savants eux-mêmes de l'unité de la science et de sa destination sociale.

L'art, les jouissances et la production artistiques semblent être le privilège d'une élite. Ici la nature, les dons innés, en tant qu'ils s'opposent au dressage social, ne reprennent-ils pas leurs droits, ne passent-ils pas au premier plan ? Que serait l'art sans les artistes, et n'est-ce pas par leur action créatrice que prennent naissance les Oeuvres belles, qui, lentement, et comme du dehors, forment la sensibilité artistique des autres hommes ? Ne jouent-ils pas le rôle d'initiateurs et d'inventeurs, qui nous apprennent à fixer notre attention sur certains aspects du monde extérieur, assemblages de sons, de formes, de couleurs, à en éprouver la valeur esthétique, que nous n'aurions pas reconnue sans eux ? Mais, en réalité, il existe aussi une société des musiciens, une autre des peintres, une autre des sculpteurs. Il n'y a pas de talent, de génie, si personnel soit-il, qui ne doive se soumettre à la discipline, à la fois technique et esthétique, de ces milieux qui comprennent des hommes rapprochés par leurs affinités naturelles, mais qui mettent en commun leurs intuitions et leurs expériences. Bien plus, ces sociétés, qui représentent en quelque sorte les organes de la sensibilité artistique dans la société au sens large, ne se forment et ne peuvent exercer leur fonction propre que s'ils demeurent en contact et en continuité avec elle. Ici encore, les artistes sont souvent victimes d'une illusion, lorsqu'ils prétendent cultiver l'art pour l'art et s'enfermer à jamais dans un monde clos.

Auguste Comte avait bien compris que l'apparente exception que font les arts à la loi du progrès s'explique par ceci, qu'il y eut des périodes de stabilité prolongée, durant laquelle, les mœurs et les façons de vivre étant fixées, les artistes pouvaient se mettre à l'unisson de la société, lui rendre ce qu'ils en recevaient, nourrir leur art des aspirations et des représentations vivantes autour d'eux, et d'autres périodes prolongées, où les coutumes et pensées évoluaient et se transformaient sans cesse, où l'artiste était en retard sur la société ${ }^{1}$. Le Tasse a écrit la Jérusalem délivrée alors que les croisades n'étaient plus qu'un souvenir, et le Don Quichotte de Cervantes ne nous offre qu'une caricature de mœurs chevaleresques depuis longtemps passées.

1 Cours de philosophie positive, tome V, pp, 328 et suivantes; tome VI, pp. 163 et suivantes. 
Un vaste champ s'ouvrirait à l'art sous toutes ses formes dans une société moderne qui aurait trouvé son assiette et pris véritablement conscience d'elle-même. Jusqu'à ce moment, l'individualisme paraît devoir s'imposer en ce domaine, et ce n'est que de façon sporadique et intermittente que des courants artistiques peuvent exercer sur les artistes comme sur le publie une action proprement collective.

Nous ne reviendrons pas sur la politique, si ce n'est pour souligner l'importance des motifs qu'elle fournit moins encore à l'activité qu'à la pensée et à la sensibilité des hommes et des groupes. Est-elle un moyen, ou une fin? Il semble bien qu'elle soit surtout une fin : qu'on songe à la place qu'elle occupe dans les préoccupations quotidiennes de l'homme moyen. Dans la pièce de Jules ROMAINS intitulée Le Docteur Knock, un médecin de campagne, qui a réussi à persuader le plus grand nombre des habitants qu'ils étaient malades et devaient se soigner, dit à un confrère, en lui montrant, par la fenêtre, le village, les maisons, les fermes : "La médecine maintenant vit ici avec intensité. » De même, les parlementaires, les états-majors des partis, les journalistes, pourraient dire, en n'importe lequel de nos pays : « La politique maintenant vit ici avec intensité. »C'est sans doute, en apparence au moins, leur oeuvre. Car la politique vit d'abord et surtout dans les milieux de ceux qui s'en occupent activement, qui inventent les mots d'ordre, fixent les programmes, font de la Propagande, occupent les postes de commande. lis sont appelés à jouer ce rôle par leur goût, par leurs aptitudes.

Mais, est-il besoin de le redire, ils ne peuvent le jouer, il n'y a de place pour ceux qui exercent ces professions, ou sentent en eux cette vocation, que dans une société où une telle activité répond à des tendances collectives étendues et profondes dans toute la masse, et qui forme à son image les organes nécessaires pour une fonction dont elle éprouve le besoin. Ordre et progrès : tels sont les deux leitmotive de la vie politique. Or les hommes, suivant leur tempérament, sans doute, mais surtout suivant leur condition sociale, leurs habitudes religieuses, la forme de leur patriotisme, leurs traditions aussi, locales ou familiales, se rangent dans l'un ou l'autre camp, aux extrêmes, ou en des positions intermédiaires. Chacun, il est vrai, n'intervient effectivement, par son vote, qu'à de rares intervalles, dans le jeu de la vie politique nationale, départementale et communale. Mais, de façon continue, ils n'en constituent pas moins l'opinion. Or, c'est sous la pression de l'opinion que les milieux politiques au sens étroit pensent et agissent. Ils la modifient, ils l'orientent, mais en se plaçant en quelque sorte dans son prolongement, en l'exprimant, en l'aidant à prendre mieux conscience d'elle-même.

Avons-nous maintenant passé en revue tous les motifs dont s'inspire la conduite des individus dans la vie sociale ? Les moralistes nous reprocheront peut-être de n'avoir pas mis au premier rang le sentiment du devoir. Nous n'avons point parlé, en effet, du devoir pur et simple, de l'impératif catégorique, de la loi morale, parce qu'elle concerne l'homme intérieur. Quant à la morale sociale, quant aux devoirs sociaux, leur forme est déterminée par les diverses sociétés dont nous faisons partie : morale de classe, morale professionnelle, morale civique, morale religieuse, et, aussi, morale du savant, morale de l'artiste : si l'on se préoccupe non de construire une théorie, mais de ce que les hommes croient, c'est-à-dire de ce qu'ils font, il apparaîtra que toute notre étude n'a pas eu d'autre objet.

Il est vrai que nous n'avons point parlé de la justice, ni de la charité. Rappelons donc, que SPENCER définissait et distinguait ces deux vertus, ou ces deux devoirs, en disant : la justice consiste dans l'obéissance aux lois établies, et se fonde sur ce que 
ces lois sont la condition de l'ordre, c'est-à-dire de la conservation de la société, à l'étape de l'évolution où elle se trouve. Elle est négative, puisqu'elle nous ordonne surtout de nous abstenir ; elle est collective, parce qu'elle est la même pour tous les membres du groupe auquel elle s'impose. La charité, c'est tout ce qu'on fait en vue d'améliorer l'état social, ou, plutôt, de supprimer le mal que la justice stricte produit, en tout cas qu'elle ne suffit pas à éliminer, l'inégalité sociale, la misère, dans chaque cas particulier où elle s'offre à nous. Elle est positive, puisqu'elle réclame de nous de l'initiative, un effort, une sorte de don de nous-mêmes ; elle est individuelle, puisqu'il appartient à chaque individu de l'exercer autour de lui, dans la partie du milieu social où il vit, et qu'il peut atteindre ${ }^{1}$.

Il y a bien là deux formes de conduite, et deux types d'hommes, qui se complètent en même temps qu'ils s'opposent. Mais, entre les deux, on peut concevoir. une justice élargie, ce que nous appelons la justice sociale, qui dépasse la justice strictement légale, et se distingue de la charité en ce qu'elle prend forme collective. C'est ce qu'on appelle la solidarité, telle qu'elle se pratique à l'intérieur des divers groupes sociaux : morale de collaboration et d'entraide, qui se moule sur les cadres de la vie sociale moderne. Il y a là tout un programme dont s'inspire une part croissante des membres de nos sociétés.

Nous préférons cependant, pour conclure une étude qui a porté surtout sur l'aspect économique de la vie sociale, insister sur une autre distinction qui répond à des préoccupations plus actuelles, celle qu'on peut faire entre la morale des producteurs et des consommateurs ${ }^{2}$.

Chaque homme, sans doute, est l'un et l'autre. Mais l'évolution économique telle qu'elle s'accomplit depuis plus d'un siècle, sous le signe du capitalisme, semble en effet s'être orientée surtout vers l'accroissement, vers un accroissement illimité de la production. On produit non pour consommer, mais pour produire, et l'on attend des consommateurs qu'ils assurent des débouchés à la production, aux prix que celle-ci exige, parce qu'ils doivent être tels pour qu'elle se développe. Condition, sans doute, d'un certain progrès économique, mais qui entraîne ce résultat paradoxal qu'avec une abondance croissante de produits, des classes entières de la population se trouvent manquer de biens que la technique moderne devrait leur assurer, et quelquefois du nécessaire. Il doit être possible de concilier le progrès économique avec une meilleure répartition des richesses accrues, qui permette de relever le niveau de vie des classes inférieures. Tel est le principe dont s'inspire la morale du consommateur, qui subordonne toute l'activité des hommes à la satisfaction des besoins pour le plus grand nombre. C'est tout le problème du régime économique qui est ainsi posé.

STENDHAL n'avait pas de plus grand intérêt que d'observer comment les hommes pratiquent « la recherche du bonheur ». C'est là, à vrai dire, le motif essentiel de la conduite, ou du moins ce devrait l'être. Les individus y réussissent plus ou moins, suivant la chance, leur tempérament, leur habileté et leur expérience. Ils vont à la chasse du bonheur isolément, et comme en ordre dispersé. Considérons cependant non plus les individus, mais les groupes. Le résultat de la civilisation urbaine a été, nous l'avons montré, de séparer nettement les deux zones de l'activité productrice et de la consommation. Mais, tandis que les travaux se sont ainsi rapprochés et

Herbert SPENCER, Justice, traduction française, 1903.

2 Horace M. Kallen, The Decline and Rise of the Consumer, a Philosophy of Consumer Cooperation, NewYork, 1936. 
combinés suivant des règles. qui correspondent aux seules nécessités de la production ou de la profession, tandis que tout l'effort des groupes s'est porté de ce côté, ont-ils réussi à organiser de façon aussi efficace l'autre partie de l'existence, celle qui est consacrée à la satisfaction des besoins, la plus importante en somme ? Car il faut prendre le mot : consommation dans le sens, non pas seulement de destruction, mais d'achèvement. Il s'agit pour l'homme de se réaliser pleinement, dans les cadres et par les moyens de la vie collective. Or celle-ci nous offre à cet égard de très riches possibilités, mais inexploitées jusqu'ici, et même inexplorées.

Les hommes s'en rendent bien compte, et ainsi s'explique l'intérêt passionné qu'ils portent depuis quelque temps et de plus en plus à toutes les formes d'association, à toutes les institutions qui s'inspirent d'un esprit communautaire. Ils comprennent que, dans notre civilisation moderne si complexe, il faut un effort collectif pour organiser la recherche du bonheur sous ses formes sociales. Le bonheur, en effet, dans un tel état, ne résulte pas automatiquement de ce que les produits, la richesse s'accroissent, se multiplient. Peut-être même, comme le pensait M. BERGSON, suppose-t-il, en certaines périodes, des limitations, un resserrement, et même une part d'ascétisme en ce qui concerne les satisfactions matérielles. Motif en somme encore indéterminé, mais qui prend forme. La condition nécessaire pour qu'il grandisse et se fortifie, c'est, sans doute, que l'attention se porte de plus en plus sur les expériences de la vie sociale, et que la science de l'homme, enfin, se constitue. Ici encore, il dépend de la société se trouver en elle les individus les plus capables de pousser leurs investigations en ce sens, et en même temps de créer les milieux favorables à l'essor de telles recherches.

$\underline{\text { Retour à la table des matières }}$ 